\title{
Nanogrid topology, control and interactions in a microgrid structure
}

\author{
by \\ Daniel Burmester
}

\author{
A thesis \\ submitted to the Victoria University of Wellington \\ in fulfilment of the \\ requirements for the degree of \\ Doctor of Philosophy \\ in Computer Science.
}

Victoria University of Wellington 2018 



\begin{abstract}
Distributed generation, in the form of small-scale photovoltaic installations, have the potential to reduce carbon emissions created by, and alleviate issues associated with, centralised power generation. However, the major obstacle preventing the widespread integration of small-scale photovoltaic installations, at a residential level, is intermittency. This thesis addresses intermittency at a household/small community level, through the use of "nanogrids". To date, ambiguity has surrounded the nanogrid as a power structure, which is resolved in this thesis through the derivation of concise nanogrid definition. The nanogrid, a power distribution system for a single house/small building, is then used to implement demand side management within a household. This is achieved through the use of a hybrid central control topology, with a centralised coordinating controller and decentralised control nodes that have the ability to sense and modulate power flow. The maximum power point tracker is used to observe the available photovoltaic power, and thermostatically controlled loads present in the household are manipulated to increase the correlation between power production and consumption. An algorithm is presented which considers the expected power consumption of the thermostatically controlled loads over a 24 hour period, to create a hierarchical ratio. This ratio determines the percentage of available photovoltaic power each load receives, ensuring the loads that are expected to consume the most power are serviced with the largest ratio of photovoltaic power. The control system is simulated with a variety of household consumption curves (altered for summer/winter conditions), and a week of realistic solar irradiance data for both summer and winter. In each simulated scenario, a compari-
\end{abstract}


son was made between controlled and uncontrolled households to ascertain the extent grid power consumed by a household could be reduced, in turn reducing the effect of intermittency. It was found that the system had the ability to reduce the grid power consumed by as much as $61.86 \%$, with an average reduction of $44.28 \%$. This thesis then explores the concept of interconnecting a small community of nanogrids to form a microgrid. While each nanogrid within the network has the ability to operate independently, a network control strategy is created to observe the possibility of further reducing grid power consumed by the community. The strategy considers the photovoltaic power production and thermostatically controlled loads operating within the network. A ratio of the network's photovoltaic power is distributed to the thermostatically controlled loads, based on their expected consumption over a 24 hour period (highest consumption receives largest ratio of power). This was simulated with a range of household cluster sizes, with varied consumption patterns, for a week with summer/winter solar irradiance. The tests show that, compared to an uncontrolled nanogrid network, the combined control can reduce grid power consumed by as much as $55 \%$, while a $7 \%$ decrease is seen when comparing the combined control to the individually controlled nanogrid networks. When compared to an uncontrolled individual house scenario, the combined control interconnected nanogrids can reduce the power purchase from the grid by as much as $61 \%$. 


\section{Papers Published From This Thesis}

1. Daniel Burmester, Ramesh Rayudu, Winston KG Seah. "Use of Maximum Power Point Tracking Signal for Instantaneous Management of Thermostatically Controlled Loads in a DC Nanogrid", IEEE Transactions on Smart Grid (in print), DOI 10.1109/TSG.2017.2704116, 2017

2. Daniel Burmester, Ramesh Rayudu, Winston KG Seah, Daniel Akinyele. "A Review of Nanogrid Topologies and Technologies", Renewable and Sustainable Energy Reviews, vol 67, p 760-775, Elsevier, 2017

3. Daniel Burmester, Ramesh Rayudu, Winston KG Seah. "A Combined Control Strategy for Load Management within an Interconnected Nanogrid Network", IEEE Innovative Smart Grid TechnologiesAsia (ISGT-Asia), 2017

4. Daniel Burmester, Ramesh Rayudu, Winston KG Seah. "Instantaneous Control of a DC Water Heater for a PV System", IEEE International Conference on Power System Technology (POWERCON), 2016

5. Daniel Burmester, Ramesh Rayudu, Winston KG Seah. "Instantaneous Nanogrid Control Using Maximum Power Point Tracking Signal", IEEE Innovative Smart Grid Technologies-Asia (ISGT-Asia), 2016 
6. Daniel Burmester, Ramesh Rayudu, Winston KG Seah. "Distributed Generation Nanogrid Load Control System", IEEE PES Asia-Pacific Power and Energy Engineering Conference (APPEEC), 2015

7. Daniel Burmester, Ramesh Rayudu, Winston KG Seah. "A Comparison Between Temperature and Current Sensing in Photovoltaic Maximum Power Point Tracking", IEEE Eighteenth National Power Systems Conference (NPSC), 2014

8. Daniel Burmester, Ramesh Rayudu, Edwin Massold. "Setup of a Nanogrid for Teaching Purposes", 21st Electronics New Zealand Conference (ENZCON), 2014

9. Daniel Burmester, Ramesh Rayudu, Edwin Massold. "Proposed Nanogrid Load Control Algorithm", 21st Electronics New Zealand Conference (ENZCON), 2014 


\section{Acknowledgments}

I would like to thank my family and friends for their support which has enabled me to pursue my research and complete this thesis. I would also like to thank my supervisors, Dr Ramesh Rayudu and Prof Winston Seah for their guidance and wisdom, the SPRES group for their advice and insightful discussions, and the wider ECS community. Lastly, I would like to thank the Victoria doctoral scholarship and Victoria doctoral submission scholarship for the financial support which has allowed me to devote time to my research. 


\section{Contents}

1 Introduction 1

1.1 Motivation ..................... 2

1.1.1 Gaps in the Research . . . . . . . . . . . . . 3

1.2 Research Statement and Objectives . . . . . . . . . . . 4

1.3 Major Research Contributions . . . . . . . . . . . . . 6

1.4 Research Strategy . . . . . . . . . . . . . . . 8

2 Literature Review $\quad 11$

2.1 Nanogrids . . . . . . . . . . . . . . . . . . 12

2.1.1 Nanogrid Control . . . . . . . . . . . . . 12

2.1.2 Nanogrid Hardware . . . . . . . . . . . . . . 15

2.2 Thermostatically controlled loads . . . . . . . . . . . 22

2.3 Interconnected nanogrid network . . . . . . . . . . . . 24

2.4 Chapter Summary . . . . . . . . . . . . . . . . . . 28

3 Nanogrid Topology and Definition 31

3.1 Definition and Background of Nanogrid . . . . . . . . . . 32

3.1.1 Nanogrid - A Definition . . . . . . . . . . . 33

3.1.2 Types of Nanogrid Technology . . . . . . . . . . . 35

3.1.3 Nanogrid Control Topologies . . . . . . . . . . . 43

3.2 Chapter Summary . . . . . . . . . . . . . . . . . . . . 49 
4 Nanogrid Control System $\quad 51$

4.1 Nanogrid System . . . . . . . . . . . . . . . . . . 51

4.1.1 Maximum Power Point Tracking . . . . . . . . . . . . . 52

4.1.2 Central and Node Controllers . . . . . . . . . . . . 59

4.2 Thermostatically Controlled Loads . . . . . . . . . . . . . 67

4.2.1 Water and Space Heating . . . . . . . . . . . . 67

4.2.2 Refrigerator ............... 78

4.3 Simulation, Results and Discussion . . . . . . . . . . . . 82

4.4 Chapter Summary . . . . . . . . . . . . . . . . 91

5 Interconnected Nanogrid Network 93

5.1 Nanogrid Network Scenarios . . . . . . . . . . . . . . . 95

5.1.1 Uncontrolled Nanogrid Network . . . . . . . . . . 95

5.1.2 Individually Controlled Nanogrid Network . . . . . 98

5.1.3 Combined Control Nanogrid Network . . . . . . . 100

5.2 Simulation, Results and Discussion . . . . . . . . . . . 107

5.2.1 The Effect of Varied PV Capacities . . . . . . . . . . . 110

5.3 Chapter Summary . . . . . . . . . . . . . . . . . . . 115

6 Conclusions and Future Work 117

6.1 Future Work . . . . . . . . . . . . . . . . . . . 123

$\begin{array}{ll}\text { A Load Characteristics } & 157\end{array}$ 


\section{Chapter 1}

\section{Introduction}

Existing power infrastructures are currently facing a number of adversities which, inherently, they are ill-equipped to resolve. These problems stem partly from the use of long distance transmission lines delivering power from large central generators to consumers [1,2]. This method of power distribution leads to major line losses, which reduces the grid's efficiency [3]. It also makes the grid susceptible to costly power outages caused by environmental (e.g. heavy rain or wind) and non-environmental (e.g. equipment failure due to age) events [4,5]. These large central power generators are often fossil fuel based solutions, contributing to the 30.8 billion tons of carbon dioxide released into the atmosphere each year [6]. Another major issue is the estimated 1.2 billion people globally, who do not have access to electricity [7]. A majority of these people live in rural or isolated communities, to where extending the grid is often considered uneconomical $[8,9]$.

For social, environmental and financial reasons these inadequacies need to be addressed and one solution under research is distributed generation (DG) $[10,11]$. DG looks to remedy the issues inherent in the current power system, by producing power close to the point of use [12]. This reduces the need for long distance transmission, increasing efficiency and creating a robust system (reducing outages) [13]. The power capacity of DG is much 
smaller than a central power generator, making it a versatile power solution [14]. So much so that it can enable a typical consumer of power to also produce power from their residential or commercial property. This makes DG a structure capable of meeting power requirements for consumers living in rural or isolated communities [15]. And as distributed generation is often, but not limited to renewable, carbon neutral energy (e.g. wind and solar), it also has the ability to reduce global carbon emissions [16].

\subsection{Motivation}

Distributed generation, particularly renewable energy (RE), has two major disadvantages preventing its widespread integration into residential/ commercial properties [17]. The first is the intermittent nature of its power output [18]. Take for example photovoltaic modules, of which the output power fluctuates with the energy produced by the sun, causing variations in magnitude frequently over the course of a day [19]. As most electricity consumers expect power instantaneously, such intermittency can deter consumers from investing in RE [20]. The second is the financial capital required to install RE sources and the lengthy payback time before seeing a financial return [21].

Globally, feed-in tariffs are offered by a number of countries to offset the set up cost, incentivising the installation of renewable energy sources (such as photovoltaic (PV) modules) [22]. However, there are a large number of countries, for instance New Zealand (NZ), where no feed-in tariff is offered. In NZ, power is purchased by the customer for approximately $28 \mathrm{c} / \mathrm{kWh}$ and around $10 \mathrm{c} / \mathrm{kWh}$ is received for power sold back to the grid $[23,24]$. This decreases the viability of PV installations, discouraging the uptake of carbon neutral power sources at a time when stringent greenhouse gas targets are being set by the government. In these instances, an alternative must be sought to incentivise PV systems, making them an economically viable option. 
The research undertaken for this thesis looks to address these issues from a technical perspective. This entails using a controlled power structure to increase the correlation between power production and consumption, exploring the potential to reduce the effects of intermittency and increase the financial viability of PV. The controlled power structure selected for this role is the nanogrid.

\subsubsection{Gaps in the Research}

Chapter 2 presents a comprehensive summary of the literature surrounding the nanogrid field of research. From this analysis a number of gaps were identified which give context to this research and further motivate the thesis. These are as follows:

- Nanogrid definition: While there are a number of characteristics suggested within the nanogrid literature to differentiate the nanogrid from other power structures, the definition itself is vague and varies.

- Thermostatically controlled loads: Undertaking a variety of roles within the literature, to offer customers financial benefits, thermostatically controlled loads typically require external influence such as pricing schemes or utility company control signals. The research fails to offer independent control strategies, utilising multiple thermostatically controlled loads, to incentivise the uptake of PV.

- Maximum power point tracking control signal: Used traditionally for maximising the output of PV modules, the maximum power point tracking signal is not used within the literature to implement load control strategies.

- Interconnected nanogrid network: Relatively new in the nanogrid literature is the concept of connecting multiple nanogrids to create a 
larger power entity (e.g microgrid). Control strategies, specifically strategies that consider all the nanogrids within the larger entity to form a cohesive control structure, are not yet presented within the literature.

The goal of addressing the disadvantages associated with household PV installations, combined with the gaps within the nanogrid literature, have led to the formation of the research statement and research objectives for this thesis.

\subsection{Research Statement and Objectives}

Small-scale renewable energy sources have the potential to both reduce carbon emissions and reduce the pressures on, and inefficiencies of, centralised energy grids. But, despite these benefits, the intermittent nature and financial cost of renewable energy presents a daunting challenge for individuals and small community users when adopting small-scale renewable energy sources. This study investigates the use of control within a nanogrid to reduce the effects of intermittency, making small-scale renewable energy more accessible to individuals and small scale community users. The control strategy will then be expanded to facilitate interactions between multiple nanogrids, forming a microgrid, to evaluate the potential to further reduce the effects of intermittency.

To achieve this research statement, the following research objectives have been set:

1. The issue with the current literature is that it leaves the definition of a nanogrid structure ambiguous, suggesting various characteristics and/or bounds to differentiate the nanogrid as its own power structure. The distinction between a nanogrid and micro-/macrogrid must be made for the following reasons: 
- Nanogrids play a different role to micro-/macrogrids in the power hierarchy. For example, by connecting multiple nanogrids a microgrid can be formed. This introduces an alternative approach to the traditional microgrid, which can only be discussed given the distinction between nanogrids and microgrids.

- The potential markets for nanogrids are different to that of micro/macrogrids. A nanogrid allows a power structure to be obtained at a relatively low cost compared to micro-/macrogrids. This then shifts the interest from large/multiple investors, to home/small business owners.

- As the nanogrid structure is confined to a single home, the technical objectives, hardware and software often vary from that of a micro-/macrogrid. By refining the subject area, it clarifies the field of research.

To ensure this distinction can be made, a concise definition of a nanogrid structure must be derived from the various characteristics suggested within the current literature.

2. A nanogrid control strategy that will increase the correlation between power consumption and PV production, reducing the negative effects of solar intermittency, will be developed. The strategy should help to reduce power purchased and sold by the consumer, from/to the power grid, helping to incentivise small scale PV systems. To avoid additional cost, an alternative to traditional purpose-specific storage methods (eg battery banks) should be sought. The system should be simulated under a variety of load/solar irradiance conditions comparing the grid consumption of the controlled nanogrid with the uncontrolled to ascertain the reduction in grid power consumed by the nanogrid.

3. A control strategy that will facilitate an interconnected nanogrid net- 
work will be developed. This will allow the sharing of power within a cluster of houses, taking advantage of the diverse power consumption patterns the households will present. The nanogrid control strategy should be extended to consider the combined consumption and production of a cluster of houses to further reduce the effects of intermittency. When simulated, a comparison between the uncontrolled cluster, individually controlled cluster and combined control cluster should be made to quantify the success of the solution. A successful solution should see the combined control reduce the grid power consumed by the cluster of houses when compared to the other two scenarios.

\subsection{Major Research Contributions}

The implementation of these research objectives will deliver the following major research contributions:

1. This thesis presents a rigorous analysis of the general nanogrid definitions given within the literature, discussing their merits and weaknesses from which a concise definition of a nanogrid structure is derived. The traditional supply side management control structures are presented and extended to include demand side management. A new control structure which improves the hybrid central control strategy is also presented.

Part of this contribution has been published in: Daniel Burmester, Ramesh Rayudu, Winston KG Seah, Daniel Akinyele. "A review of nanogrid topologies and technologies", Renewable and Sustainable Energy Reviews, vol 67, p 760-775, Elsevier, 2017

2. This thesis develops a novel nanogrid control scheme that makes use of thermostatically controlled loads to address intermittency of photovoltaic (PV) modules, negating the need for traditional storage 
and enabling the user to reduce grid power consumed. This strategy shifts away from direct or indirect control signals received from the utilities and introduces the concept of using a maximum power point tracking signal to instantaneously shift electricity consumption, dynamically matching local PV production. Simulated under a variety of load and solar irradiance conditions, the nanogrid control scheme shows the ability to reduce grid power consumed by $44 \%$.

Part of this contribution has been published in: Daniel Burmester, Ramesh Rayudu, Winston KG Seah. "Use of Maximum Power Point Tracking Signal for Instantaneous Management of Thermostatically Controlled Loads in a DC Nanogrid", IEEE Transactions on Smart Grid (Accepted for publishing), DOI 10.1109/TSG.2017.2704116, 2017

3. This thesis presents a control scheme that facilitates the interconnection of multiple nanogrids. This scheme extends the capabilities of the single nanogrid control to dynamically match the consumption and production of a cluster of interconnected households. This control scheme further reduces the effect of intermittency, taking advantage of diversity of consumption within a cluster of houses. A comparison of grid power consumed by the cluster of houses is presented, considering uncontrolled, individually controlled and the combined control scenarios. The simulated tests show that, compared to an uncontrolled nanogrid network, the combined control can reduce power purchased by as much as $55 \%$, while a $7 \%$ decrease is seen when comparing the combined control with the individually controlled nangrid networks. When compared to an uncontrolled individual house scenario, the combined control interconnected nanogrids can reduce the grid power consumed by as much as $61 \%$. 


\subsection{Research Strategy}

This thesis investigates the topology, control and interconnection of nanogrids to motivate the uptake of PV at a household level. In order to achieve the goals set out, the following research strategy was developed:

- To situate the research within the nanogrid field and gain knowledge of the area of research, it was important to perform an initial literature review. From this, the successful control approaches could be identified to help guide the research direction, and gaps in the control theory could be identified, delivering avenues for improvement. As nanogrid research is frequently progressing, it was also important to regularly update the literature review, staying informed of the state of the art.

- Once this knowledge base was established and gaps in research identified, initial ideas for a new solution were mind mapped. These were refined into a pseudo algorithm which address the mains points of action for the solution. A mathematical representation of the pseudo algorithm was developed, before it was coded.

- In order to evaluate the impact of the solution, it was decided a simulated comparative case study would be implemented. The comparative study would observe the grid power consumed by a household, with and without the proposed solution. The success of the outcome would be quantified by the magnitude in which the grid power consumed by the household was reduced. To ensure the modelled household load curve did not present biased results, ten different household loadlines were established, which were simulated with solar irradiance data for a week in summer and winter.

- Once the simulated test scenarios were established, an iterative process was established which involved analysis of results, reflection 
and progression. The analysis looked successful the solution was and where there was room for improvement. Then, during the reflection, strategies were developed for addressing the shortcomings of the solution, of which the most effective was selected. This was then added to the solution and the progressed model was re-simulated and evaluated. 


\section{Chapter 2}

\section{Literature Review}

In order to situate the research presented in this thesis and affirm its novelty, the research areas surrounding the thesis have been reviewed and presented in this chapter.

The contributions of this thesis include work in the nanogrid control area, so the major trends and contributions in the nanogrid control literature are outlined and discussed. While nanogrid hardware is not a focus of this thesis, it closely relates to the control and is a major research area within the nanogrid literature. For this reason, the hardware and its function within the nanogrid is presented as well as the novel converter types offered by the nanogrid literature.

In this thesis, the nanogrid control would not be possible without the use of thermostatically controlled loads. In fact, the manner in which they are used within the system itself adds novelty to the thesis. For this reason, the literature concentrating on thermostatically controlled loads is reviewed giving an overview of the definition, motivations and implementations of these flexible loads.

Lastly, interconnected nanogrid network research presented in the literature is reviewed with the advantages, future directions, and the state of the art analysed. 


\subsection{Nanogrids}

Nanogrids first made an appearance within the literature in 2004 [25], increasing in popularity from 2010 as shown with the plot of a keyword search (Elsevier and IEEE database) in figure 2.1. The literature can be split roughly into the following groups: Nanogrid control; Nanogrid hardware; Interconnected nanogrid networks; Works summarising the nanogrid concept including future developments. The majority of the literature falls into the first two categories (control and hardware), with a small number of conceptual papers and the relatively recent addition of the interconnected nanogrid network topic.

An in-depth discussion of the nanogrid topology and definition is presented in chapter 3 , but for clarity and context within the literature review, a nanogrid is defined as:

" a power distribution system for a single house/small building, with the ability to connect or disconnect from other power entities via a gateway. It consists of local power production powering local loads, with the option of utilising energy storage and/or a control system."

\subsubsection{Nanogrid Control}

Nanogrid control can be divided into two categories; supply side management (SSM) and demand side management (DSM). Supply side management focuses on controlling the nanogrid's supplies and energy storage (such as PV, small scale wind turbines, battery banks, etc) to ensure the demand (load) is met and/or the state of charge (battery banks) is optimised. This is an important aspect of nanogrid control as often multiple sources exist and their integration needs to be balanced in such a way that a specific source can be selected to supply the nanogrid (eg with a grid tied PV system, it is favourable to supply the loads with the PV first, before supplying the unmet load with the grid).

The most popular form of SSM within the nanogrid literature is droop 


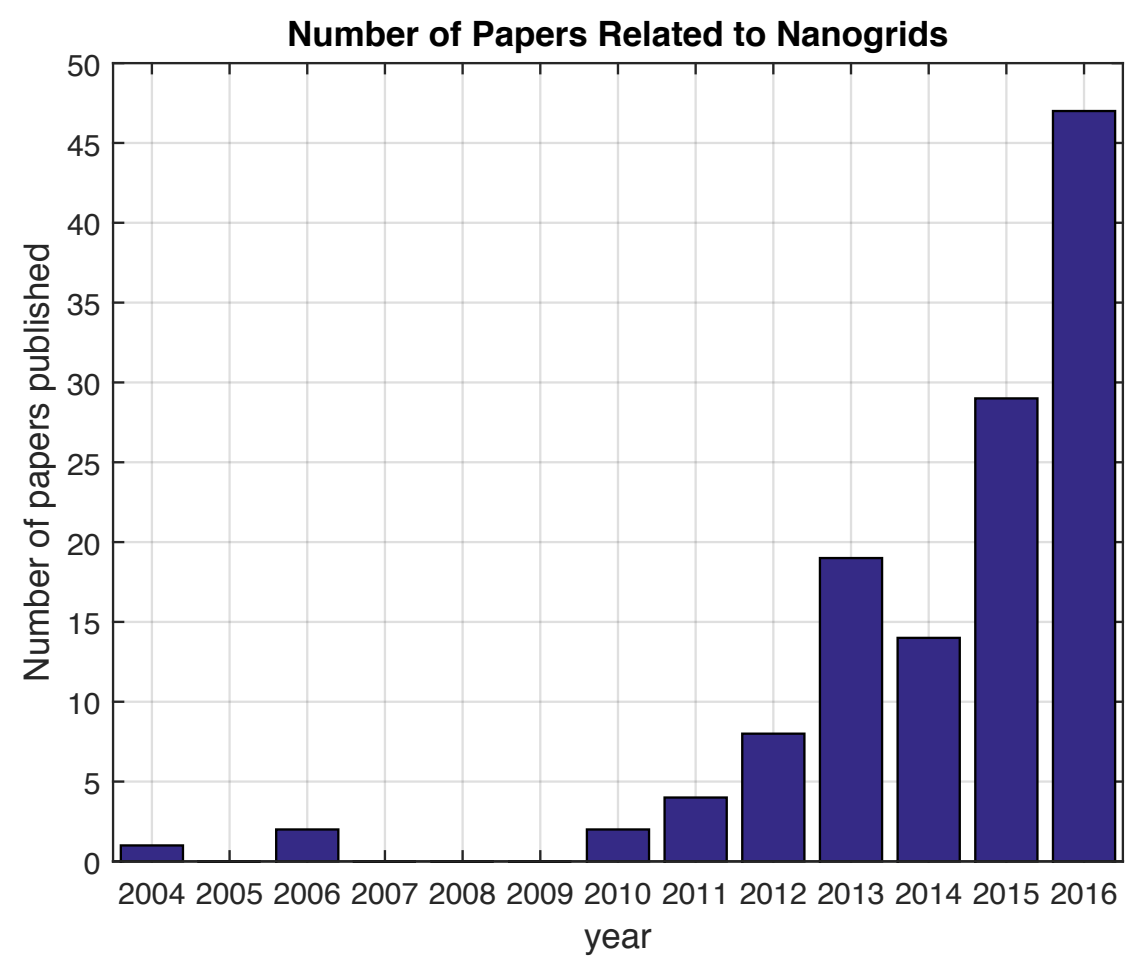

Figure 2.1: Number of nanogrid papers published since its realisation.

control [25-34]. In DC nanogrids the bus voltage is monitored, as the load increases, the bus voltage "droops" (while in AC, frequency droop can be used) with certain voltage levels engaging the appropriate supply (eg 380V-375V photovoltaic supply, 375V-370V battery bank supply added, 370V-365V grid supply added).

There are also alternative solutions, for example using nodes to route power as suggested in [35]. The goal of the system is to ensure all loads are supplied with the appropriate power while ensuring the generators are not overloaded. This is achieved with multi-port nodes that can select the appropriate path between a generator and load via communication and a "request/offer" routing algorithm.

Maximum power point tracking is often used in nanogrids when pho- 
tovoltaic modules are used as a supply. Typically these are in series with the photovoltaic modules, adjusting the impedance seen by the modules in order to ensure the maximum power is extracted from them. In [36] however, SSM is implemented within the nanogrid to create a maximum power point tracker that operates in parallel with the photovoltaic modules. It adjusts the power from an additional power source (eg grid) to meet the difference between the load's requirement and the maximum power point of the photovoltaic modules, which reduces losses in the system.

Demand side management on the other hand, manipulates the load to meet the characteristics of the supply, which is the focus of the research presented in this thesis. This can be achieved in a number of ways, with a variety of different primary motivations.

Load shedding is a DSM technique where the loads are switched off to achieve a desired control goal. Authors of [26] and [37] use load shedding to reduce peak load demand and to prevent overloading of the DC bus. Much like the droop control discussed above, DC bus signalling is used (droop control) in this case to switch off designated loads when certain voltage levels are reached.

Load scheduling adds a level of flexibility to DSM. Rather than switching off loads, the control strategy calculates an appropriate time for the load to operate. The control signals, techniques and indeed motivations for implementing this control strategy varies throughout the literature. In [38] and [39], the control signal is obtained for the utilities (grid power supplier) in the form of real time pricing. This takes advantage of dynamic power pricing, shifting consumption to times when a low power price is offered (off peak price). [38] defines this as an optimisation problem, in the form of an "optimal stopping problem", with the goal of minimising cost or maximising profit. In [39], a rule-based method is used to move or reduce the load when the price of power is high. Storage is also con- 
sidered in this system, either charging or discharging the battery bank to anticipate future increases in the power price.

Another objective of load scheduling is flattening peak demand as suggested in [40]. The motivation behind this system is to reduce the difference between peaks and troughs of a household's power usage. This in turn creates a flatter demand reducing the grids operational costs, including transmission, generation, and fuel costs. This system uses "Least Slack First" policy, inspired by the "Earliest Deadline First" algorithm to shift thermostatically controlled loads based on control signals received from the utility companies (real-time electricity prices and demand-response signals from the grid).

\subsubsection{Nanogrid Hardware}

There are a variety of technologies used with nanogrids, but the subject that dominates the nanogrid literature is converter topologies. Converters are responsible, within the nanogrid, for manipulating voltages to meet the requirements of a specific task. This is typically (but not limited to) interfacing the nanogrid's sources with the system's bus and the national grid, along with interfacing the nanogrid's loads with the bus as shown in Fig. 2.2 [41]. The common categories of converters used in nanogrids are, $\mathrm{DC}$ to DC, DC to AC and AC to DC [42].

DC to DC converters accept a DC voltage at the input and output a modified DC voltage. The amplitude of the converter's output voltage can be smaller or larger than the input voltage. To achieve this change in amplitude, the converters use reactive components (capacitors and inductors) and switching components such as diodes, metal-oxide-semiconductor fieldeffect transistors (MOSFETs) and insulated-gate bipolar transistors (IGBTs) $[43,44]$. By rapidly switching the converter between states, using pulse width modulation (PWM), the necessary output voltage can be attained. Moreover, by measuring the output (or input) voltage (or current) 


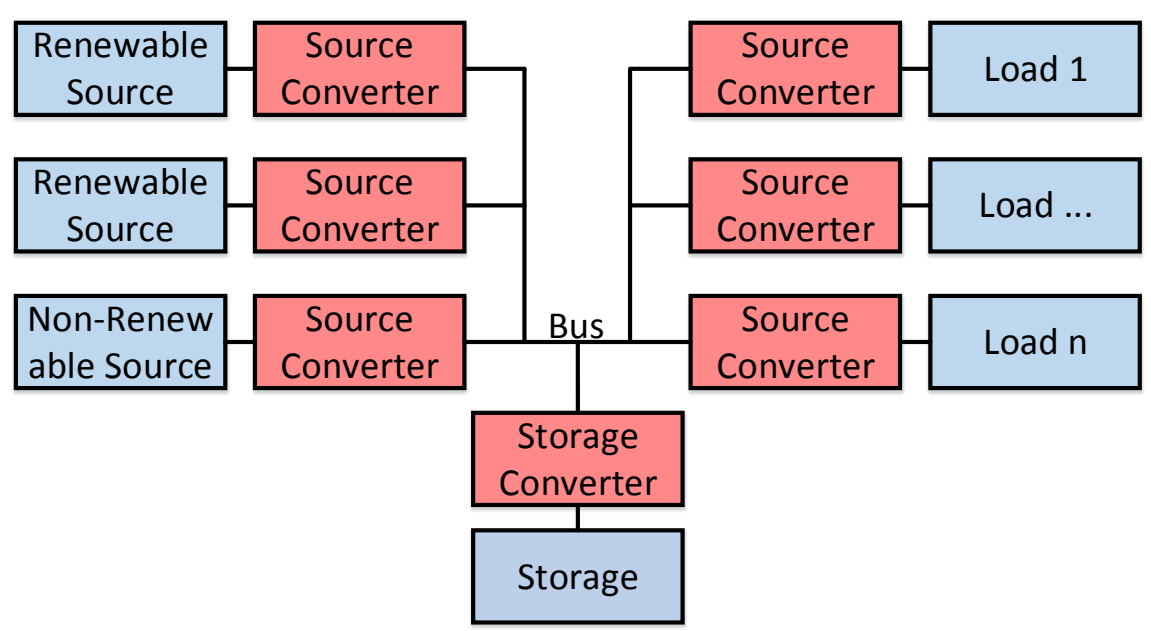

Figure 2.2: Hardware structure of a nanogrid

of the converter, the PWM can be altered to ensure the output voltage remains stable even when the input voltage varies. This property is essential when implementing nanogrid control strategies such as droop control. The most commonly used DC to DC converter topologies are buck style converters (output voltage is always less than the input), boost style converters (output voltage is always greater than the input) and buckboost style converters (output voltage can be either greater or less than the input).

It is easy to see then, how these converters may be used within a DC nanogrid. Take for example Fig. 2.2, here the source converters would take the varying/low DC input voltage and boost the output to the required $380 \mathrm{~V}$ for the DC bus. At the other end of the chain the load converter will buck (reduce) the bus voltage $(380 \mathrm{~V})$ to a level the loads can use $(12 \mathrm{~V}, 24$ $\mathrm{V}$ or $48 \mathrm{~V})$.

There are other tasks the converters can perform within the nanogrid, such as maximum power point tracking (MPPT) of a renewable source or charge controlling a battery bank. The goal of MPPT is to address the nonlinearities presented to a system by a renewable source (primarily photo- 
voltaics but can also apply to wind turbines) [45]. A converter being used for MPPT is controlled with the PWM, according to an MPPT algorithm, to present an optimum impedance to renewable energy source. This is to ensure the source is always operating at its maximum power output [46]. Charge controllers make use of converters to regulate the speed of charging and ensure battery banks are not overcharged, which lengthens the life of a battery bank [47].

DC to AC converters accept a DC voltage at the input and output an AC voltage. This procedure is also implemented with reactive components, switching components and PWM. DC to AC converters often have a DC to DC converter front end to ensure the DC input is of the right amplitude for the AC conversion. The DC to AC converter has similar characteristics to the AC to DC converter, which accepts an AC voltage as an input and outputs a DC voltage. In fact it is not rare to see bidirectional converters of this nature. As the name would suggest, these are converters that can work as an AC to DC converter, and in reverse, a DC to AC converter. This is ideal for grid tied DC nanogrids which will in some circumstances feed the grid AC power, and in others receive power from the AC grid which will need to be converted to DC for the nanogrid.

The research undertaken within the nanogrid literature is focused on increasing the efficiency of the converters used within the nanogrid. It also looks to improve power quality for the loads that require high power quality, reduce the physical size of the nanogrid system and increase the ease of controllability within the nanogrid. These goals are achieved by researching multiple input/ output converters, switching variations, galvanic isolation and alternative topologies [48]. Table 2.1 outlines some novel converter hardware contributions within the research on nanogrids. 
Table 2.1: Novel converter hardware contributions from nanogrid research

\section{Converter technology Type of con- Hardware novelty verter}

Dual-active-bridge based Bidirectional This converter makes use of Lithiumbidirectional micro- DC to AC Ion Ultra-Capacitors (LICs) for inverter [49] short term storage in a synchronous boost converter, which improves the nanogrid's power quality by reducing the $\mathrm{dP} / \mathrm{dt}$ factor of photovoltaic modules and increases fuel economy of the diesel generators.

Multi-port power con- DC to DC verter architecture [50] The proposed converter topology replaces the control switch of a conventional boost converter with a fullbridge network consisting of four switches creating both an isolated and non-isolated output for devices that require galvanic isolation and those that do not.

Boost-derived hybrid con-

$\mathrm{DC}$ to $\mathrm{DC}$ and verter [51] $\mathrm{DC}$ to $\mathrm{AC}$ The control switch of a conventional boost converter is replaced with a bidirectional single-phase bridge network. This provides an AC output and DC output simultaneously which is a benefit when operating a nanogrid with both AC and DC loads. 
Multi-input single- DC to DC inductor converter [52]

Dual-input interleaved DC to DC buck/boost converter [53]

Single-stage multistring DC to AC photovoltaic inverter [54]
The conventional topology of a multiinput, single-output DC-DC converter uses multiple inductors to filter the output voltage. The multi-input single-inductor converter replaces the multiple inductors with a single inductor reducing the cost of the converter.

Proposed is a dual-input isolated dcdc converter which interleaves a buck and boost converter circuit. This converter also makes use of galvanic isolation on the output, making the system ideal for use in hybrid renewable energy systems with an energy storage system present.

This inverter is a grid-tied multistring converter with a high-frequency AC link, soft-switching operation, and high-frequency galvanic isolation. This means an arbitrary number of photovoltaic modules can be connected and the converter can gain maximum power from each. This converter provides high efficiency, high power density and high reliability. 
Multi input single control DC to DC

Grid-interface bidirec- Bidirectional tional converter [56], [57] DC to AC and [58] converter [55]

This converter is a multi-input boost topology, but rather than controlling each input of the converter individually, it takes a single control approach. It does so by assigning the status of master source to one input and slave source to the remaining $\mathrm{N}-1$ inputs. The master source controls the duty cycle of the mutual switch.

This two-stage single-phase converter uses two phase legs as the full bridge to interface the grid. It then introduces a third phase leg as a bidirectional switching regulated DC to DC converter. This increases circuit protection, simplifies black starts and looks to improve power density by reducing the size of the DC-link capacitor.

Current-Fed Switched In- DC to AC and verter [59] and [60] DC to DC
Here, a new inverter technology is presented that can supply both DC and AC loads. This converter is derived from the current-fed DC to DC topology which uses an input inductor, as does the inverter, meaning continuous input current. The inverter exhibits improved electromagnetic interference (when compared to other commonly used inverters) which is the reason for some failures within inverters. 
Isolated bidirectional Bidirectional ACDC converter [43]

Switched boost in- DC to AC and verter [61] and [41]

Cuk-derived hybrid converter [48]
$\mathrm{AC}$ to DC
$\mathrm{DC}$ to $\mathrm{AC}$ and $\mathrm{DC}$ to DC
This converter suggests the use of multiple switching technologies including insulated-gate bipolar transistors (IGBTs) without an antiparallel diode, MOSFETs, and silicon carbide $(\mathrm{SiC})$ diodes. With this comes a frequency detection method using an advanced filter compensator, a fast quad-cycle detector, and a finite impulse response (FIR) filter.

This inverter is based on the inverse Watkins-Johnson topology. However, it implements a DC output on the diode leg of the DC to DC converter section. It also makes use of shoot through current, meaning this converter can either buck or boost its output voltage.
To create both AC and DC power from a Cuk converter, the control switch is replaced with a single phase voltage source inverter bridge network. Three modes of operation are then defined by utilising the bridge switches allowing the Ćuk-derived hybrid converter to achieve the required goal of creating AC and DC power. 
Sepic derived hybrid con- DC to AC and Much like the Ćuk-derived hybrid verter [62] DC to DC

Single-Input-Multi- $\quad$ DC to DC Output (SIMO) Converter [63] converter [48], the Sepic derived hybrid converter replaces the control switch with a inverter bridge network either single phase or, in this case, three phase. Again there are 3 control modes which achieve the AC and DC output.

While receiving a single input, this modified boost converter outputs three voltage levels. Outputting three DC voltages has the advantage of low switching losses and high power quality waveforms. The SIMO converter consists of an input circuit, an output voltage low, output voltage mid and output voltage high.

\subsection{Thermostatically controlled loads}

Thermostatically controlled loads are loads that require little to no human input, instead operate autonomously inside a temperature bound (eg water heater, space heating, refrigerator). These loads make up a large portion of the daily residential consumption (61\% of in home electricity consumption [64]), with, for example, the water heater using $2 k W-4 k W$ of power for extended periods of the day.

Thermostatically controlled loads have the advantage of being able to store energy (as heat), with their slow thermal dynamics offering an opportunity to shift the loads' consumption to a required time (within reason). 
The majority of the literature surrounding the use of thermostatically controlled loads concentrates on implementing control based on signals received from grid operators (utility companies) [65-104]. There are a number of motivations for the utility companies to pursue this control, eg; grid frequency control, grid voltage control, help to mitigate the negative effects of increased renewable energy penetration in the grid. The control signals come in two forms, direct and indirect control.

Direct control systems receive instruction directly from the utility companies which allow them to turn on/off thermostatically controlled loads when necessary. While this technique has fast feedback, it can create a level of discomfort for the end user. The user comfort, for example having hot water when required, is a topic of much discussion within the direct control scheme literature.

Indirect control on the other hand is implemented by the user with incentives supplied by the utility companies to ensure cooperation. The thermostatically controlled load algorithms in this area of research concentrate on controlling the on/off times of the loads to coincide with off peak pricing. The motivation for the end user is a reduction in their cost of power, and in turn allows the utility companies to offer off peak pricing during times of low power use.

Thermostatically controlled loads have also been used within microgrids to address the stabilisation of high renewable energy source penetration systems. This can refer to grid tie-line, smoothing power fluctuations, and improving power quality $[105,106]$. Another strategy is to use thermostatically controlled loads to avoid large spikes in the consumption curve and to match the stochastic power generation of renewable energy sources. This is addressed in [107], where a microgrid central load serving entity is implemented to perform direct load control. The central load serving entity can set the temperature of a building's air conditioning unit to shift its consumption. It considers the renewable energy production to 
be a wind turbine, with simplified "on" or "off" output.

At a single house level, optimisation techniques (such as particle swarm optimisation) and/or scheduling algorithms are used to shift thermostatically controlled loads to accommodate events such as charging of electric vehicles, reduction of peak power and optimisation of energy use [108-111].

The research presented in [112] looks to increase the photovoltaic "selfconsumption ratio" (photovoltaic power used in the home) through the control of an electric water heater. The control system has the ability to access the two elements in the electric water heater separately to give it three consumption levels (each element is a different load and the third is the two elements on simultaneously). The system is then optimised to use the three levels of power consumption to better utilise the local photovoltaic power consumed.

\subsection{Interconnected nanogrid network}

A nanogrid is a versatile power structure, as it addresses the power requirements of the end user. This makes it ideal for creating a hierarchical power system that takes advantage of diversity within a community. By interconnecting nanogrids, sharing power and communication, a microgrid can be created.

Much like a nanogrid, a microgrid is a power distribution system with the ability to island itself from other power entities. However, a nanogrid's capabilities are targeted at powering a single house/small building, while a microgrid spans hospitals, university campuses and/or small communities (as the case may be with interconnecting nanogrid networks).

Although the theory behind interconnected nanogrid networks, in general, is still at a high level, exploration has begun and implementation is being pursued.

The advantages and future research topics for nanogrid networks are 
outlined in [113-117], these are:

- Bidirectional power sharing is the main function of a nanogrid network. Houses/small buildings are almost guaranteed to have varied instantaneous power consumption curves and may also have varied power production capabilities. The diversity of electronic devices and consumer behaviour is responsible for the variety of consumption curves. This is similar with power production, where the renewable energy source, capacity, and use of storage all play a role in creating varied production patterns. In the case of a nanogrid network, the diversity works in its favour to utilise the sharing of excess power [118]. As consumption/production peaks and troughs of individual nanogrids vary within the nanogrid network, it is likely that the demand can be met by the various connected nanogrids. By sharing power within the nanogrid network, the need to purchase power from an external source (national grid) is reduced. This equates to financial savings for the consumers within the network.

- Communication is an important aspect within the nanogrid network as it lies at the heart of information sharing, which is what creates an intelligent network [119]. There are multiple layers of communication within a nanogrid network and as with any information sharing, a number of technical and security based considerations. The layers consist of internal nanogrid communication, which the nanogrid controller uses to gather data and implement control strategies pertaining to single house/building level power flows. The next layer is microgrid communication which organises power offers/requests between individual nanogrids and may deal with the financial aspect of selling/buying power within the network and to the national grid. The national grid level will focus on DSM/SSM at the national level but would also be expected to have minimal involvement in day to day communication. This then creates a complex communi- 
cation network where delicate information is shared. Although the technical aspects of a communication network fitting a nanogrid network still requires research/ definition, it is not confined to novelty as appropriate data protocols such as ModBus, TCP/IP and RS485 already exist $[120,121]$.

- Financial benefit is a motivating factor for operating a controlled nanogrid and is also an incentive for the interconnection of multiple nanogrids (nanogrid network) [114]. By adding a financial cost to power shared within the nanogrid network, this motivation can be realised. Within the nanogrid network, a nanogrid can either be a source of power (if excess power is available from the nanogrid) or a load (if power is required by a nanogrid). If a source, the nanogrid can sell power either to another connected nanogrid at a negotiated price, or to the national grid at the set buyback price. As the price within the nanogrid network can be negotiated based on variables such as quantity of available excess power and grid buyback/purchase price, the cost of power can be customised to benefit both the buyer and seller. Meaning power can be sold within the network at a price less than the grid purchase price but greater than the buyback price.

- Withstanding power grid outages is important now our lives rely so heavily on power. The nanogrid network has the ability to island itself from the national grid in the case of a blackout. In islanded mode the nanogrid network will be an individual power entity, servicing the connected nanogrids. This means the production and storage power within the nanogrid network, like a microgrid, can continue to power loads for a period of time [122]. The period of time is dependent on renewable energy availability (sun/wind) and storage capacity, but if well designed the network should be able to withstand a lengthy blackout.

- Gradual introduction is an advantage to the nanogrid network paradigm. 
As nanogrids operate at a single house level, it is envisioned that the introduction of small nanogrid networks can take place over an appropriate length of time [118]. This negates the need for investing large sums of money on replacing central power plants over a short time period. Instead, nanogrid networks can be integrated into the existing national grid at a manageable rate.

- Grid stability is another consideration, though not yet pursued within a nanogrid network context. It has been suggested that the nanogrid network has the ability to respond quickly to commands from the utility grid. This gives the nanogrid network the opportunity to participate in grid stabilisation, voltage and frequency control and realtime pricing at a national grid level.

In these early stages of interconnected nanogrid network research, papers are beginning to emerge which discuss some level control. Presented in [123] and [124], is the analysis and optimisation of power flows between nanogrids (within a network). This control is focused on ensuring the power flows between nanogrids and the state of charge of the battery banks are optimised for DC and hybrid (DC and AC) systems. However, these papers do not pursue demand side management nor do they attempt to increase the correlation between PV production and network consumption.

The research presented in [125] motivates the interconnected nanogrid network approach to microgrids by comparing central and distributed architectures. It concludes that the distributed generation distributed storage architecture (nanogrid network) has a higher efficiency, lower line losses and less voltage drops when compared to a centralised scheme. This solidifies the necessity of further research into the field of interconnected nanogrid networks.

A multi-objective optimisation model is presented in [126] which works to achieve a minimised net cost of electricity for each nanogrid within the 
network. It uses a local buy/sell power price scheme, as well as prices offered by the grid to implement energy management for local production and storage. The price scheme developed encourages the sharing of power between nanogrids by offering a favourable price when compared to that offered by the grid.

One research group in particular is making progress in the area of interconnected nanogrid networks with the implementation of a testbed. In the papers $[118,120]$, the team present a reasonably in depth discussion on the nanogrid network they are currently installing. The proposed nanogrid network operates on DC power, where the network itself is not connected to the grid, but this option is available to individual nanogrids. The system operates on the concept that power is not sold back to the grid, but instead power is shared exclusively within the network. A power sharing control technique (other than non-droop) for the testbed is presented in [127] which facilitates the sharing of power within a cluster of houses.

\subsection{Chapter Summary}

An in-depth analysis of the related works presented in the literature has been undertaken and summarised. The topics and general conclusions from the literature review are as follows:

- Nanogrid Control: The goal of control within a nanogrid, for the user, is to increase the system's efficiency and reduce the cost of power, and from a utilities perspective, gaining stability for the grid. The two main control strategies within a nanogrid are SSM and DSM, which work to control the power sources and loads respectively. The major SSM technique is droop control, with only a small number of alternatives offered in the literature. DSM is varied with a number of algorithms and optimisation techniques presented. However, 
within the literature, there are no attempts to motivate the use of photovoltaics utilising the maximum power point tracking signal or modulating the voltage to thermostatically controlled loads to vary the power consumed.

- Nanogrid Hardware: Nanogrid control and hardware are closely related, as the hardware within nanogrids are responsible for manipulating voltages, implementing maximum power point tracking, grid connection and controlling loads. Power electronic converters are the main focus within the literature, which has in turn offered a number of novel converter topologies to increase efficiency and allow the integration of AC and DC loads/sources. While hardware is not a major focus of this thesis in terms of novelty, the nanogrid presented does rely on converters in a number of areas.

- Thermostatically Controlled Loads: Thermostatically controlled loads can be used to implement DSM, shifting loads to address a variety of control objectives. Generally speaking, they are used in conjunction with control signals, directly or indirectly obtained from the utilities. This allows the utility company to manipulate consumption in exchange for incentives offered to the customer. In other cases, thermostatically controlled loads can be utilised to implement independent control within a household to serve the customer directly. The control strategy outlined in this thesis uses multiple household thermostatically controlled loads to increase the correlation between household consumption and PV power production, which is an unexplored area within the literature.

- Interconnected Nanogrid Network: The topic of interconnected nanogrid networks is relatively new within the literature, explored mainly at a conceptual level until recently. While a small amount of control research is beginning to appear, the strategies are concentrating on power flows and SSM, there is no DSM strategies presented. The 
interconnected nanogrid combined control exhibited in this thesis utilises thermostatically controlled loads to implement a cohesive DSM control strategy for a cluster of nanogrids. 


\section{Chapter 3}

\section{Nanogrid Topology and Definition}

The majority of the available nanogrid literature focuses on the control and hardware, with a variety of algorithms and power converter topologies being discussed. The idea of utilising the nanogrid's modular nature to form a network of interconnected nanogrids is also presented within the literature, though in most cases this is still at a conceptual level. The problem with the current literature is that it leaves the definition of a nanogrid itself reasonably ambiguous, suggesting various characteristics and/or bounds to differentiate the nanogrid as its own power structure.

In this chapter, the general definitions given within the nanogrid literature are collated and their merits and weaknesses are discussed, from which a concise definition of a nanogrid structure is developed. An overview of the control topologies are then presented, discussing not only their use for supply side management but extending it to demand side.

Part of this chapter has been published in: Daniel Burmester, Ramesh Rayudu, Winston KG Seah, Daniel Akinyele. "A review of nanogrid topologies and technologies", Renewable and Sustainable Energy Reviews, vol 67, p 760-775, Elsevier, 2017 


\subsection{Definition and Background of Nanogrid}

Defining a power structure is a challenging task as opinions vary and often the boundaries between power structures are hazy. A good place to start is a point of reference. As [27-29,113, 115-117,120,128-130] suggest, a nanogrid is analogous to a microgrid. So we will begin by discussing the similarities between nano- and microgrids before identifying some key characteristics that can be used to separate the two power structures.

At the most basic level, by all accounts, a nanogrid is a power distribution system, as is true for microgrids [57,58,61,116,131-138]. Nanogrids have the capability of operating in islanded or grid connected mode which again is a characteristic also found when discussing microgrids $[15,28,29$, $113,116,139-141]$. Another common trait is their ability to operate as either DC, AC or hybrid power structures [27,116, 142-148] although the nanogrid literature clearly favours DC [25, 37, 60, 61, 131, 142, 149-153]. They both consist of a source, not confined to but often, renewable energy [37,116,153-157] and some sort of load [114,131,154,158-161].

When abstracting nanogrids from microgrids, one does not have to look past their names to get an intuitive idea as to what separates them. The implication of relative size is given, but needs to be refined further to create a quantitative perimeter.

Terms such as low power and complexity, used in $[41,60,113-117,128$, $131,152,162]$ to characterise nanogrids, can be difficult to define. In [60] low power is defined as a few Watts to $5 \mathrm{~kW}$, whereas $[113,116]$ define it as $10-100 \mathrm{~kW}$. And as nanogrid research progresses, so does the complexity of the control strategies, optimisation techniques and structures $[30,35,37,41$, 154]. This is not to say the statements are not valid, nanogrids are often of lower power and less complexity than microgrids. These inconsistencies, however, do permit a level of ambiguity around the definition.

In $[114,115]$ another definition is introduced (also referred to in papers $[117,162])$ which changes the structure of the nanogrid somewhat. 
Here nanogrid is defined as a single domain for voltage, price, reliability, quality and administration, which still works with the general consensus. However, the research then suggests that the local generation is not considered part of the nanogrid itself.

This characterisation of a nanogrid is interesting as it allows systems such as universal serial bus (USB), power over Ethernet (PoE), universal power adaptors and a variety of other power structures which are not conventionally thought of as nanogrids, to be included under the nanogrid definition. And although value can be seen in this broad generalisation of the structure, it tends to add confusion to the use of the term nanogrid as it was originally intended.

This leaves a simple but effective defining characteristic, given in [29, $118,120,129,163-165]$, of a nanogrid belonging to a single home or building. Microgrids often span multiple homes/buildings as shown in [15,134, 166-173]. And although there is nothing in the microgrid definition to say it cannot be confined to a single home/ building, we suggest that single home/building microgrids should adopt the term nanogrid.

Therefore using a single house/building power distribution system to define a nanogrid and a multiple house/build scenario for microgrids, a clear boundary is set. It allows the discussion of a power distribution system for a single home/building to take the title "nanogrid" and a multiple home/building distribution system to fall into the "microgrid" category.

\subsubsection{Nanogrid - A Definition}

With the information presented above, we can establish a concise definition of the nanogrid:

"A nanogrid is a power distribution system for a single house/small building, with the ability to connect or disconnect from other power entities via a gateway. It consists of local power production powering local loads, with the option of utilising energy storage and/or a control system." 


\section{Components/structure of a nanogrid}

The basic structure of a nanogrid is shown in Fig. 3.1 which consists of the following components:

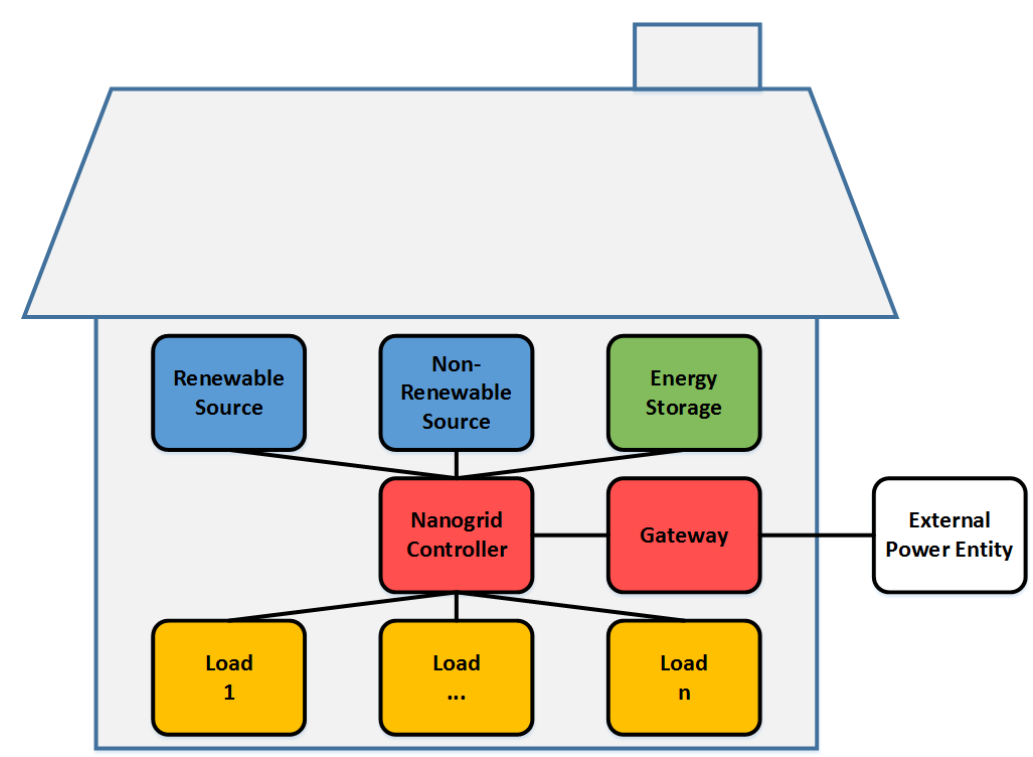

Figure 3.1: Nanogrid block diagram

- Local power production. One of the main features of a nanogrid is its ability to increase the efficient use of residential sized distributed generation. These structures can support the integration of a variety of renewable and/or non-renewable energy sources. The typical renewable energy sources are solar and wind, whereas the nonrenewable may be sources such as diesel generators or fuel cells [25, 60].

- At least one local load. Local loads are electrical household appliances which are supplied power by local production via the nanogrid [174]. Some examples are loads such as a water heater, lighting, oven, television etc. 
- A gateway. The gateway is a bidirectional power connection between other nanogrids, microgrids or the national grid. Where possible this will include communication with other power entities, conveying the nanogrid's power requirements. However, in the case of connecting to the national grid, communication may not be possible. The gateway also has the ability to disconnect from external power entities, allowing the nanogrid to operate in islanded mode. The gateway allows the nanogrid to purchase power from, and sell power to, connected power entities, increasing the financial benefit of owning distributed generation $[114,115]$.

- Energy storage. The energy storage is considered optional in a nanogrid structure, but is usually present as it adds stability. The energy storage most suited to nanogrids, due to capacity and residential location, is a battery bank.

- Nanogrid Controller. Another element which is not completely essential, but usually present, is a nanogrid controller. The controller will be discussed further in the "Nanogrid Control" chapter.

\section{Nanogrid versus microgrid}

It should be noted that while encouraging the distinction between a nanoand microgrid, the two are not necessarily mutually exclusive. The modular nature of the nanogrid delivers an opportunity to connect multiple nanogrids to then form a microgrid [165]. Fig. 3.2 shows how this grouping may be arranged.

\subsubsection{Types of Nanogrid Technology}

The debate between alternating current (AC) and direct current (DC) power is not a new argument. As we know, for the national grid AC emerged the 


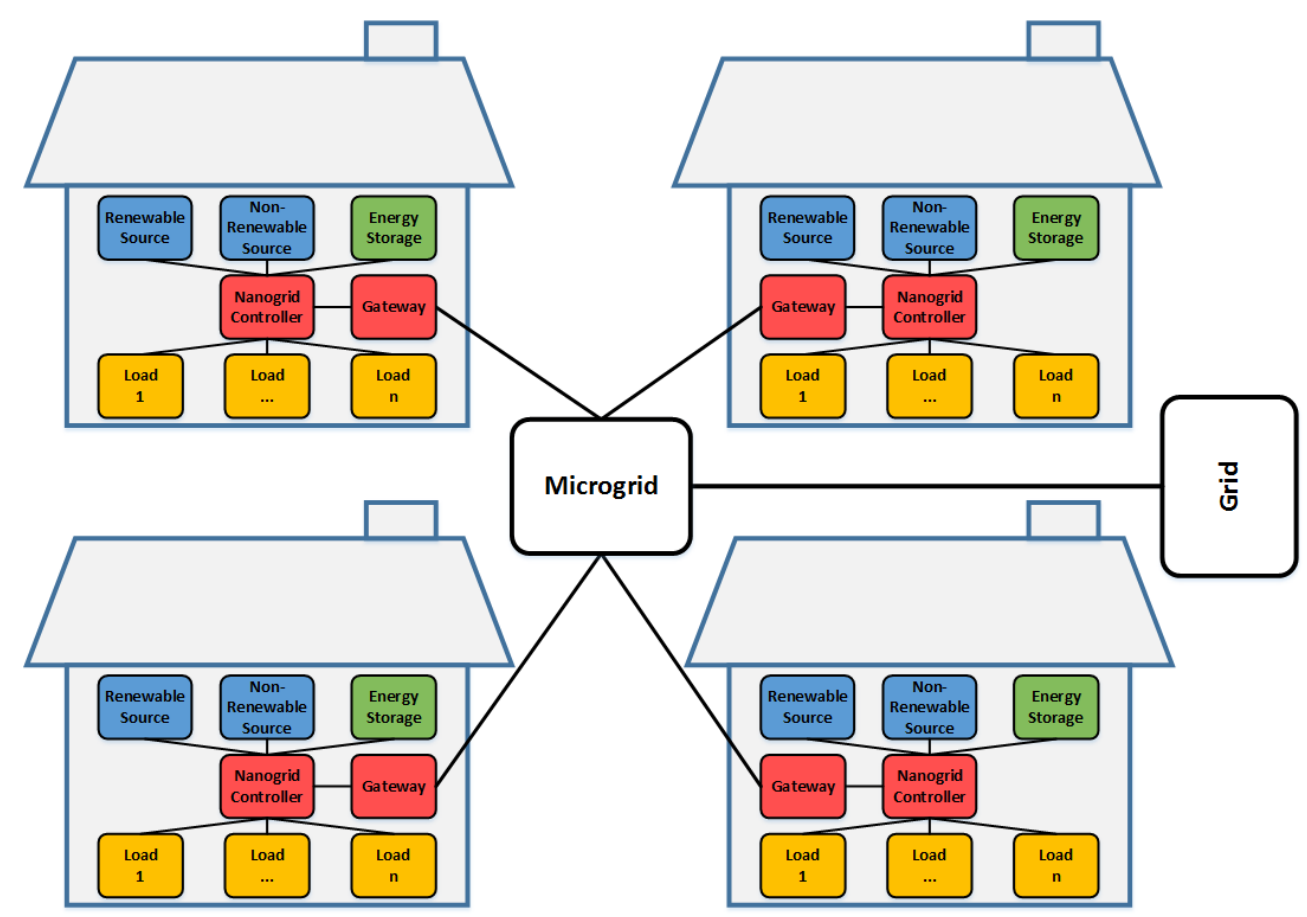

Figure 3.2: Microgrid made up of multiple nanogrids

victor, mainly due to the technical limitations at the time the grid was established [175]. With increased research into the benefits of distributed generation, where the supply and storage is often DC, the advantages of a DC grid are still regularly discussed. This is also a subject that frequently arises in microgrid and nanogrid literature, the reason being an increase in efficiency when distributing DC power [61].

A basic block diagram of the DC and AC nanogrids are displayed in Figs. 3.3 and 3.4 respectively. There are similarities between the two topologies at the source end of the power chain, these are as follows:

- DC Source. Although there are no limitations as to what type of renewable/non-renewable resource is used to generate power, some are more practical than others (eg hydro is not often used in nanogrids as it requires access to a body of water, which most residential or 


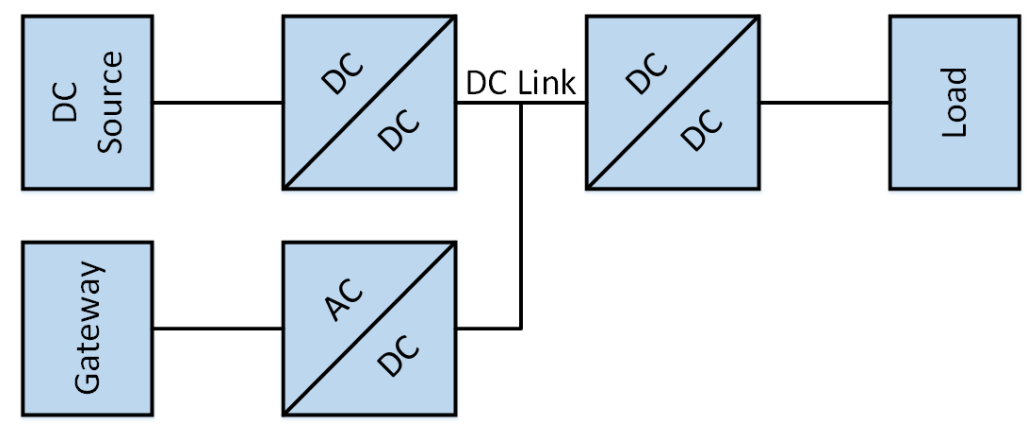

Figure 3.3: Basic block diagram of DC nanogrid

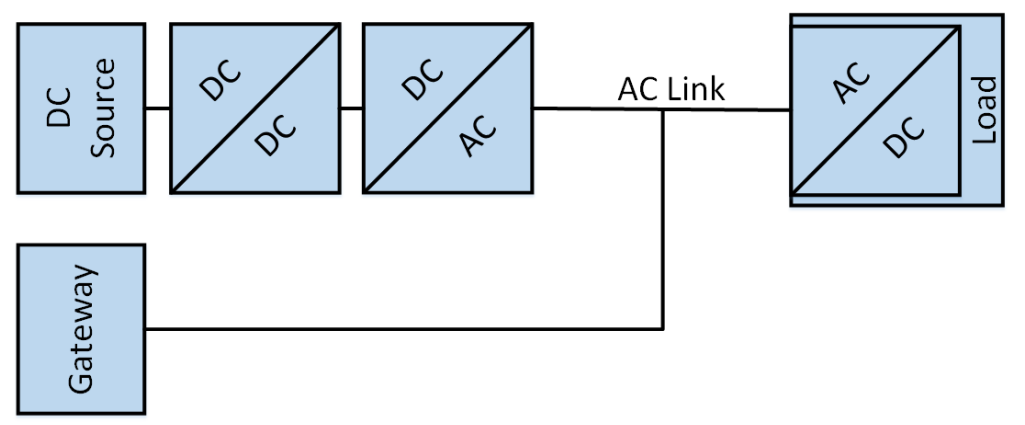

Figure 3.4: Basic block diagram of AC nanogrid

commercial properties do not have). Commonly used resources are solar (photovoltaic modules (PV)), wind (small scale wind turbines (SSWT), which do generate AC but usually output DC as the AC frequency varies) and battery storage (which is envisioned to include plug-in hybrid electric vehicles (PHEVs) in the future) [55, 128]. Diesel generators and fuel cells are also mentioned within the nanogrid literature, but not as regularly as SSWT, PV and batteries $[60,176]$.

A SSWT or PV module typically output voltage which is less than $50 \mathrm{~V})[55,128]$. Table 3.1 shows the voltage range and output power (rated capacity) of a number of SSWT, as does Table 3.2 for PV units. 
This is not a comprehensive list of available SSWT/PV technologies, merely an example of voltage outputs/rated capacities.

There are a vast multitude of batteries available for storing charge which can be used during times of low SSWT or PV power production [177]. These typically come in denominations of $2 \mathrm{~V}$ which means, by creating a series string of multiple batteries, most values can be achieved $(2 \mathrm{~V}, 4 \mathrm{~V} \ldots 24 \mathrm{~V}, 48 \mathrm{~V})$. Of course the SSWT and PV modules can also be arranged in either series, increasing voltage (five $24 \mathrm{~V}, 10 \mathrm{~A}$ PVs in series would make $120 \mathrm{~V}$ at $10 \mathrm{~A}$ ), or parallel, increasing current (five $24 \mathrm{~V}, 10 \mathrm{~A}$ PVs in parallel would make $24 \mathrm{~V}$ at $50 \mathrm{~A}$ ). The number of SSWT/PV modules selected would vary depending on the power requirements of the loads powered by the nanogrid.

Table 3.1: Small Scale Wind Turbines for use in Nanogrids.

\begin{tabular}{c|c|c} 
Brand & Rated capacity (W) & Voltage output (VDC) \\
Southwest Windpower Air x & 400 & $12,24,48$ \\
Marlec Rutland & 720 & 12,24 \\
Aerogen Aero6gen & 300 & 12,24 \\
Bergey Excel 1 & 1000 & $12-48$ \\
Silentwind Windgenerator & $420-500$ & $12,24,48$
\end{tabular}

Table 3.2: Photovoltaic modules for use in Nanogrids.

\begin{tabular}{c|c|c} 
Brand & Rated capacity (W) & Voltage output (VDC) \\
Canadian Solar CS6X-305M & 305 & 36.6 \\
Samsung LPC247SM & 247 & 30.4 \\
Grape Solar GS-S-260 & 260 & 31.6 \\
Renesola Virtus II & 260 & 30.1 \\
Schutten STM5-200W & 200 & 36.6
\end{tabular}

- Source DC-DC Converter. A DC-DC converter is a circuit that takes an input voltage and either steps it up or down depending on the 
required output voltage. The source DC-DC converter can be used to fulfil a number of functions:

- Multiple Source Interface. Nanogrids can have a variety of sources at any one time, for example a hybrid system may have a PV array, SSWT and storage supplying power to the nanogrid. Each source has its own operating characteristics. In order to integrate the various sources into the nanogrid, each requires a DCDC converter. The converter ensures regulation of the supply and provides protection [55].

- Bus Voltage. The Source DC-DC converter can also be used to convert the source voltage up to a DC bus voltage level of $380 \mathrm{~V}$ $[165,178]$. This $380 \mathrm{~V}$ has become an industry-standard intermediate $\mathrm{dc}$ voltage level [128]. In the case of the AC topology, the voltage can then be rectified. The DC bus voltage has the additional advantage of simplifying the control of the nanogrid, which is discussed in the Nanogrid Control chapter [42].

- Maximum Power Point Tracking. The behaviour of the SSWT and $\mathrm{PV}$ is nonlinear. Under specific environmental conditions there is only one point of operation that ensures the maximum power output. This maximum power point is dynamic and by utilising sensors to observe the behaviour of the renewable source/environmental conditions, this point can be tracked. This is done by varying the duty cycle controlling the source DC-DC converter, essentially presenting the source with a variable load. By creating the ideal load for the environmental condition, the source is forced to operate at its maximum power point [179].

The source DC-DC converter is usually of the boost or buckboost variety as the source voltage typically needs stepping up [60]. The efficiency of the these converters are greater than $85 \%$ and in some cases can achieve high nineties (\%) $[43,180]$. 
As the DC source and load converter for both topologies are equal, at this point the efficiencies are the same. From here, at the load end of the power chain, the two topologies differ.

\section{DC nanogrid}

At the other end of the power chain from the DC source, is the load. The load has a DC-DC converter to interface it with the DC bus and the gateway requires $\mathrm{AC}$ power. The conversions are as follows:

- Load DC-DC Converter. This DC-DC converter is used to step down the bus voltage to a device (load) level. For the DC nanogrid the conversion is performed by an external DC-DC converter such as a buck converter. Like the boost converter, the buck has an efficiency greater than $80 \%$ (in some cases greater than 90\%) [181]. The favoured voltage levels for this stage are $24 \mathrm{~V}$ or $48 \mathrm{~V}$ which is the standard telecom voltage [153,163]. Most existing DC loads are designed to run either at $12 \mathrm{~V}, 24 \mathrm{~V}$ or $48 \mathrm{~V}$. The range of DC loads available to purchase, in comparison to AC loads, is still extremely limited [182].

- Bi-directional AC-DC converter. A bidirectional converter is needed to interface the national grid or other power entities with the local nanogrid [183,184]. As the nanogrid functions on DC voltage and the grid AC, as power passes between them it needs to be converted from AC-DC and vice versa. The reason a bidirectional converter is required is because when the nanogrid has excess power, it will sell the additional power to the grid (DC-AC) [185]. If the load requirements are greater than the local production, the nanogrid will need to purchase power from the grid (AC-DC). The efficiency of a bi-directional AC-DC converter should not be less than $80 \%$ (if designed properly) and well designed converters can reach efficiencies in excess of $95 \%$ [43]. 


\section{AC nanogrid}

When compared to the DC nanogrid, the AC has additional conversions that take place to ensure the correct power is supplied to the load. These additional conversions are where the AC nanogrid loses efficiency, and these conversions take place with [186]:

- DC-AC Converter. The DC-AC converter takes the DC voltage from the source converter and outputs $230 \mathrm{~V}$ AC (or $120 \mathrm{~V}$ AC depending on origin) which can be used by the majority of consumer loads sold today. This is also the voltage level supplied to a nanogrid from the national grid. This means if a converter is used that can synchronise to the grid's frequency of $50 \mathrm{~Hz}$ (60 Hz depending on origin), power can be shared easily between the power entities. With technologies like the inverter discussed in [54], this conversion can reach efficiencies in excess of $90 \%$.

- Load AC-DC Converter. The AC voltage is then converted to DC, this conversion takes place in a power adaptor (also known as a wall wart) or in the device itself. For AC loads that draw less than $15 \mathrm{~W}$ of power (e.g. cell phones), the DC-DC conversion is often executed by a linear power supply. The efficiency of these devices can vary from $20 \%$ to $75 \%$. Loads that draw high power, implement switchmode power conversion which is more efficient, ranging from 50\% to $90 \%$ [187]. Table 3.3, with data from [182], shows the conversion efficiencies of some common household loads.

\section{DC nanogrid/AC nanogrid comparison}

There are a number of elements to consider when comparing nanogrid topologies (DC or AC), making it difficult to determine which is "superior". If efficiency is of utmost importance, the DC nanogrid has the advantage [27]. For both topologies the source DC-DC converter has a sim- 
Table 3.3: AC to DC conversion efficiency of AC appliances [116].

\begin{tabular}{c|c} 
Appliance & Average AC-DC conversion efficiency (\%) \\
Home Audio & 79 \\
Refrigerator & 87 \\
Personal Computer & 80 \\
Television & 85 \\
Lighting & 82 \\
Electric Water Heater & 88 \\
Oven (range) & 88
\end{tabular}

ilar efficiency. The DC-AC converter hardware also has the same efficiency for the two topologies but operating conditions (how often power is passed through and the magnitude of power) may have an overall effect on the systems efficiency. The largest loss in the AC nanogrid comes at the device level AC-DC conversion, this adds an average loss of approximately $14 \%$ to the system [182].

Is a DC nanogrid practical in the foreseeable future? Currently most consumer products in homes, retail stores and rolling out of production factories are still AC loads. To retrofit a current house with a DC power system will require either replacing AC loads with the limited DC compatible loads available to purchase, or modifying the AC loads to function on DC power. So although the increased efficiency of a DC system would equate to a financial saving in the long run, replacing/retrofitting AC loads will increase initial capital required to install distributed generation in a household. Of course this is only a relevant point if retrofitting, when the initial setup of a house is intended for DC, loads can be selected for DC compatibility. As PV/battery banks begin to have a larger impact on power structures, companies are beginning to produce more DC appliances to meet demand. One can see how this could create a paradigm shift in power systems, driven by demand, products become available, which 
further drives demand for efficiency DC systems.

Within the DC nanogrid literature, protection also arises as an issue $[42,188]$. The topic of this discussion focuses on protection against short circuit line fault, and ground fault [154]. These faults can occur at output terminals, loads and switching devices, and severely damage a DC system [80]. These faults can be mitigated by including fault protection such as traditional arcing-type circuit breakers, or more advanced protection strategies as in [154] and [189].

\subsubsection{Nanogrid Control Topologies}

The control of a nanogrid, implemented by the nanogrid controller, is what gives the system the ability to coordinate multiple sources and optimise power production and consumption. It is the "brains" of systems and if implemented correctly, can increase the efficient operation of the nanogrid. Within a nanogrid structure there are two categories for control, supply side management (SSM) and demand side management (DSM). Supply refers to the nanogrid's source of power, for example photovoltaic modules, small scale wind turbines, grid, etc. The demand is the consumption of power by the household loads, for example refrigerator, television, heater, etc.

Both the supply and demand are extremely dynamic, frequently changing from maximum to minimum consumption/production during a single day $[190,191]$. Unfortunately high consumption/production times rarely coincide in an uncontrolled nanogrid system. It is for this reason that supply/demand side management is an integral part of nanogrid control.

Supply side management is used to optimise the behaviour of the nanogrid's power sources in order to best match power production to the consumption curve and utilise renewable energy sources. Demand side management is used to optimise the consumption curve of the nanogrid's loads to match the power output of the nanogrid's sources. 
There are a number of control topologies that can be used to implement SSM and DSM with various levels of success. Using nanogrid control topologies, implementation of supply side management is presented in $[28,149]$. Below is an explanation of how each topology is set out for both supply side and demand side management with the advantages/disadvantages of each system.

- Centralised control consists of a central controller that acts on information from sensors measuring the power production and consumption of the system (and in some cases other variables such as temperature). Fig. 3.5 shows the block diagram of the centralised control topology, where the communication lines are shown in red and power in black. As all control decisions are made from a central location, this topology has in-depth knowledge of the system dynamics and so has the ability to implement a cohesive control strategy. The centralised controller measures parameters in real time, making the system fast when implementing control. One disadvantage to this topology is its reliance on a high-bandwidth communications line for collecting data from its sensors in order to implement control in a timely fashion. Another disadvantage is by centralising the control to a single controller, the system becomes susceptible to failure. If a communication line or the central controller itself is damaged, the system will no longer have the ability to implement control.

- Decentralised control has a series of control nodes operating independently to sense the status of each local source or load. The information gathered by the node is then used to control the local source/load (as shown in Fig. 3.6). Unlike centralised control, decentralised control does not require an extensive communication line, negating this reliance. As this topology has many independent controllers, it is also more robust than the centralised control. This makes the decentralised topology fast and reliable. However, as a control topology, 


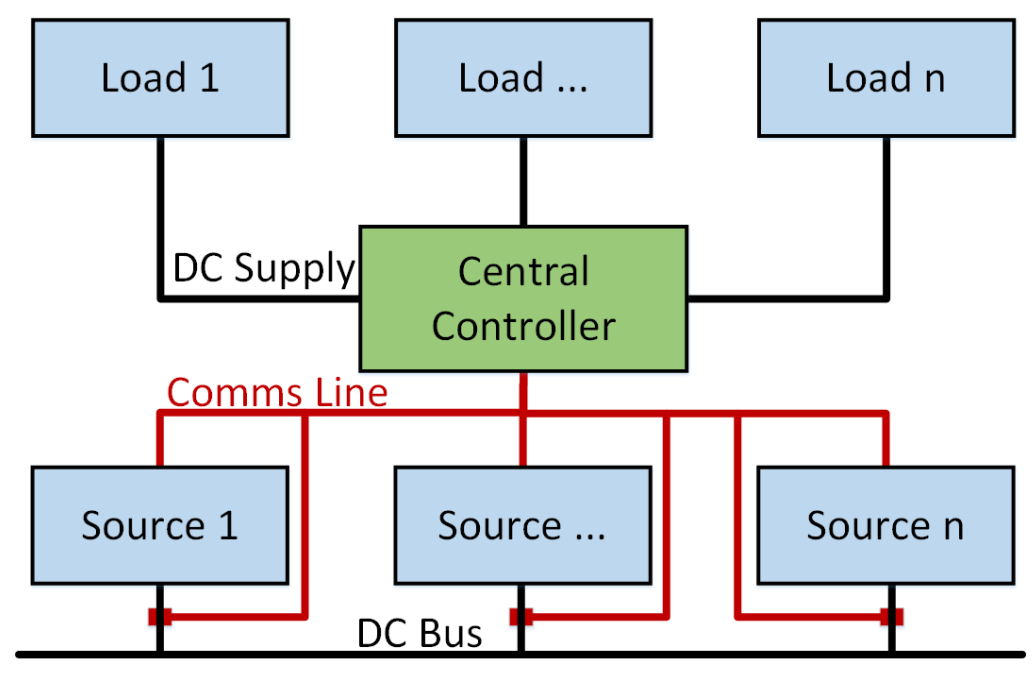

Figure 3.5: Centralised control block diagram

the decentralised scheme is limited in its usefulness. This is due to the lack of communication between the system's nodes. Most control strategies rely on the ability to force a reaction within a power system, to an event that may only be sensed by a single node. This can only be implemented if communication between nodes exists, which in this case, it does not [28].

- Distributed control takes the decentralised topology and adds communication between nodes via a communication line as in the centralised control [192]. This means the distributed system adopts certain characteristics of both systems. It remedies the shortcomings of the decentralised scheme by enabling each node to communicate its power status. As each control node stores segments of an overlying control scheme (pertaining to its own relationship to the system), the network as a whole then creates a cohesive control strategy. Distributed control, like decentralised control, has the advantage of multiple controllers reducing the likelihood of complete failure within in the system. However, like the centralised control, this 


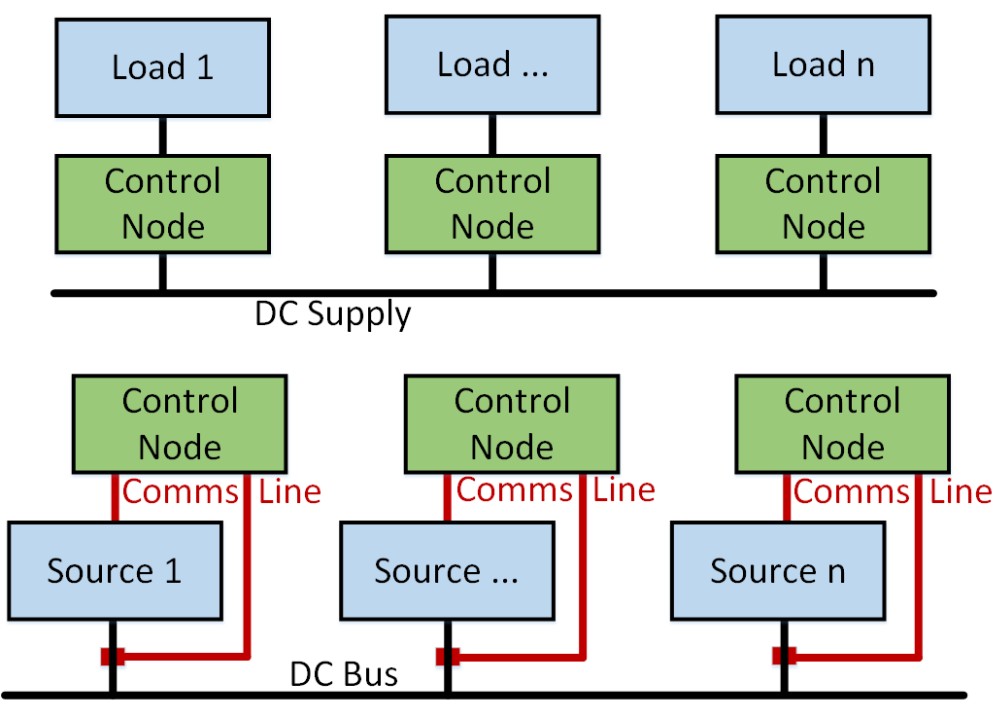

Figure 3.6: Decentralised control block diagram

topology is dependent on communication lines. The block diagram of the distributed control is shown in Fig. 3.7.

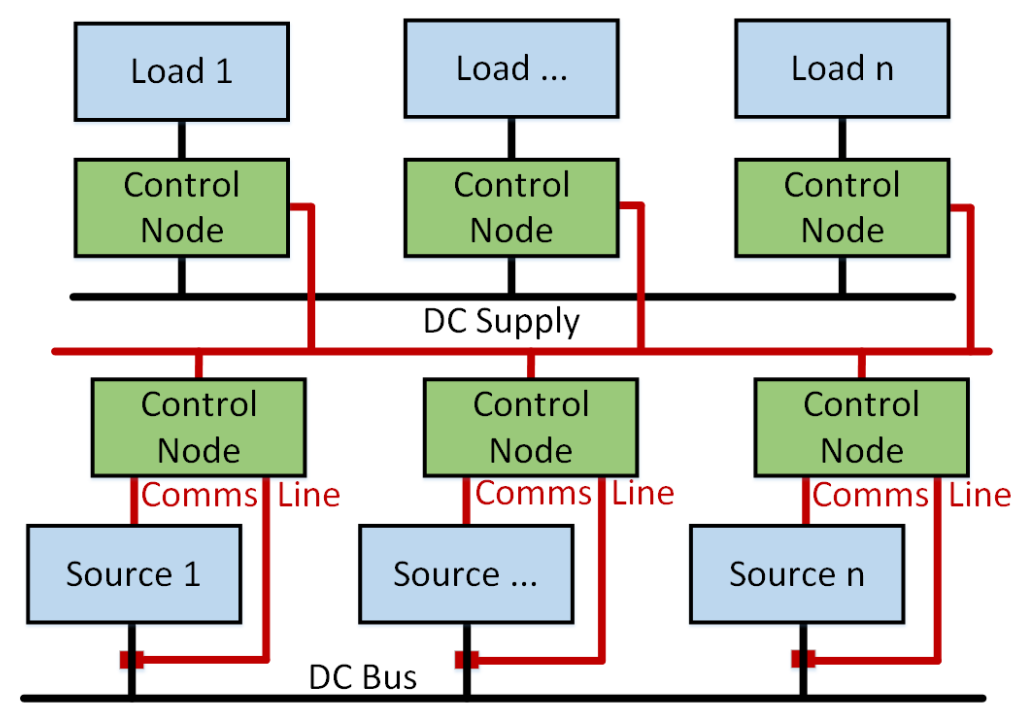

Figure 3.7: Distributed control block diagram 
- Hybrid Distributed control is, as the name would suggest, a hybrid of the distributed control and decentralised control. As in the distributed topology, the nodes can communicate creating a cohesive control strategy. However, the hybrid system looks to improve on the distributed control topology by avoiding the need to use a communication line, as shown in Fig. 3.8. It does so by utilising the DC bus/supply lines to communicate between nodes, as used by the popular droop control [193]. This means the hybrid distributed control does not need to rely on a communications link, increasing the reliability of the system.

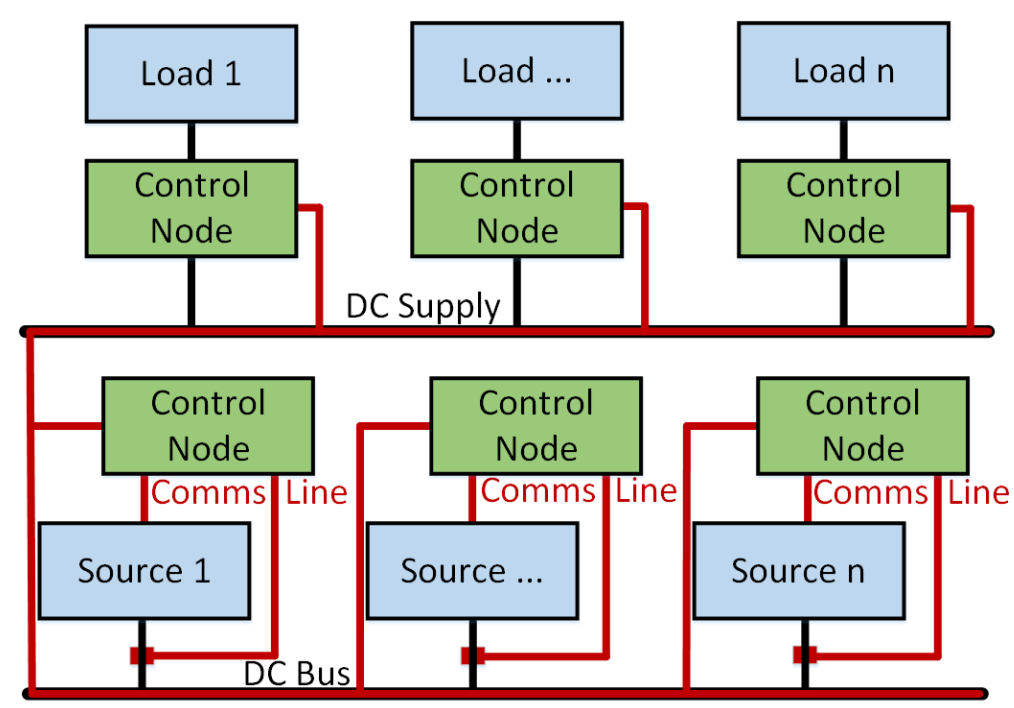

Figure 3.8: Hybrid distributed control block diagram

- Hybrid Central control is taken from the centralised control scheme which is combined with decentralised control. This creates a system with a central controller that communicates with decentralised control nodes as shown in Fig. 3.9. The control nodes implement the source/load level control, whereas the central controller coordinates each node. The hybrid central control delivers a powerful and fast 
control system with an increased resilience to failure. However, the system relies on communication lines which can still make it vulnerable to faults.

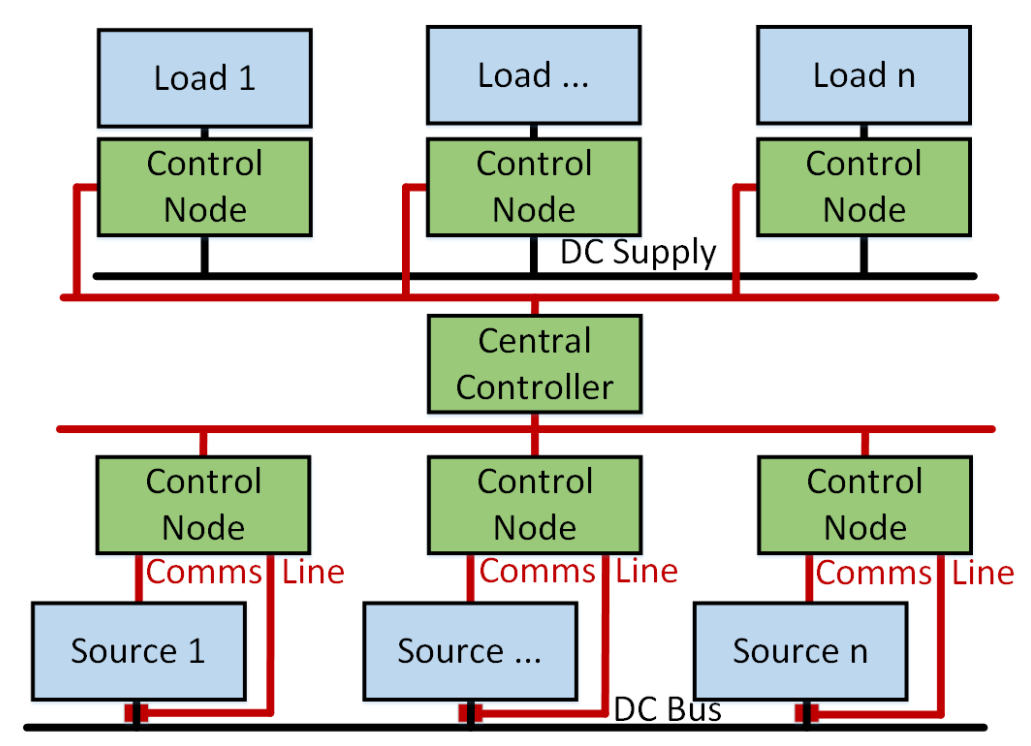

Figure 3.9: Hybrid central control block diagram

- There are alternatives to the traditional communication lines emerging as communications play an increasingly important role within nanogrid, microgrid and smart houses/buildings/cities. Technologies such as power line communication (PLC) and DC bus signalling make it possible to send control signals via the nanogrid's DC/AC lines. For a control scheme such as the hybrid central control, this negates the disadvantage of relying on a designated communications line. Figure 3.10 displays a topology which has the advantage of a powerful and fast control system, an increased resilience to failure and is without the vulnerability associated with the hybrid central control scheme. 


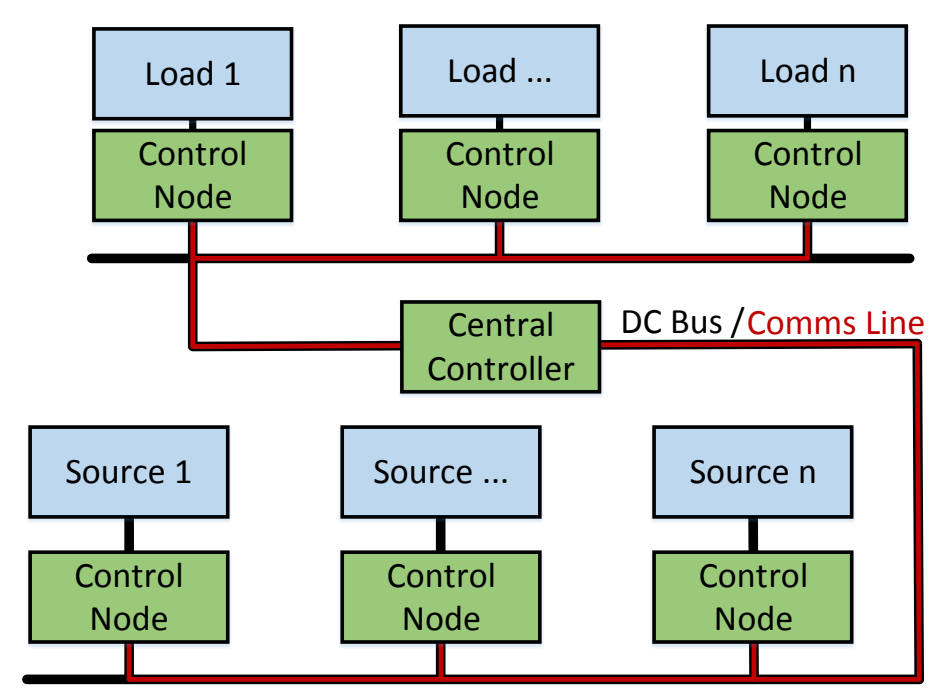

Figure 3.10: Hybrid central PLC control block diagram

\subsection{Chapter Summary}

In this chapter, a definition for the nanogrid power structure is derived, motivated by the ambiguity of current defining attributes within the literature. The various defining characteristics used within the literature to describe the nanogrid power structure are considered, discussed and collated to develop a concise definition. The definition is as follows:

"A nanogrid is a power distribution system for a single house/small building, with the ability to connect or disconnect from other power entities via a gateway. It consists of local power production powering local loads, with the option of utilising energy storage and/or a control system."

The chapter then presents the nanogrid structure, giving a description of the components used to create a nanogrid. An in-depth discussion on the hardware similarities and variations of DC and AC power schemes within a nanogrid is given, before the motivating factors and considerations of selecting either of the power schemes is presented.

The remainder of the chapter discusses the control topologies used by 
a nanogrid to implement demand and supply side management. These consist of three main structures; centralised, decentralised and distributed control, as well as the hybrid topologies derived from these. 


\section{Chapter 4}

\section{Nanogrid Control System}

\subsection{Nanogrid System}

In this chapter a novel control strategy for a DC nanogrid is presented. It utilises the system's maximum power point tracking signal to implement load control taking advantage of a household's thermostatically controlled loads. The control topology selected for this system is hybrid central control with the distributed control nodes implementing real time control, while the central controller takes on a coordinating role. The block diagram displayed in figure 4.1 is an overview of the nanogrid system. Each block's functionality is explained before the control strategy is discussed and simulated results are presented.

Part of this chapter has been published in: Daniel Burmester, Ramesh Rayudu, Winston KG Seah. "Use of Maximum Power Point Tracking Signal for Instantaneous Management of Thermostatically Controlled Loads in a DC Nanogrid", IEEE Transactions on Smart Grid (Accepted for publishing), DOI 10.1109/TSG.2017.2704116, 2017 


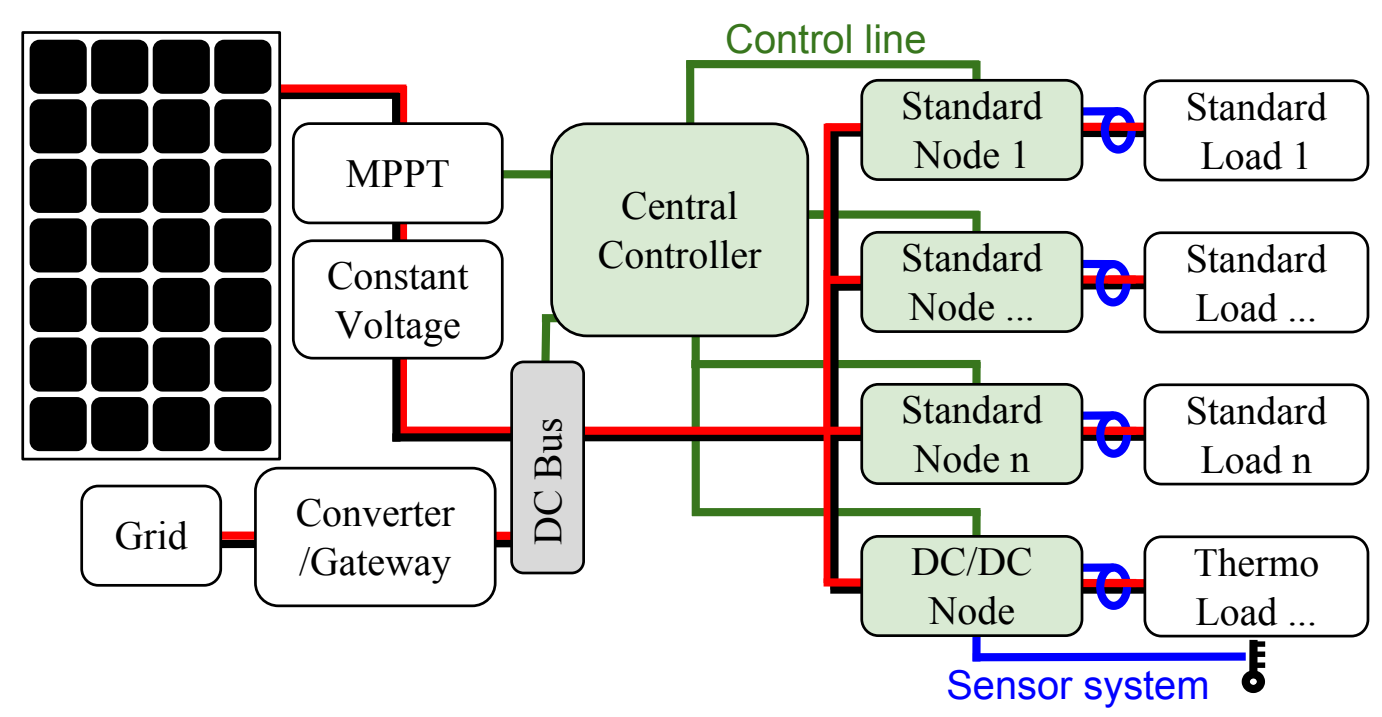

Figure 4.1: Nanogrid block diagram

\subsubsection{Maximum Power Point Tracking}

The maximum power point tracker (MPPT) consists of a DC /DC converter connected in series with a photovoltaic (PV) system and a control algorithm. The MPPT is used because the characteristics of a PV module determine that, for a particular environmental condition (specifically solar irradiance/ambient temperature), there is only one operating point where the maximum power can be extracted [194]. To obtain this operating point, the control algorithm monitors the appropriate variables (in most cases, PV output voltage and current) and alters the duty cycle to the DC/DC converter to present the PV system with the required impedance [194].

In the nanogrid controller, the information acquired by the MPPT is not only used for the traditional purpose of extracting the maximum power, it is also used for load control. The MPPT ensures the maximum PV power output is not dependent on the load activities by altering the duty cycle to counteract load variations. This means the nanogrid control algorithm is presented with the maximum available PV power at any partic- 
ular time step, whether the system is drawing said power or not. This allows the load control algorithms to make instantaneous decisions based on the available PV power.

\section{MPPT Hardware}

Traditional boost converters are regularly used in maximum power point tracking applications with successful results $[195,196]$. For this system, an interleaved boost converter was selected due to its reduced input and output current ripple and higher efficiency [197]. The design process outlined in [197] was followed, with component selection outlined in equations (4.1) to (4.4). An explanation of each variable within these equations is given in table 4.1. $D_{M a x}$ and $D_{M i n}$ can also be calculated, however due to the nature of MPPT, a wide range is required so $D_{\text {Max }}=0.9$ and $D_{\text {Min }}=0.1$ were assumed. The input capacitor was selected during simulation, to suit the system dynamics $\left(C_{I n}=100 u F\right)$. Figure 4.2 shows a schematic of the simulated interleaved boost converter.

$$
\begin{gathered}
I_{L_{\text {Ave }}}=\frac{0.5 \times I_{\text {Out }}}{1-D_{\text {Max }}} \\
I_{\text {Peak }}=I_{L_{\text {Ave }}}+\frac{\Delta I_{L}}{2} \\
L_{\text {Min }}=\frac{\left(V_{\text {In }_{\text {Min }}}-V_{\text {On }}\right) \times D_{\text {Max }}}{f_{s} \times \Delta I_{L}} \\
\Delta V_{\text {Out }}=\frac{I_{\text {Out }} \times\left(1-D_{\text {Min }}\right)}{f_{s} \times C_{\text {Out }}}+I_{\text {Peak }} \times E S R
\end{gathered}
$$

\section{MPPT Algorithm}

The well defined "incremental conductance" algorithm, described in [198], was selected due to its high yield under changing conditions and its lower oscillations when compared to the perturb and observe algorithm (also 
Table 4.1: Explanation of variables in equation (4.1) to (4.4)

\section{Variable Description}

$I_{L_{\text {Ave }}} \quad$ Average inductor current

$I_{\text {Out }} \quad$ Output current

$I_{\text {Peak }} \quad$ Peak inductor current

$\Delta I_{L} \quad$ Inductor current ripple

$L_{\text {Min }} \quad$ Minimum inductance value $(220 \mathrm{uH})$

$V_{I n_{\text {Min }}} \quad$ Minimum input voltage

$V_{O n} \quad$ On stage voltage of the MOSFET

$f_{s} \quad$ Switching frequency

$\Delta V_{\text {Out }} \quad$ Output voltage ripple

$I_{\text {Out }_{\text {Max }}} \quad$ Maximum output current

$C_{\text {Out }} \quad$ Output capacitor (180uF)

ESR Equivalent series resistance of the capacitor

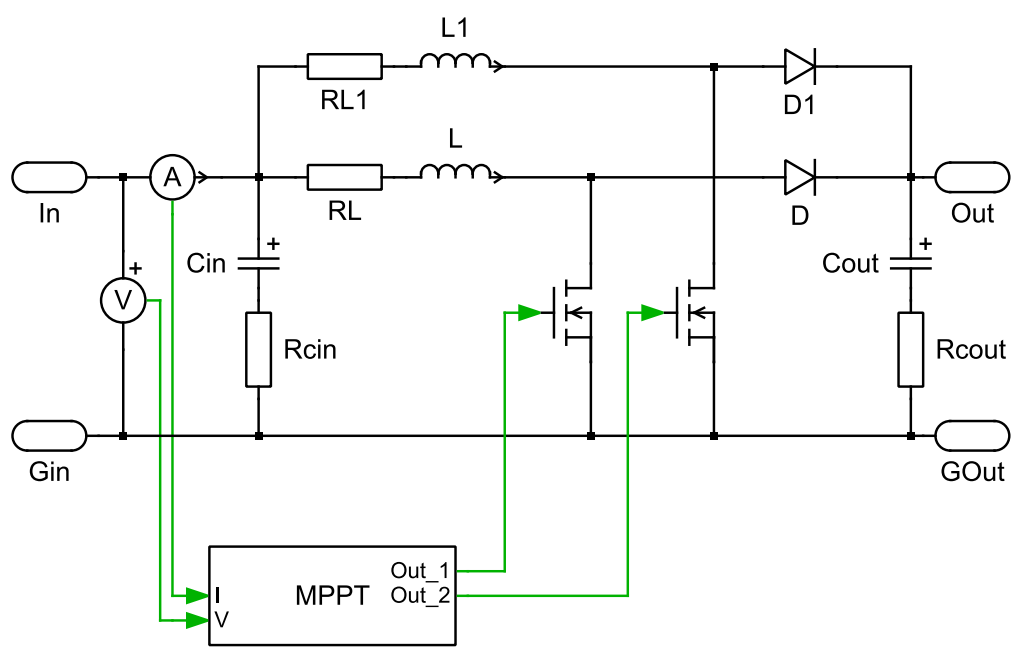

Figure 4.2: Maximum power point tracking interleaved boost converter

commonly used) [198]. Incremental conductance works on the premise that the derivative of the power, with respect to voltage, is equal to zero 
$\left(\frac{d P}{d V}=0\right)$ at the maximum power point. If $\frac{d P}{d V}$ is negative or positive, the duty cycle needs to be altered to ensure the value is returned to zero. Figure 4.3 shows the flow diagram for programming the incremental conductance algorithm.

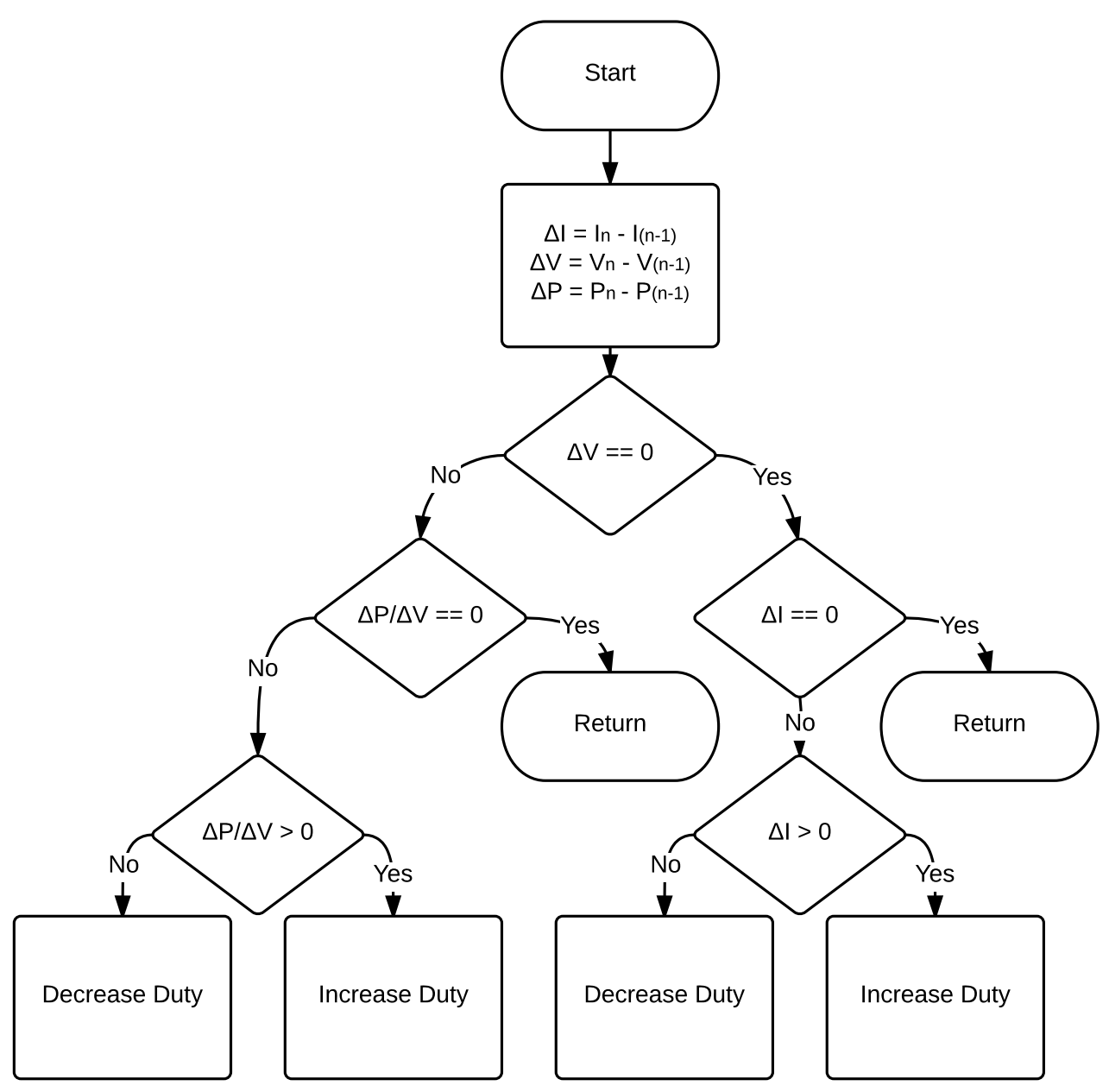

Figure 4.3: Incremental conductance algorithm flow diagram 


\section{Constant voltage output}

While altering the duty cycle of the interleaved boost converter, to ensure operation at the maximum power point delivers the desired result at the input, the output voltage has the potential to vary over a large range. For this reason a buck converter is cascaded with the interleaved boost converter enabling the system to output a constant voltage $(380 \mathrm{~V})$.

A synchronous buck converter was selected to achieve this due to its high efficiency and low component count (when compared to alternative DCDC converters e.g. SEPIC) [199]. Figure 4.4 shows the schematic of the buck converter, equation (4.5) was used to select the required inductor. Equation (4.6) was then used to calculate the capacitor value for the required output voltage ripple. However, in order to size the capacitor correctly for transient response, a larger capacitor was required which was calculated with equation (4.7) (variables for equations (4.5), (4.6) and (4.7) explained in table 4.2) [200,201].

$$
\begin{gathered}
L=\frac{V_{\text {Out }} \times\left(V_{\text {In }}-V_{\text {Out }}\right)}{\Delta I_{L} \times f_{s} \times V_{\text {In }}} \\
C_{\text {Out }_{\text {min }}}=\frac{\Delta I_{L}}{8 \times f_{s} \times \Delta V_{\text {Out }}} \\
C_{\text {Out }_{\text {min }}}=\frac{L \times I_{L_{M A X}}^{2}}{\left(V_{\text {Out }}+V_{\text {OS }}\right)^{2}-V_{\text {Out }}^{2}}
\end{gathered}
$$

The feedback controller was designed as outlined in [202]. Equations (4.8) and (4.9) were used to locate the poles and zeros of the system and $f_{0}$ was set to a tenth of the switching frequency. This allowed the use of a type 2 proportional-integral (PI) feedback loop as the conditions in (4.10) were met. $R_{f 1}$ was set to an arbitrary value in the low $k \Omega$ range, and the remaining variables were calculated using equations (4.11) through (4.14) ( $E S R$ is the equivalent series resistance of $C_{\text {Out }}, V_{\text {ref }}$ is the feedback's 
Table 4.2: Explanation of variables in equation (4.5) to (4.7)

$\begin{array}{ll}\text { Variable } & \text { Description } \\ L & \text { Inductor value }(1.5 \mathrm{mH}) \\ V_{\text {Out }} & \text { Output voltage } \\ V_{\text {In }} & \text { Input voltage } \\ \Delta I_{L} & \text { Inductor current ripple } \\ f_{s} & \text { Switching frequency } \\ C_{\text {Out }} & \text { Minimum output capacitance } \\ & \text { (1500uF) } \\ \Delta V_{\text {Out }} & \text { Output voltage ripple }\end{array}$

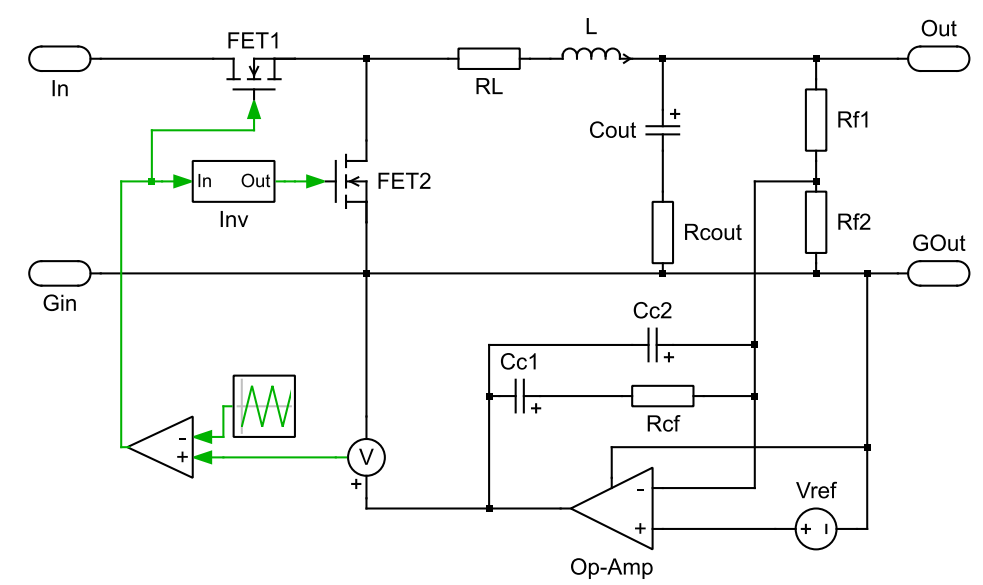

Figure 4.4: Constant voltage output buck converter

reference voltage, $f_{S}$ is the switching frequency and $V_{o s c}$ is the amplitude of the triangle wave). The feedback is shown in figure 4.4 .

$$
\begin{aligned}
f_{L C} & =\frac{1}{2 \times \pi \times \sqrt{L \times C_{\text {Out }}}} \\
f_{E S R} & =\frac{1}{2 \times \pi \times E S R \times C_{\text {Out }}}
\end{aligned}
$$




$$
\begin{gathered}
f_{L C}<f_{E S R}<f_{0}<\frac{f_{S}}{2} \\
R_{f 2}=\frac{R_{f 1} \times V_{r e f}}{V_{\text {Out }}-V_{r e f}} \\
R_{C 1}=\frac{R_{f 1} \times f_{E S R} \times V_{o s c} \times f_{0}}{V_{\text {in }} \times f_{L C}^{2}} \\
C_{C 1}=\frac{1}{1.5 \times \pi \times R_{C 1} \times f_{L C}} \\
C_{C 2}=\frac{1}{\pi \times R_{C 1} \times f_{s}}
\end{gathered}
$$

\section{MPPT Nanogrid Control Application}

To demonstrate the MPPTs ability to function as a control signal for the nanogrid control system, Figure 4.5 and Figure 4.6 display a simulated test scenario with a constant solar irradiance $\left(1000 \mathrm{~W} / \mathrm{m}^{2}\right)$ under varying load conditions. Figure 4.5 shows the schematic of a PV array (with the maximum output power of $3120 \mathrm{~W}$ ), the interleaved boost converter cascaded with the constant voltage converter supplying three loads. It can be seen in Figure 4.6 that initially the system draws $320 \mathrm{~W}$ of power, at 1 minute it draws $2 k W$, at 2 minutes $4 k W$ before returning back to $320 \mathrm{~W}$ at the 3 minute mark. This shows that the maximum power signal remains unchanged even when the PV power production is exceeded by the load and the grid must supply the deficit power.

Figure 4.7 shows the PV output power and the output voltage of the constant voltage converter under a number of solar irradiance conditions. The $380 \mathrm{~V}$ system output has an initial transient lasting $0.3 \mathrm{~s}$ after which it remains within its $0.4 \mathrm{~V}$ ripple, even during large irradiance transitions. The MPPT has an initial transient that lasts for $0.35 \mathrm{~s}$, it settles within $0.15 \mathrm{~s}$ on transitions after this point. Both the MPPT and constant voltage output are unaffected by changes in output load. 


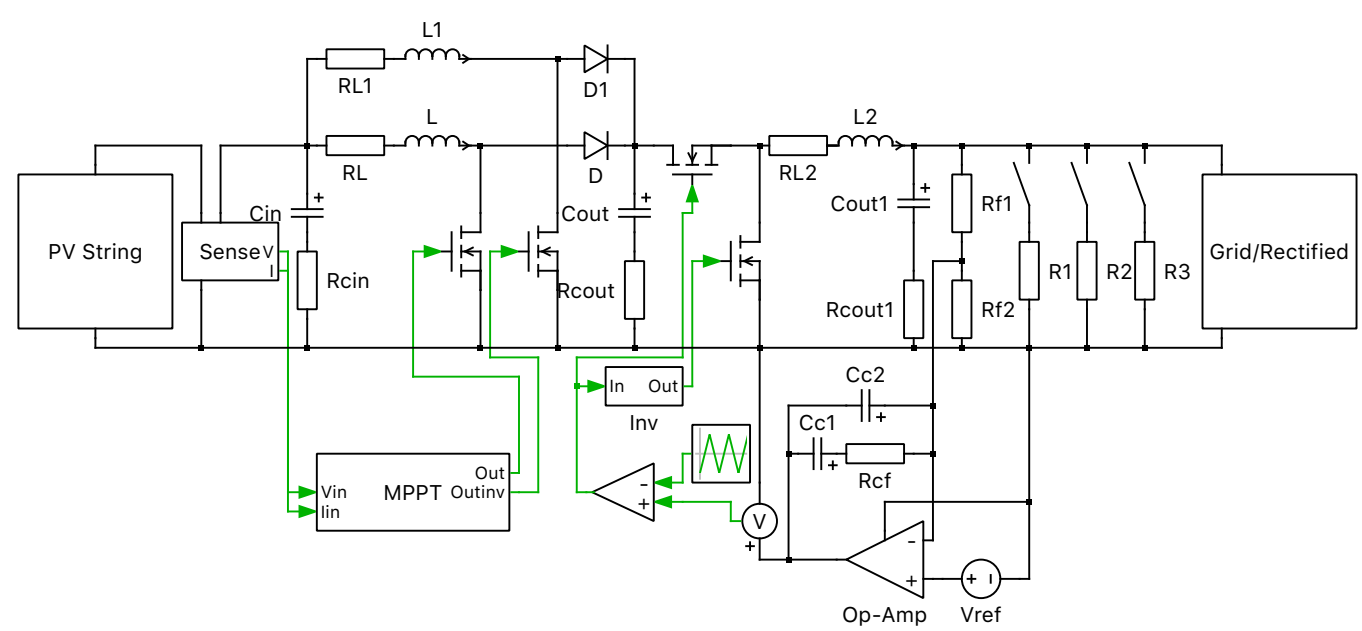

Figure 4.5: PV module, MPPT, constant voltage converter and grid feeding 3 loads

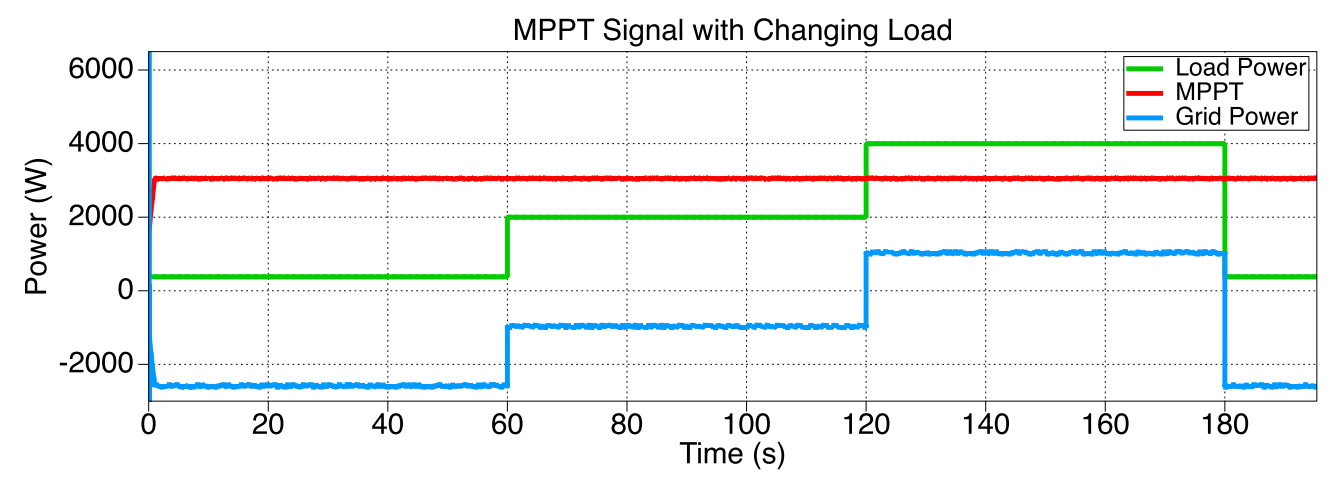

Figure 4.6: MPPT output under load varying conditions

\subsubsection{Central and Node Controllers}

The system control is distributed across the central controller and multiple control nodes. The central controller has a coordinating role within the control scheme gathering information from the MPPT and nodes, facilitating interactions.

The system's control nodes are split into two categories; standard household loads and thermostatically controlled household loads. Category one control nodes utilise current and voltage sensors to monitor the power 

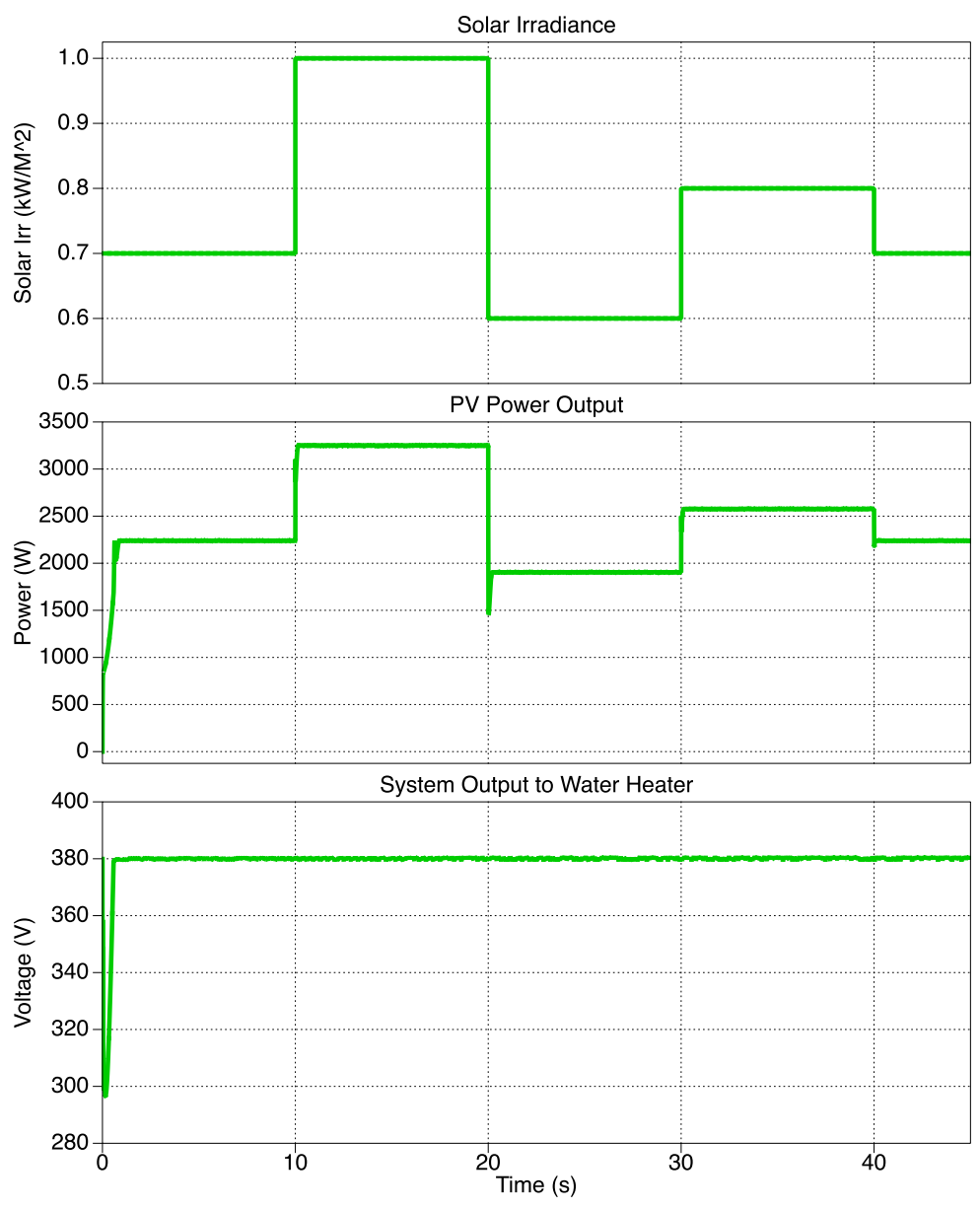

Figure 4.7: Test solar irradiance (top), MPPT input power (middle) and constant voltage out (bottom)

draw of each standard household load, have the ability to switch the loads on/off when required and implement the control delegated by the central controller. The second category of the control nodes, associated with the thermostatically controlled loads, not only implement the category one functions but are also equipped with temperature sensing capabilities. They also have the ability to vary the power consumed by the thermostatically controlled loads via a DC to DC step down converter (Buck 
converter). These capabilities are used by the nanogrid to distribute adequate power to the thermostatically controlled loads, ensuring the control scheme and save operation of the load is implemented.

\section{Control Node}

Within the nanogrid, it was favourable to implement control law prior to the load drawing power from the main nanogrid supply. To do so, a control node was developed with the ability to observe a loads behaviour, report back to the nanogrid central controller and receive instructions before the associated load began drawing power.

Figure 4.8 shows a basic block diagram of the node, where the DC supply and load is equivalent to the nanogrid's DC bus and a household appliance respectively. The node's hardware consists of three switches (in this case p-channel MOSFETs) and storage in the form of a capacitor bank (capacitor bank selected rather than batteries to allow various voltage values to be used). The switches are controlled by a microcontroller which monitors the current and voltage of the capacitor bank and node's output, making localised control decisions based on these variables. The microcontroller also sends and receives information to/from the central controller, relaying the load's status and implementing control designated by the nanogrid.

Figure's 4.9 through 4.12 show the functionality of the node with an explanation of each operating mode given below.

- Charge mode: The node utilises a capacitor bank to store charge which is used to supply a load with power momentarily while control decisions are made by the nanogrid. The microcontroller monitors the voltage level of the capacitor bank. If the capacitor bank drops below a predetermined level (eg $23.8 \mathrm{~V}$ on a $24 \mathrm{~V}$ line), due to leakage current or load activity, the "charge switch" $(P 1)$ is activated until the voltage returns to an adequate level. While this occurs, the capacitor 


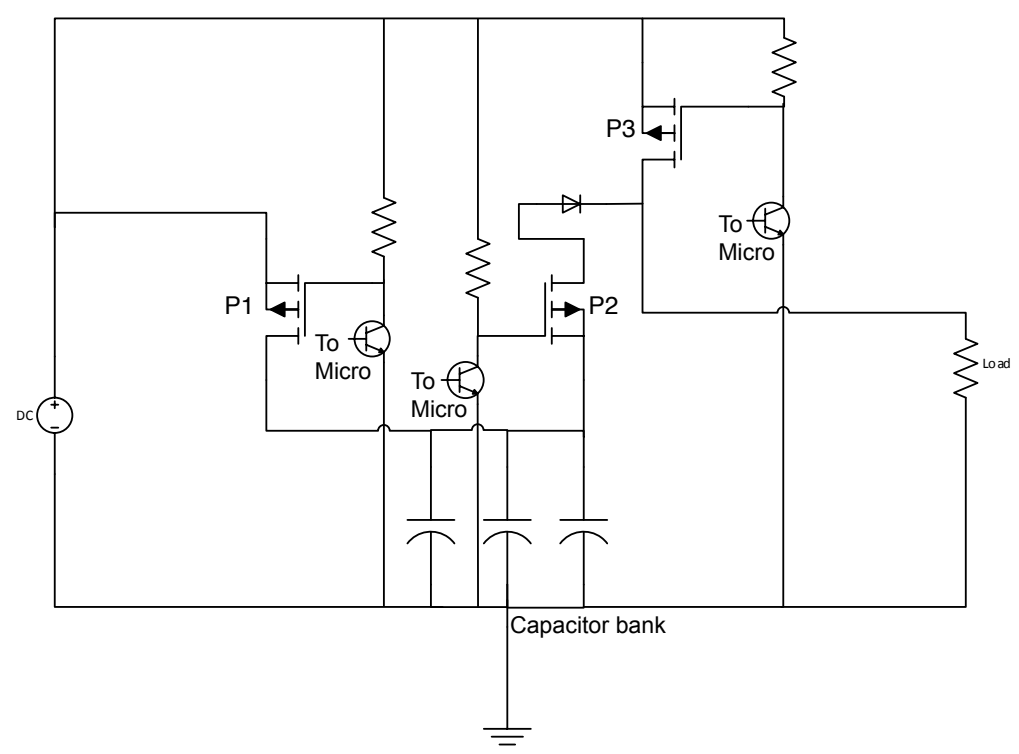

Figure 4.8: Node Block diagram

bank to load switch $(P 2)$ is set to "off" to ensure the load is not serviced via this route. The supply to load switch $(P 3)$ is switched "off" unless the conditions outlined in the supply to load mode are met. If this occurs, P3 will be switched "on", P2 will remain "off" and P1 will continue to charge the capacitor bank when necessary. A block diagram of the charge mode procedure is shown in figure 4.9, with the current path displayed in red.

- Capacitor bank to load idle mode: Once the capacitor bank is charged, P2 is switched "on" ready for the load to be switched on. The output current and voltage is monitored, and while no current is drawn, the node will remain in this idle state. Figure 4.10 displays a block diagram of this mode.

- Capacitor bank to load draw mode: Once the load is switched on, it begins to draw current from the capacitor bank. The microprocessor will note the current draw and voltage level on the output of the 


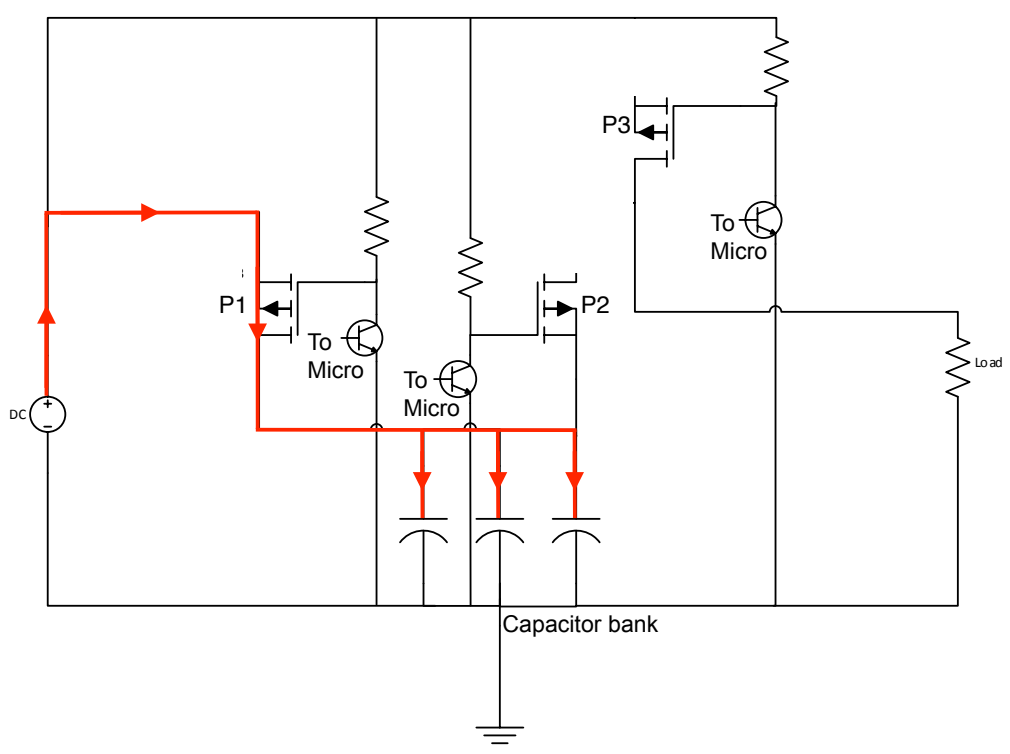

Figure 4.9: Node Block diagram

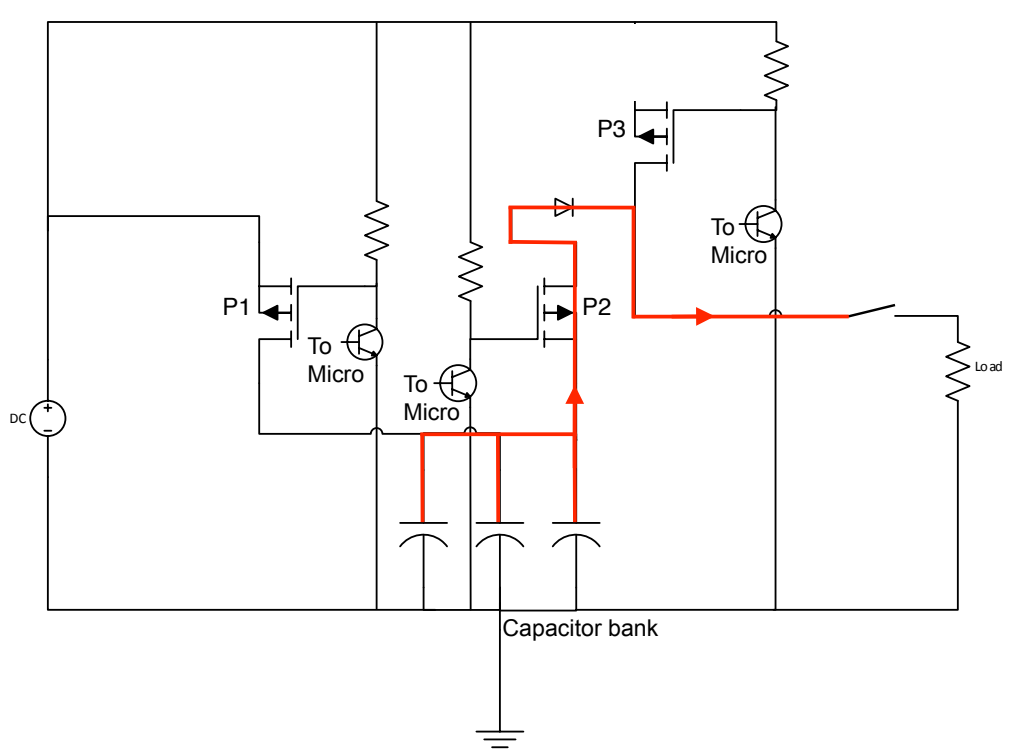

Figure 4.10: Node Block diagram 
node, calculating the load's power draw. This information is then sent to the central controller and instruction is awaited. The Capacitor bank to load draw mode is shown in figure 4.11

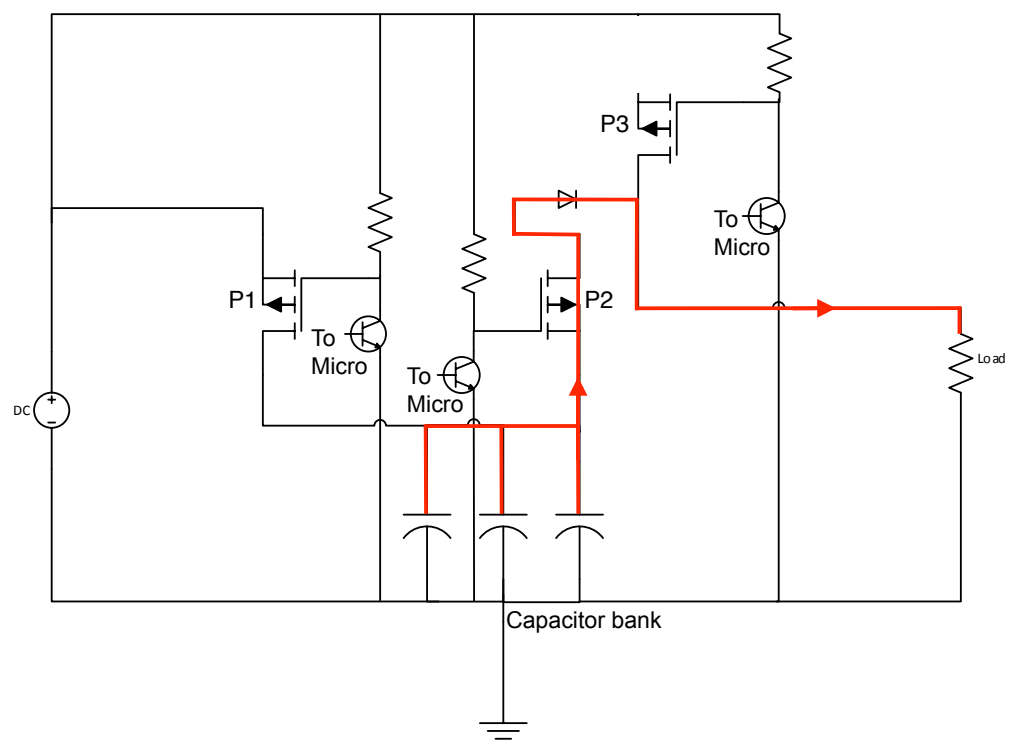

Figure 4.11: Node Block diagram

- Supply to load mode: At this stage a signal is received by the node from the central controller, confirming or denying the availability of power. If there is not adequate power available to operate the load, $P 3$ will remain off. However, if power is available (or made available by the central controller), $P 3$ is switched on and the power is pulled from the supply as shown in figure 4.12. As previously discussed, P2 will remain off during this procedure, allowing the capacitor bank to charge. Once the output current draw is returned to zero, the system will reset, returning to "charge mode".

Figure 4.13 shows the simulated results of a node supplying a $48 \mathrm{~V}$, 250W load which switches on at $t=10$ minutes. The capacitor bank initially supplies the load while the nanogrid controller assesses the availabil- 


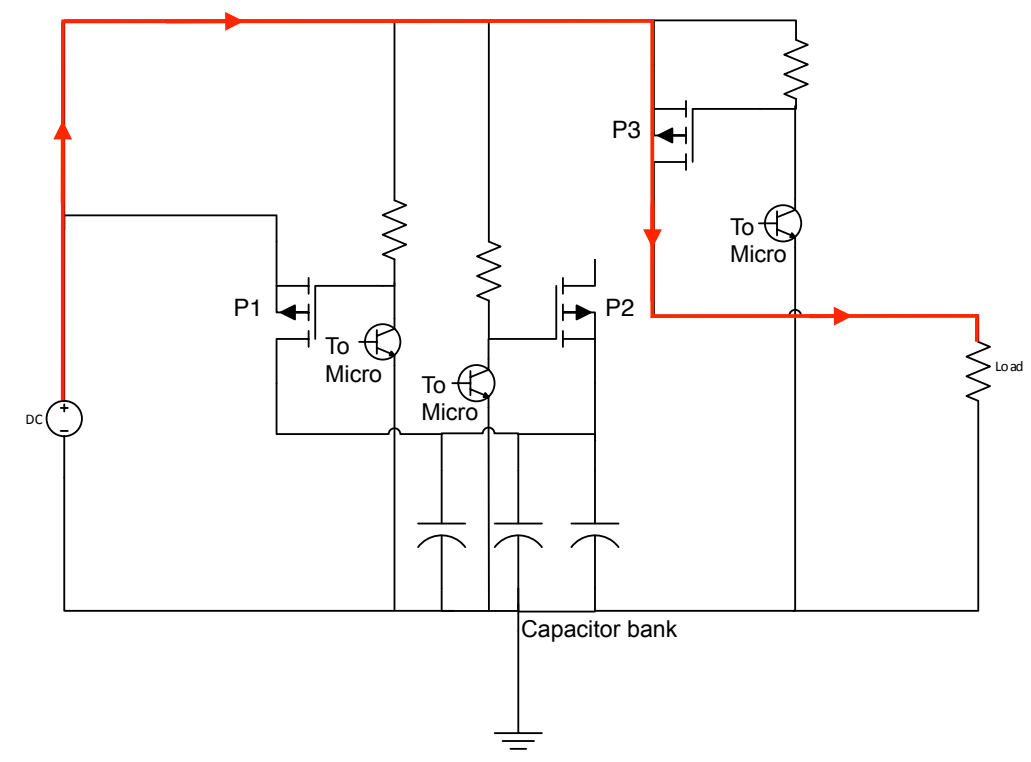

Figure 4.12: Node Block diagram

ity of power. Once it is established that the nanogrid has adequate power, the nanogrid begins to supply the load at which point the capacitor bank is recharged. During this transaction (as shown in the top plot of figure 4.13 ), the capacitor voltage drops to $47.78 \mathrm{~V}$ while the capacitor supplies the load (a drop of approximately $0.42 \%$ and well within an acceptable margin).

\section{Thermostatically controlled load nodes}

The thermostatically controlled loads node has an additional feature allowing the nanogrid controller to vary the power consumed by the load. This is implemented by a buck converter which varies the voltage to the thermostatically controlled load (in turn altering the power). The design process follows that of the buck converter utilised by the MPPT minus the closed loop feedback control. The duty cycle instead is controlled directly by the control scheme based on a number of variables discussed in section 


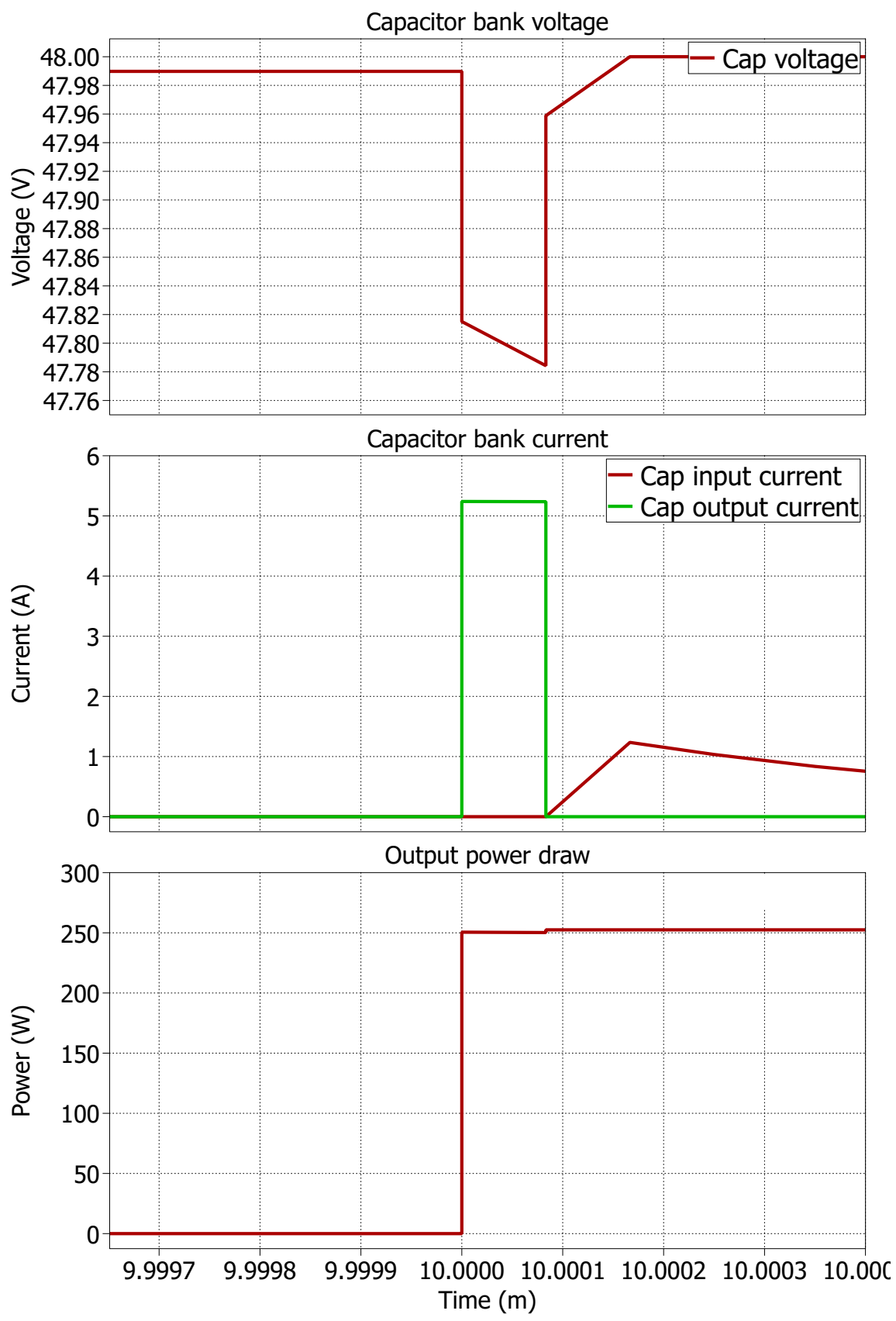

Figure 4.13: Node simulated operation 
4.2.1. Figure 4.14 shows a block diagram of the thermostatically controlled loads node.

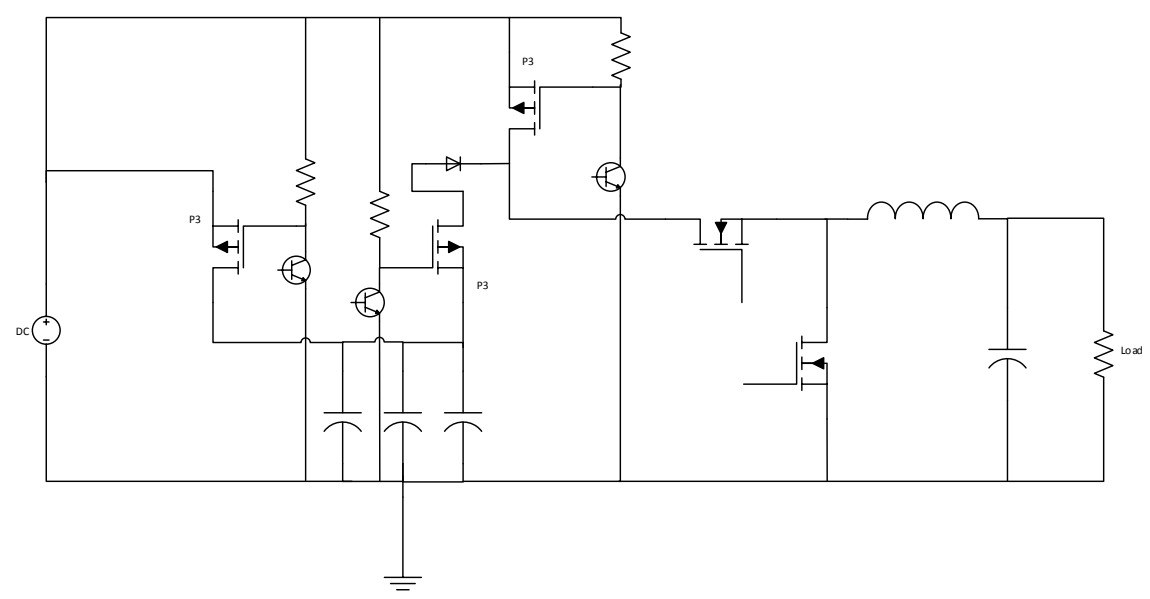

Figure 4.14: Thermostatically controlled load node

\subsection{Thermostatically Controlled Loads}

The nanogrid makes use of household loads with a thermal output, relying on their relatively slow dynamics to store energy which can be used outside of PV production times. During the design of the nanogrid, three thermostatically controlled loads were identified as large/frequent consumers of power and selected for analysis and control. These were the electric water heater, refrigerator and space heating, for which the analysis and control theory are presented below.

\subsubsection{Water and Space Heating}

It makes sense to discuss the water and space heating collectively, as the control strategies are connected. The water heater considered in this research is the common domestic electric hot water storage tank, while the 
space heating is implemented by a storage heater (sometimes referred to as "night storage heaters"). Each load is presented below, before the control strategy is discussed.

\section{Water Heater}

Heating water for use in showers and the sink requires an electric water heater to operate for hours each day (the time depending on hot water use), typically drawing power in excess of $2 k W$. This makes it one of the largest household loads and when controlled, gives it the potential to shift a substantial portion of the daily consumption. The water heater's thermal behaviour is governed by the differential Eqn. (4.15) [203], with the variables explained in Table 4.3.

$$
M c \frac{d T_{W}}{d t}=\dot{m} c\left(T_{i}-T_{W}\right)-h A\left(T_{W}-T_{a}\right)+q
$$

Eqn. (4.15) can be rearranged to calculate the change in temperature over a specific time period (4.16), and from here, the change in time for a specific temperature change can be derived (4.17). With Eqn. (4.17), the thermal autonomy (time the water temperature can remain above a predetermined threshold) of the water heater can then be calculated, as can the time required to heat the water to an upper temperature threshold. As the temperature difference between the upper and lower temperature threshold increases, the time between "on" cycles $\left(T_{o n}\right)$ also increases.

This property can be utilised in the design of the nanogrid controller by bypassing the standard thermostat and selecting an upper/lower water temperature to give the desired on/off time interval. In the nanogrid controller simulated for this work, $81^{\circ} \mathrm{C}$ was selected as the upper temperature while $55^{\circ} \mathrm{C}$ was selected for the lower, giving 24 hours thermal autonomy (while $\dot{m}=0$ ).

Figure 4.15 displays the water heater's thermal autonomy plotted against 
Table 4.3: Explanation of variables in Eqn. (4.15)

\begin{tabular}{|c|c|c|}
\hline Variable & Description & Simulation Values \\
\hline$M$ & Mass of water $(\mathrm{kg})$ & $88 L$ to $300 L$ \\
\hline$c$ & Specific heat of the water $\left(\mathrm{J} / \mathrm{kg}^{\circ} \mathrm{C}\right)$ & $4179 \mathrm{~J} / \mathrm{kg}^{\circ} \mathrm{C}$ \\
\hline$\dot{m}$ & Flow rate $(k g / h)$ & $9 L / m$ \\
\hline$T_{W}$ & $\begin{array}{l}\text { Temperature of the water in the tank } \\
\left({ }^{\circ} \mathrm{C}\right)\end{array}$ & $55^{\circ} \mathrm{C}$ to $81^{\circ} \mathrm{C}$ \\
\hline$T_{i}$ & $\begin{array}{l}\text { Temperature of the water entering the } \\
\operatorname{tank}\left({ }^{\circ} \mathrm{C}\right)\end{array}$ & $7^{\circ} \mathrm{C}$ \\
\hline$h$ & $\begin{array}{l}\text { Heat transfer coefficient (for convec- } \\
\text { tion to ambient) }\left(W / m^{2 \circ} \mathrm{C}\right)\end{array}$ & $1.5 \mathrm{~W} / \mathrm{m}^{2 \circ} \mathrm{C}$ \\
\hline$A$ & Area of the tank $\left(m^{2}\right)$ & $1.84 m^{2}$ to $3.85 m^{2}$ \\
\hline$T_{a}$ & Ambient temperature $\left({ }^{\circ} \mathrm{C}\right)$ & $20^{\circ} \mathrm{C}$ \\
\hline$q$ & Heat rate of the heating element $(W)$ & $2 \mathrm{~kW}$ to $3 \mathrm{~kW}$ \\
\hline$t$ & time $(\mathrm{s})$ & \\
\hline
\end{tabular}

water consumption for a variety of initial temperatures.

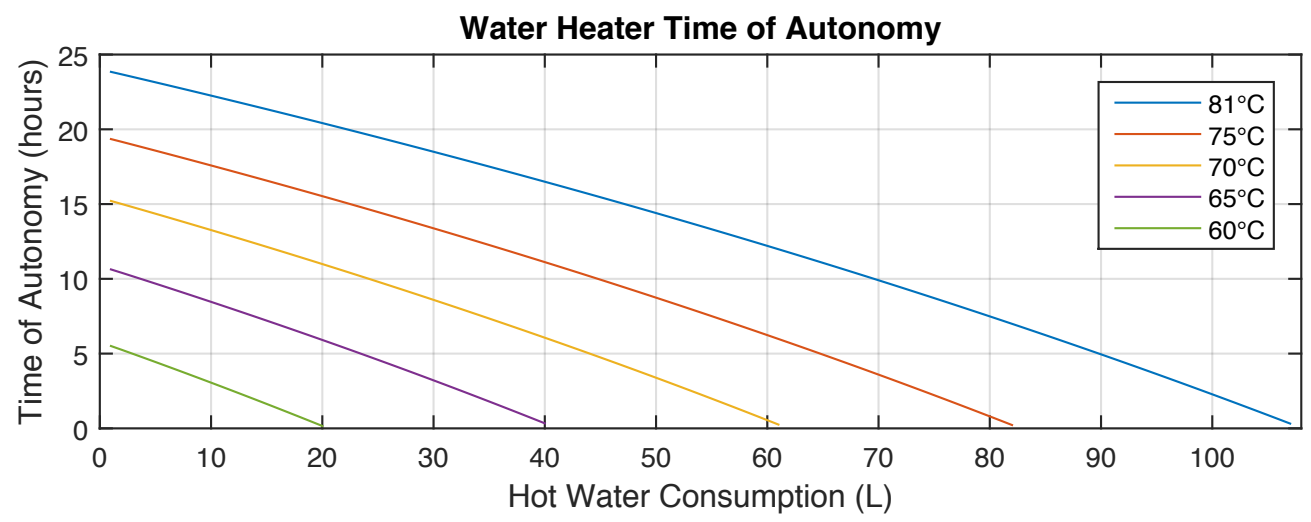

Figure 4.15: Initial water temperature and its thermal autonomy vs water consumed 


$$
T_{W}=\frac{a T_{i}+d T_{a}+q}{a+d}+k e^{-\left(\frac{a+d}{b}\right) t}
$$

where $a=\dot{m} c, b=M c$ and $d=h A$.

$$
t=\frac{b \times \log (x)}{a+d}
$$

where $x=\frac{k}{T_{W}-f}$ and $f=\frac{a T_{i}+d T_{a}+q}{a+d}$, with $k$ being the integration constant.

Increasing the upper temperature of the water to $81^{\circ} \mathrm{C}$ raises safety issues, as temperatures at this level can scald users. To counteract this negative effect, it is recommended that a thermostatic mixing valve is added to the output of the hot water tank. This device mixes cold with hot water to give a constant (safe) output water temperature, and will switch off the hot water in the absence of cold. It should also be noted, from eqn. (4.15), that with the increased water temperature, the loss to ambient will also increase. However, if the heat transfer coefficient $(h)$ is altered by adding insulation to the water heater (eg insulating blanket), these losses can be negated [204].

\section{Storage Heater}

Initial tests were conducted with the hot water tank and refrigerator controlled by the nanogrid. It was found that, although the solution produced a reduction in external power consumed by the nanogrid, space heating limited its effectiveness. This motivated the inclusion of space heating into the control regime.

A storage heater, consisting of elements heating insulated bricks (as shown in Figure 4.16), was selected for the solution due its high thermal autonomy. The bricks are heated during times of high PV production and 
the heat is stored until it is required, at which stage a fan is activated to achieve the required room temperature. If there has been insufficient PV production to heat the bricks during a single day, the heater draws the required power at time of use (from the grid).

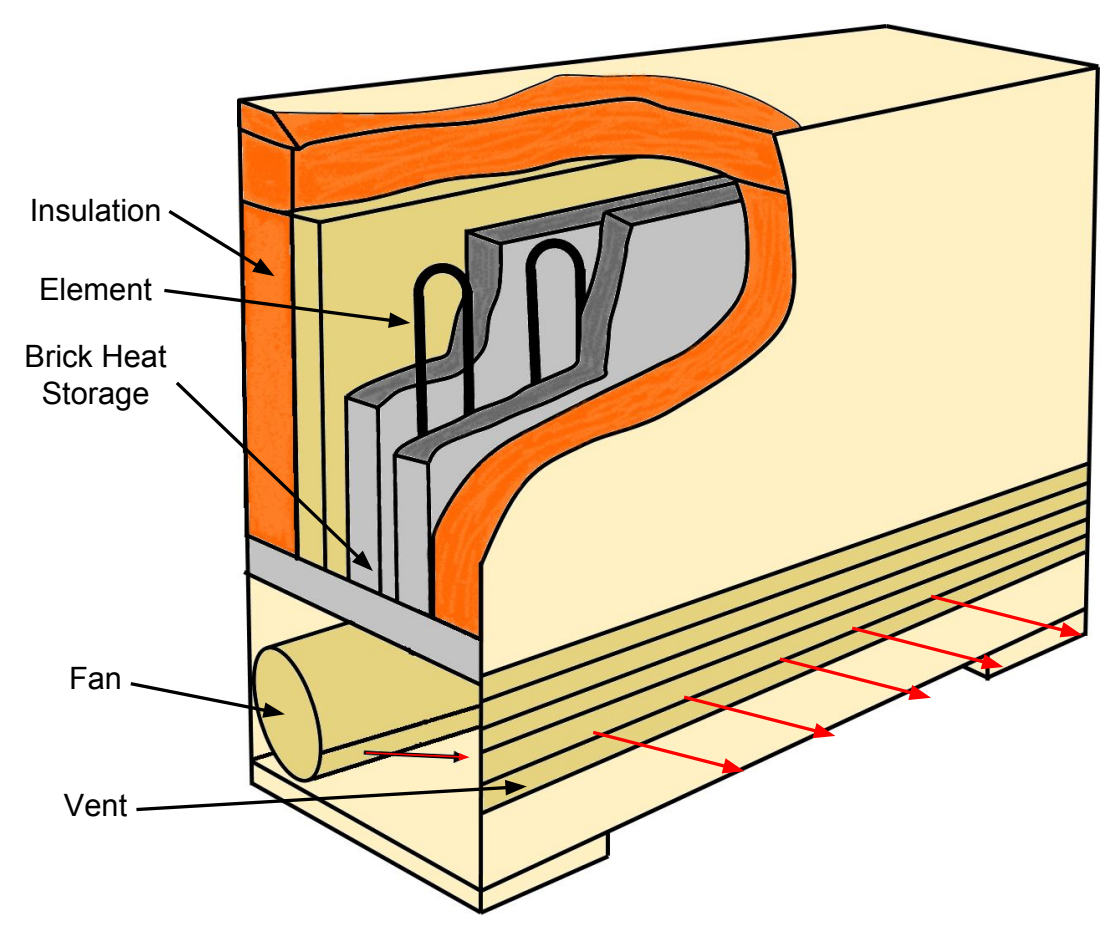

Figure 4.16: Storage Heater Diagram

Eqn. (4.18) describes the behaviour of the storage heater, eqn. (4.19) shows the losses during fan "off/on" operation (where $Q_{O u t}$ increases with the temperature of the bricks) and eqn. (4.20) displays the input power [205]. The variables of the storage heater equations are outlined in Table 4.4 .

$$
M_{b} c_{b} \frac{d T_{b}}{d t}=Q_{\text {In }}-Q_{O u t}
$$




$$
\begin{gathered}
Q_{\text {Out }}=\left\{\begin{array}{l}
Q_{f b}+Q_{s}+Q_{v n} \text { Fan off } \\
Q_{f b}+Q_{s}+Q_{v f} \quad \text { Fan on }
\end{array}\right. \\
Q_{\text {In }}= \begin{cases}R \times i^{2} & \text { Charge } \\
0 & \text { Discharge }\end{cases}
\end{gathered}
$$

\begin{tabular}{|c|c|c|}
\hline Variable & Description & Simulation Values \\
\hline$M_{b}$ & Mass of the bricks $(\mathrm{kg})$ & $60 \mathrm{~kg}$ \\
\hline$c_{b}$ & $\begin{array}{l}\text { Specific heat of the bricks } \\
\left(J / k g^{\circ} \mathrm{C}\right)\end{array}$ & $670 \mathrm{~J} / \mathrm{kg}^{\circ} \mathrm{C}$ \\
\hline$T_{b}$ & Temperature of the bricks $\left({ }^{\circ} \mathrm{C}\right)$ & $20^{\circ} \mathrm{C}$ to $600^{\circ} \mathrm{C}$ \\
\hline$Q_{f b}$ & $\begin{array}{l}\text { Insulated front and back con- } \\
\text { duction losses }\end{array}$ & See table 4.5 \\
\hline$Q_{s}$ & $\begin{array}{l}\text { Insulated side, top and bottom } \\
\text { conduction losses }\end{array}$ & See table 4.5 \\
\hline$Q_{v n}$ & $\begin{array}{l}\text { Natural convection via fan out- } \\
\text { let }\end{array}$ & Temperature dependant \\
\hline$Q_{v f}$ & Forced convection via fan outlet & Temperature dependant \\
\hline$R$ & $\begin{array}{l}\text { Resistance of heating elements } \\
(\Omega)\end{array}$ & $26.4 \Omega$ \\
\hline$i$ & $\begin{array}{l}\text { Current through heating ele- } \\
\text { ments }(A)\end{array}$ & $8.7 A$ \\
\hline
\end{tabular}

Table 4.4: Explanation of variables in Eqn. (4.18), (4.19) and (4.20)

Eqns. (4.18), (4.19) and (4.20) need to be expanded and rearranged to calculate the time of autonomy under fan off/on conditions. The derivations for the "Fan off", then "Fan on", are as follows: 
Fan off: During fan off times, the area where the fan extracts the heat is still exposed so must be considered as a natural convection output. This is the main point of loss for the storage heater and can cause a room's temperature to raise during the charge cycle. The variables used in Eqn. (4.21) to explain the operation of the fan off cycle, are shown in Table 4.5. The equation is then rearranged in (4.22) and (4.23).

$$
M_{b} c_{b} \frac{d T_{b}}{d t}=Q_{I n}-\frac{k_{f b} A_{f b}}{l_{f b}} \Delta T-\frac{k_{s} A_{s}}{l_{s}} \Delta T-k_{v n} A_{v n} \Delta T
$$

where $\Delta T$ is temperature of the bricks $\left(T_{b}\right)$ minus the temperature of the $\operatorname{room}\left(T_{R}\right)$.

Table 4.5: Explanation of variables in equation 4.21

$$
\begin{aligned}
& \text { Variable Description } \\
& \text { Simulation Values } \\
& k_{f b} \\
& \text { Thermal conductivity of front and } 0.021 \mathrm{~W} / \mathrm{m}^{\circ} \mathrm{C} \\
& \text { back }\left(W / m^{\circ} \mathrm{C}\right) \\
& A_{f b} \quad \text { Area of the front and back }\left(m^{2}\right) \quad 0.698 m^{2} \\
& l_{f b} \quad \text { Thickness of the front and back }(m) \quad 0.009 m \\
& k_{s} \quad \text { Thermal conductivity of the } 0.04 \mathrm{~W} / \mathrm{m}^{\circ} \mathrm{C} \\
& \text { sides/top/bottom }\left(W / m^{\circ} \mathrm{C}\right) \\
& A_{s} \quad \text { Area of the sides/top/bottom }\left(m^{2}\right) \quad 0.345 m^{2} \\
& l_{s} \quad \text { Thickness of the sides/top/bottom } 0.05 \mathrm{~m} \\
& (m) \\
& k_{v n} \quad \text { Natural convection heat transfer coef- } \quad 10.45 \mathrm{~W} / \mathrm{m}^{2 \circ} \mathrm{C} \\
& \text { ficient }\left(W / m^{2 \circ} \mathrm{C}\right) \\
& A_{v n} \quad \text { Heat transfer area of the surface }\left(m^{2}\right) \quad 0.034914 m^{2} \\
& T_{b}=\frac{Q_{\text {In }}+(a+b+c) T_{R}}{a+b+c}+w e^{-(a+b+c) t} \\
& t=\frac{\log \left(\frac{w}{T_{b}-p}\right)}{a+b+c}
\end{aligned}
$$


where $a=\frac{k_{f b} A_{f b}}{l_{f b} M_{b} c_{b}}, b=\frac{k_{s} A_{s}}{l_{s} M_{b} c_{b}}, c=\frac{k_{v n} A_{v n}}{M_{b} c_{b}}$,

$p=\frac{Q_{\text {In }}+(a+b+c) T_{R}}{a+b+c}$ and $w$ is the constant of integration.

Fan on: During the fan on cycle, the natural convection losses are exchanged to forced convection losses extracting heat from the storage heater at a much faster rate. This can be controlled by a room thermostat, ensuring the temperature of the room is adequate.

The variables in Eqn. (4.24) can be taken from Table 4.5 with the exception of $k_{v f}$ which is the forced convection heat transfer coefficient, and $A_{v f}$ is equal in area to $A_{v n}$.

$$
M_{b} c_{b} \frac{d T_{b}}{d t}=-\frac{k_{f b} A_{f b}}{l_{f b}} \Delta T-\frac{k_{s} A_{s}}{l_{s}} \Delta T-k_{v f} A_{v f} \Delta T
$$

where $\Delta T$ is temperature of the bricks $\left(T_{b}\right)$ minus the temperature of the room $\left(T_{R}\right)$. Eqn. (4.25) and (4.26) make time the focus in order to calculate the storage heater's thermal autonomy.

$$
\begin{gathered}
T_{b}=T_{R}+w e^{-(a+b+d) t} \\
t=\frac{\log \left(\frac{w}{T_{b}-T_{R}}\right)}{a+b+d}
\end{gathered}
$$

where $a=\frac{k_{f b} A_{f b}}{l_{f b} M_{b} c_{b}}, b=\frac{k_{s} A_{s}}{l_{s} M_{b} c_{b}}, d=\frac{k_{v f} A_{v f}}{M_{b} c_{b}}$ and $w$ is the constant of integration.

\section{Water/Storage Heater Control Strategy}

The water and storage heater control strategy looks to maximise PV power consumed, store the energy until required and ultimately reduces the external power consumed by the nanogrid.

As the electric elements in both the water and storage heaters are resistive, it allows each load's power consumption to be varied as required by 
the control system. To achieve this, a buck converter (DC-DC step down converter controlled by its duty cycle) was added to the control nodes of these thermostatically controlled devices.

The buck converter's output voltage $\left(V_{o}\right)$ is derived from the input voltage $\left(V_{I n}\right)$ via the duty cycle $(D)$ as shown in Eqn. (4.27). Also, the output power $\left(P_{o}\right)$ is equal to the input power $\left(P_{I n}\right)$ scaled by the buck converter's efficiency $(\mathscr{E})$ (Eqn. (4.28)), giving Eqns. (4.29) and (4.30) (where $I_{I n}$ and $I_{o}$ are input and output current respectively).

$$
\begin{gathered}
V_{o}=D V_{I n} \\
P_{o}=\mathscr{E} P_{I n} \\
D V_{I n} I_{o}=\mathscr{E} V_{I n} I_{I n} \\
D=\frac{\mathscr{E} V_{I n} I_{I n}}{V_{I n} I_{O}}=\frac{\mathscr{E} I_{I n}}{I_{o}}
\end{gathered}
$$

For the control to make use of the available PV power, the duty cycle needs to be a function of the maximum power point tracker's power output signal $\left(P_{M P P T}\right)$. Eqn. (4.31) is rearranged in Eqn. (4.32), and the relationship between duty cycle and PV power is shown in Eqn. (4.33).

$$
\begin{gathered}
P_{M P P T}=P_{I n}=V_{I n} I_{I n} \\
I_{I n}=\frac{P_{M P P T}}{V_{I n}} \\
D=\frac{\mathscr{E} P_{M P P T}}{I_{o} V_{I n}}
\end{gathered}
$$

At this point, by measuring the buck's input voltage, output current, and utilising the MPPT signal, a single thermostatically controlled load 
(e.g. water heater) could consume all of the available PV power without exceeding its capacity.

However, to be effective, this control concept is expanded to include standard household loads and interactions between the water and storage heaters. Eqn. (4.34) expands on Eqn. (4.33) to include data from the central controller $\left(L_{\text {total }}\right)$, accounting for the power consumed by the standard household loads. It also adds a multiplier $(m)$, which is used to calculate the ratio of PV power received by the water and storage heaters based on their "urgency".

$$
D_{\text {ratio }}=m \frac{\mathscr{E}\left(P_{M P P T}-L_{\text {total }}\right)}{I_{o} V_{I n}}
$$

The measure of urgency is derived from the thermal autonomy of the heaters (water or storage). By inserting the current temperature of each load in real time, into Eqns. (4.17) (water heater) or (4.23) (storage heater fan off) and (4.26) (storage heater fan on), the time until the next "on" cycle is calculated $\left(t_{o f f}\right)$. In the same manner, the time required to heat the load to its upper limit could also be calculated with the above mentioned equations $\left(t_{o n}\right)$. Multiplying the time required to heat the load by its power draw (" $P$ ", which at this stage is manually entered from datasheet information with continued research on automating a calibration process), and considering the ratio of on/off cycles in a single day, the urgency of the load is calculated as shown in Eqn. (4.35). By giving preference to the most urgent loads, the control strategy operates on the load which is likely to draw the most power outside of PV production times.

$$
x=P \frac{t_{\text {on }}}{t_{\text {on }}+t_{\text {off }}} / d a y
$$

Once the measure of urgency is calculated, the ratio term $\left(m_{. .}\right)$can be derived for the water and storage heaters as shown in Eqn. (4.36). This means $100 \%$ of the power produced by PV can now be consumed by household loads, and the more urgent thermostatically controlled load 
(out of the water and storage heater) is serviced with the majority of the remaining PV power.

$$
m_{. .}= \begin{cases}\frac{x_{W H}}{x_{W H}+x_{S H}} & \text { Water Heater } \\ \frac{x_{S H}}{x_{W H}+x_{S H}} & \text { Storage Heater }\end{cases}
$$

To ensure the safety and comfort of the users, there were exceptions to the control law discussed above. These are as follows:

- Water Lower Temperature Threshold The water stored in the water heater must stay above the temperature at which legionella bacteria can breed. For this reason, if the temperature drops below $55^{\circ} \mathrm{C}$, the water heater's element will turn on regardless of PV power availability. If PV power is not available, the water is heated to a lower temperature threshold $\left(60^{\circ} \mathrm{C}\right)$ and is only heated to upper limit threshold $81^{\circ} \mathrm{C}$ once PV power is available.

- Room Temperature The storage heater will be required to keep the room at a specific temperature for a time period determined by the user. If there has been insufficient PV power to heat the bricks to a temperature at which the storage heater can sustain the user's requirements, additional power will be needed. As with the water heater, the storage heater will draw power regardless of PV availability to ensure the room is kept at the appropriate temperature.

- Upper Temperature Limits Both the water and storage heater have upper temperature limits under which the devices can operate safely. If these limits are reached and PV power is still available, the load is allowed to cool to an upper temperature threshold before it is heated again. If the upper limit is reached and PV power is no longer available, the temperature will be allowed to reach its lower limit.

Figure 4.17 shows the flow diagram of a typical interaction between a nonthermostatically controlled load and a thermostatically controlled load. In 
this situation, the former load is switched on by a user and the latter a response to the change in household consumption.

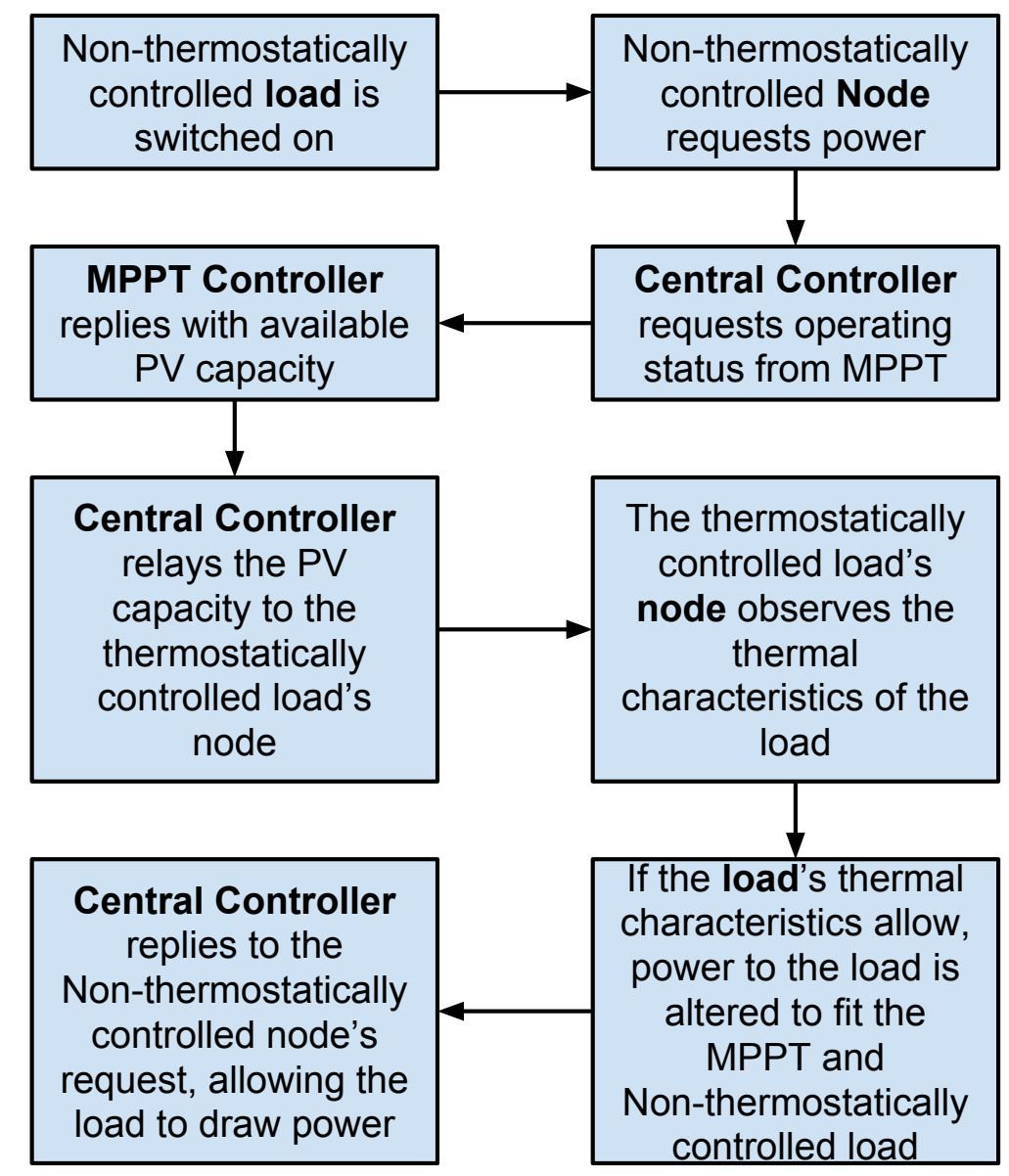

Figure 4.17: Flow diagram of a typical load interaction

\subsubsection{Refrigerator}

Although the refrigerator is not a large load compared to the water heater, it is far more frequent and its power draw is characterised by a large current spike on start up (due to the compressor). This is also the reason the refrigerator cannot take part in the buck style control system developed 
for the water and space heating. However, as the refrigerator is a thermostatically controlled load, it can still help to reduce the power consumed by the nanogrid (from an external source).

The thermal characteristics are described by Eqn. (4.37) (with variables explained in Table 4.6) a first order piece-wise approximation where Case 0 is when the refrigerator is OFF and Case 1 when it is ON [206].

$$
\frac{d T_{F}}{d t}= \begin{cases}\frac{T_{a}-T_{F}}{C_{c} R_{i}} & \text { Case } 0 \\ \frac{T_{a}}{C_{c} R_{i}}+\frac{T_{e}}{C_{c} R_{e c}}-\frac{T_{F}}{C_{c} R_{i} R_{e c}} & \text { Case } 1\end{cases}
$$

Table 4.6: Explanation of variables in Eqn. (4.37)

\section{Variable Description}

$T_{F} \quad$ Cabinet temperature

$T_{a} \quad$ Ambient temperature

$T_{e} \quad$ Inlet temperature of the refrigerant evaporator

$C_{c} \quad$ Heat storage capacity

$R_{i} \quad$ Thermal resistance of the insulation

$R_{e c} \quad$ Thermal resistance of the wall between the cabinet and evaporator

As with the water heater, this equation can be rearranged to calculate temperature change (4.38) and the change time (4.39). The time equation is used to create a control algorithm to manipulate the thermal autonomy of the refrigerator.

$$
T_{F}= \begin{cases}T_{a}+k e^{\frac{1}{C_{c} R_{i}} t} & \text { Case } 0 \\ z\left(\frac{T_{a}}{C_{c} R_{i}}+\frac{T_{e}}{C_{c} R_{e c}}\right)+k e^{\frac{1}{z} t} & \text { Case } 1\end{cases}
$$

where $z=C_{c} R_{i} R_{e c}, k$ is the constant of integration, and the time taken to $\mathrm{cool} /$ heat the refrigerator cavity is given by: 


$$
t_{\text {cool } / \text { heat }}= \begin{cases}C_{c} R_{i} \log \left(\frac{k}{T_{F}-T_{a}}\right) & \text { Case } 0 \\ z \log \left(\frac{k}{T_{F}-z\left(\frac{T_{a}}{C_{c} R_{i}}+\frac{T_{e}}{C_{c} R_{e c}}\right)}\right) & \text { Case } 1\end{cases}
$$

where $z=C_{c} R_{i} R_{e c}$ and $k$ is the constant of integration.

\section{Refrigerator Control Algorithm}

The goal of the refrigerator control is to reduce the frequency of "on" time while PV power is unavailable. Figure 4.18 shows a flow diagram of the algorithm (variables explained in table 4.7). In the algorithm there is a lower/upper threshold temperature, $1^{\circ} \mathrm{C}$ and $2.4^{\circ} \mathrm{C}$ respectively, and lower/upper limit temperature $\left(0^{\circ} \mathrm{C}\right.$ and $4^{\circ} \mathrm{C}$ respectively).

If sufficient PV power is available to accommodate the refrigerator's power requirements, the refrigerator is cooled to the lower limit where it oscillates between the lower limit and lower threshold. If there is insufficient power for the refrigerator, the temperature is allowed to increase to the upper limit and oscillates between the upper limit and upper threshold. 


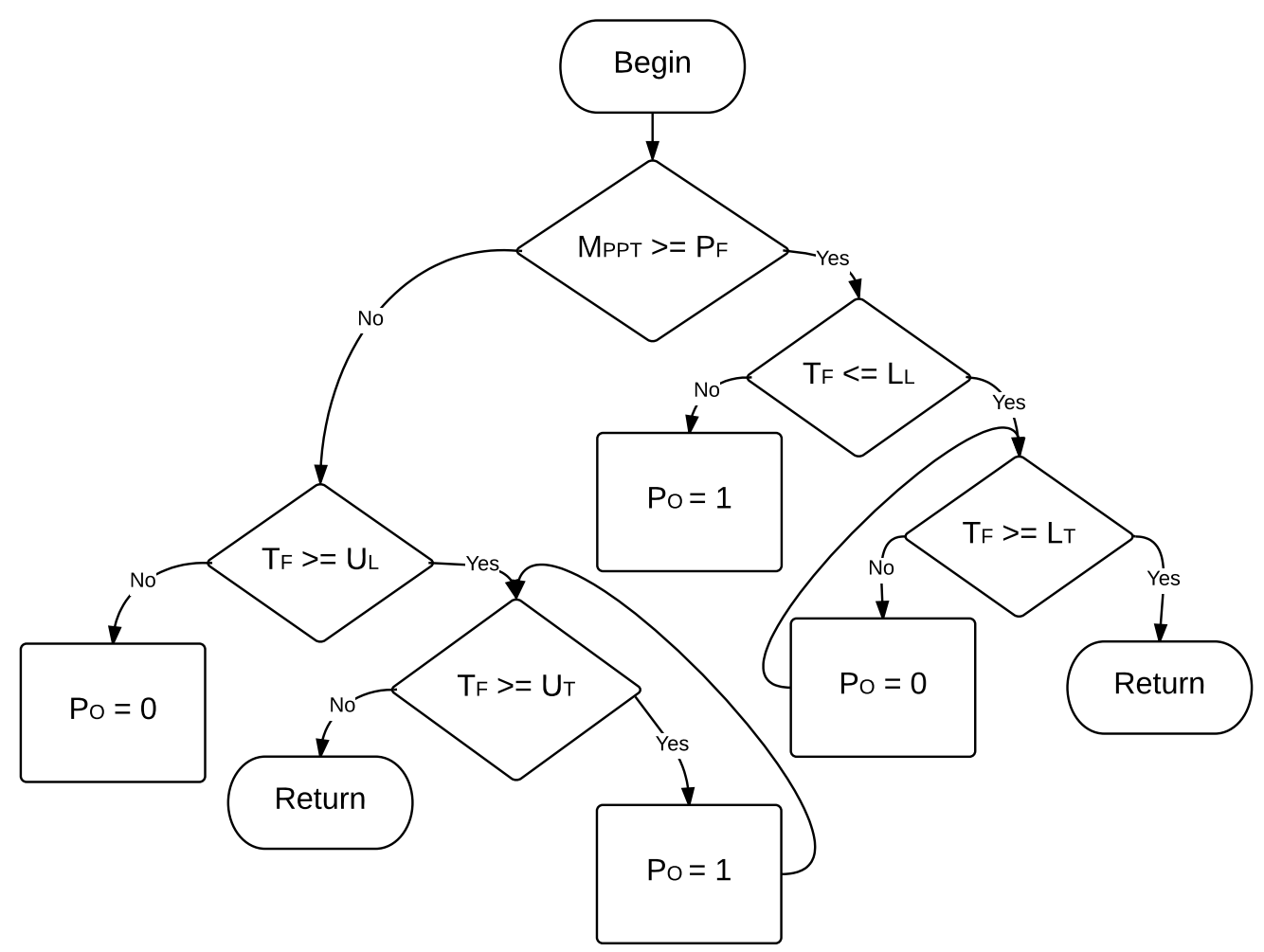

Figure 4.18: Flow diagram of the refrigerator autonomy control algorithm

Table 4.7: Explanation of variables in refrigerator autonomy control algorithm

$\begin{array}{ll}\text { Variable } & \text { Description } \\ M_{P P T} & \text { Maximum power point signal } \\ P_{F} & \text { The power requirements of the refrigerator } \\ T_{F} & \text { Temperature of the refrigerator } \\ L_{L} & \text { Lower temperature limit } \\ L_{T} & \text { Lower temperature threshold } \\ P_{O} & \text { Output power status } \\ U_{L} & \text { Upper temperature limit } \\ U_{T} & \text { Upper temperature threshold }\end{array}$




\subsection{Simulation, Results and Discussion}

With the objective of the nanogrid being "to reduce grid power consumed, by utilising locally produced PV power", a method of quantifying this outcome needed to be established. A model was developed in "PLECS" simulation software (an extension of Matlab's Simulink), which consisted of the following considerations:

- Relevant solar data: To ensure the nanogrid control was simulated under realistic conditions, the solar calculator developed by the National Institute of Water and Atmospheric research (NIWA) was used [207]. This calculator used 18 years of data from the nearest climate station combined with local landscape to obtain an estimate of a region's solar energy. The selected location for the tests was Kelburn in Wellington, New Zealand (-41.29 latitude, 174.76 longitude). To observe the extreme ends of the available solar, a week of solar data from the middle of Summer and Winter was selected, Figure 4.19 shows the selected weeks with the maximum power output of the $6 \mathrm{~kW}$ PV installation used for the simulations.

- Varied load curves It was important to test the nanogrid controller under a variety of load conditions to observe the controller's behaviour and to ensure a specific loadline did not produce a biased result. The model was designed so that multiple on/off times and power draw of the household loads shown in Table 4.8 could be varied (along with the additional details discussed in the table) to create multiple household scenarios. Appendix A presents the on/off times for all loads used within the 10 houses, along with refrigerator parameters, shower times/lengths and hot water cylinder characteristics. With the exception of the refrigerator (which had an inductive element in the model), the loads were modelled as resistive loads with curves derived from either; the behaviour of physically 
measured loads (television, toaster, stereo, kettle, refrigerator, hot water tank, heater), responses from literature (dishwasher) [208] or assumed responses for smaller loads (lights, lamps, phone charger, computer/laptop, alarm clocks). Ten household curves were then designed to test the nanogrid controller as shown in Figure 4.20. In this figure, the blue block area depicts the $k W h$ consumption of the summer load, while the red block area the winter (note the red block is consumption additional to the blue). The red lines in the figure display the instantaneous summer consumption, while the blue lines the instantaneous winter $(\mathrm{kW})$.

- Comparison between controlled and uncontrolled: Two versions of each of the ten households were developed, one with the nanogrid controller and the other without control. These were then tested under the varied solar irradiance condition with an identically sized PV array, MPPT (to ensure the output of the PV array was comparable) and grid connection. The power consumed from the grid by each scenario was monitored in order to validate the nanogrid's ability to meet its objective.

Figure 4.21 shows the simulation setup of a typical house within the PLECS modelling environment.

The results shown in Table 4.9 (Winter) and 4.10 (Summer) give a comparison between the power consumed from the grid by the controlled and uncontrolled nanogrid in $\mathrm{kWh}$ consumed per day, and the reduction of power consumed as a percentage.

The results show that as a percentage, the reduction of power consumed from the grid during the summer (in this geographic location) is greater than in winter. However, because the household consumption is much larger in the winter (than in summer), the reduction of power consumed from the grid is more significant during this season. 
Table 4.8: Loads within the modelled house

$\begin{array}{ll}\text { Variable } & \text { Description } \\ \text { Lights } & \text { Six available } \\ \text { Lamps } & \text { Three available } \\ \text { Phone charger } & \text { Three available } \\ \text { Computer/Laptop } & \text { Three available } \\ \text { Alarm clocks } & \text { Two available } \\ \text { Showers } & \text { Variable time and length of showers (9L/m flow rate) } \\ \text { Sink } & \text { Variable hot water used for dishes etc (L) } \\ \text { Hot water tank } & \text { Variable water capacity, physical size } \\ \text { Dishwasher } & \text { Full cycle } \\ \text { Refrigerator } & \text { Variable initial tamp, thermostat high and low temp } \\ \text { Oven } & \text { Four separate elements and/or oven } \\ \text { Heater } & \text { Bar heater considered for uncontrolled house } \\ \text { Storage heater } & \text { Outdoor temperature varied throughout day/night } \\ \text { kettle } & \text { Heating 1L } \\ \text { Toaster } & \text { On time 3 minutes } \\ \text { Television } & \text { Single available } \\ \text { Stereo } & \text { Single available }\end{array}$

Figure 4.22 shows a controlled and uncontrolled household's consumption over a 24 hour period in winter. It can be seen here that the controlled system consumes a large percentage of the available PV power (blue shaded area), in turn reducing grid power consumption. In comparison, for the majority of the uncontrolled PV production time, little more than the refrigerator is operating.

While this plot does not represent the consumption of every household, every day, it does depict the general trend and shows how the algorithm achieves its reduction in power consumed.

To get an idea of the potential reduction in power consumed from the 


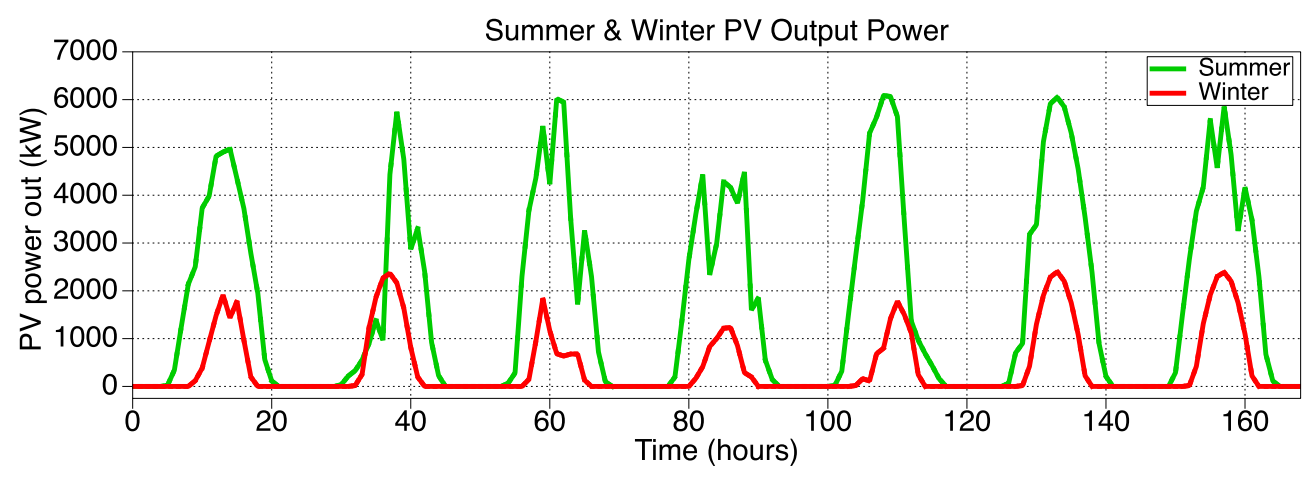

Figure 4.19: PV output power

grid delivered by the system over a year, figure 4.23 was plotted. This considers the load curve of house 1 operating under the average solar irradiance for a day of each month of the year (provided by NIWA [207]). The PV capacity was varied from $500 \mathrm{~W}$ to $10 \mathrm{~kW}$ for both the controlled and uncontrolled operating conditions, and the power consumed from the grid was observed. It can be seen that for lower PV capacities, the reduction is not as drastic as $5 \mathrm{~kW}$ and above where the reduction settles at approximately $44 \%$. 
Table 4.9: Comparison of power consumed by controlled and uncontrolled households in Wellington, NZ during Winter

\begin{tabular}{llll} 
House & Uncontrolled $\mathbf{k W h} /$ day & Controlled $\mathbf{k W h} /$ day & Reduction $\%$ \\
1 & 15.94 & 8.89 & 44.21 \\
2 & 19.78 & 13.89 & 29.76 \\
3 & 18.31 & 11.31 & 38.25 \\
4 & 15.75 & 8.89 & 43.54 \\
5 & 32.72 & 25.39 & 22.38 \\
6 & 24.12 & 13.58 & 43.68 \\
7 & 21.16 & 10.28 & 51.43 \\
8 & 21.17 & 11.69 & 44.81 \\
9 & 17.76 & 9.18 & 48.34 \\
10 & 11.14 & 5.45 & 51.06 \\
\hline Ave $\%$ & & & 41.75
\end{tabular}

Table 4.10: Comparison of power consumed by controlled and uncontrolled households in Wellington, NZ during Summer

\begin{tabular}{llll} 
House & Uncontrolled kWh/day & Controlled kWh/day & Reduction $\%$ \\
1 & 8.42 & 4.18 & 50.40 \\
2 & 11.54 & 8.53 & 26.04 \\
3 & 7.66 & 3.24 & 57.66 \\
4 & 5.02 & 1.91 & 61.86 \\
5 & 7.33 & 4.71 & 35.84 \\
6 & 11.13 & 7.07 & 36.48 \\
7 & 6.68 & 3.08 & 53.89 \\
8 & 8.46 & 4.46 & 47.33 \\
9 & 9.68 & 5.36 & 44.61 \\
10 & 7.08 & 3.27 & 53.88 \\
\hline Ave $\%$ & & & 46.80
\end{tabular}



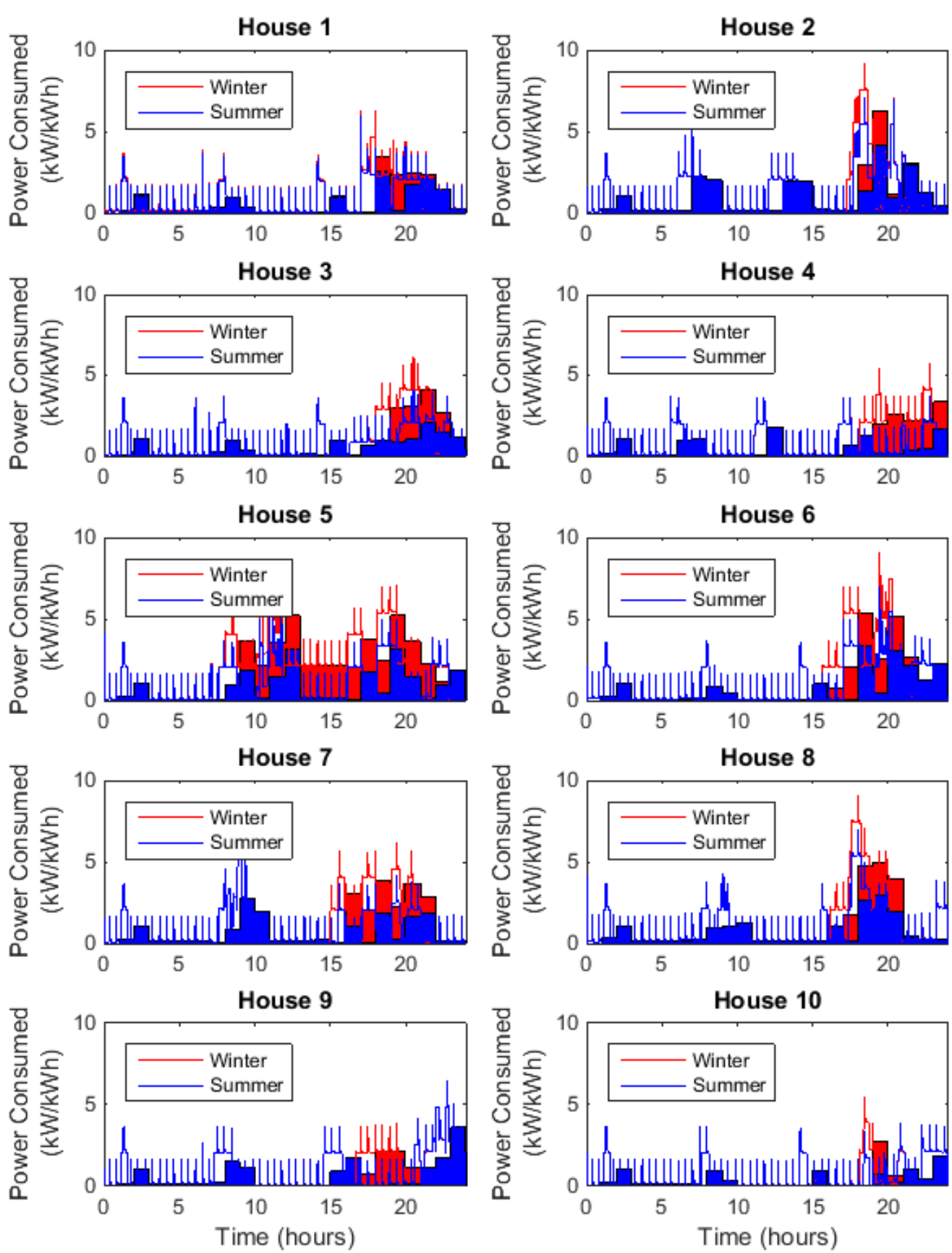

Figure 4.20: Uncontrolled household consumption curves displayed in instantaneous (lines) and kWh (blocks) 


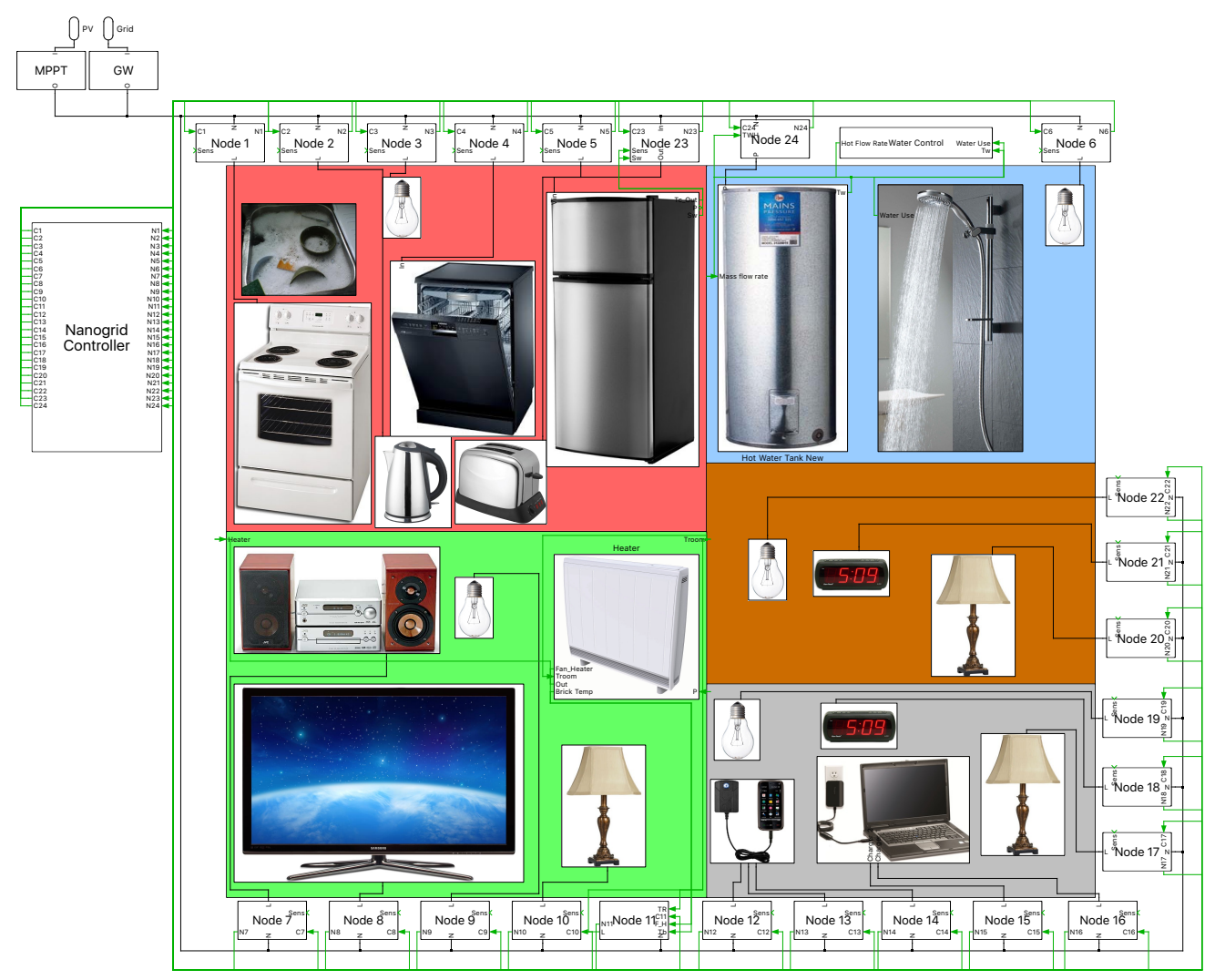

Figure 4.21: Schematic of PLECS simulation set up 

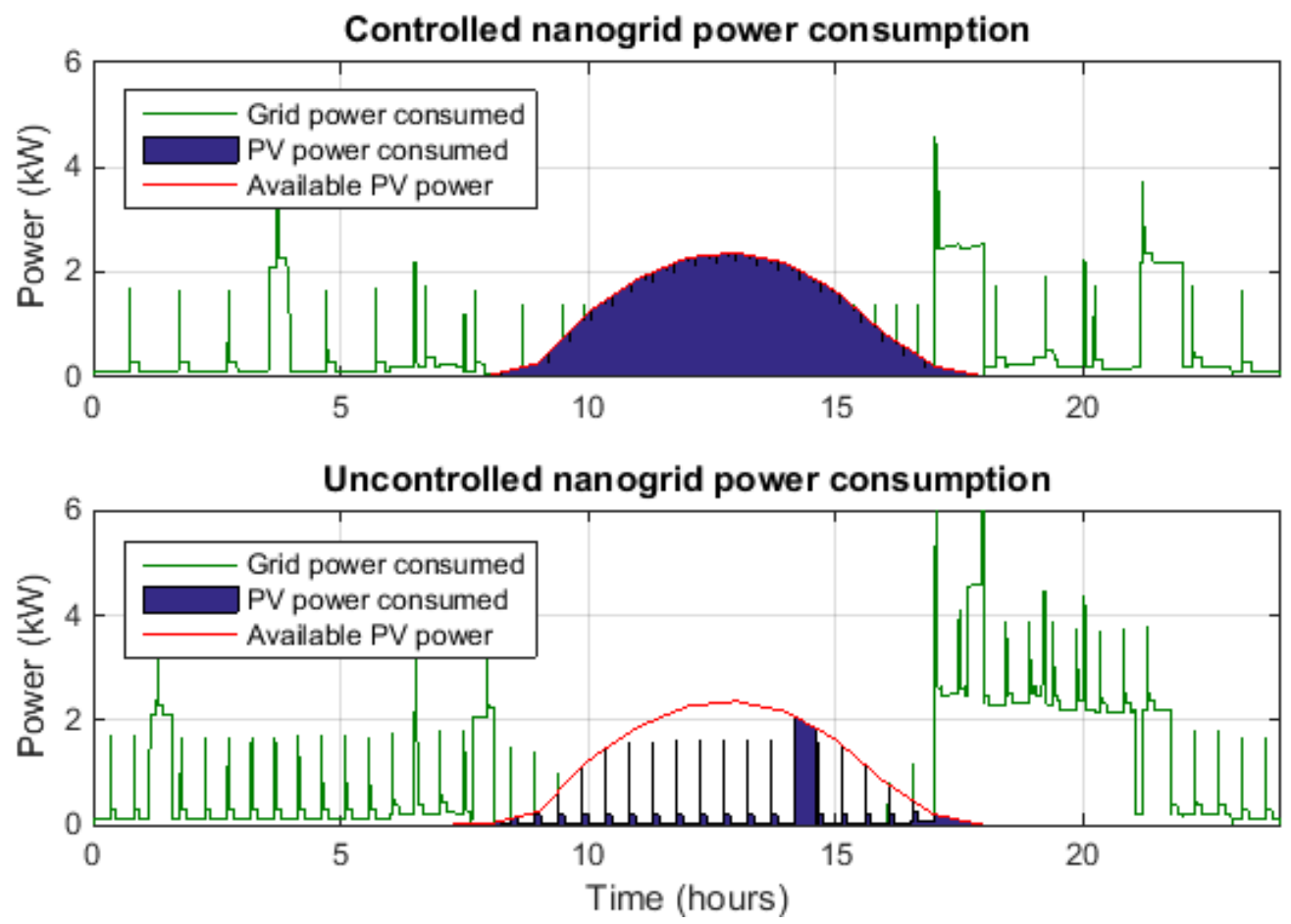

Figure 4.22: Comparison of controlled and uncontrolled households over a 24 hour period in Winter 


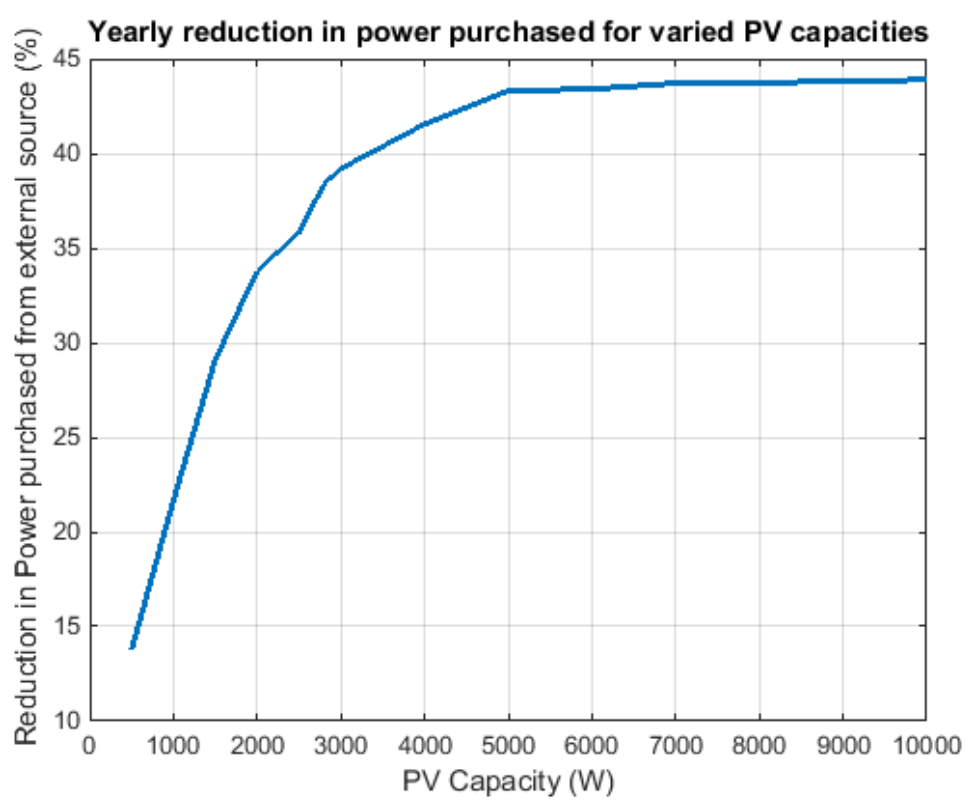

Figure 4.23: Yearly reduction in power consumed by house 1 under varied PV capacities 


\subsection{Chapter Summary}

This chapter presents a novel nanogrid control strategy designed to reduce grid power consumed by a single house or small building. This is achieved by utilising thermostatically controlled loads, storing energy while PV power is available to be used when little to no PV power is present.

The nanogrid controller implements MPPT to achieve a high power yield from the PV modules. It also uses the MPPT signal as a control input, enabling control decisions to be made based on available PV power. The MPPT consists of an interleaved boost converter and control algorithm for which both the hardware and software design process is outlined. The interleaved boost converter's output is then cascaded with a synchronous buck converter to give the DC bus a constant 380V.

The nanogrid control topology is hybrid central control, with a central controller coordinating interactions between control nodes which implement real time load control. There are two types of control nodes which both sense the current and voltage applied to their associated load, with the ability to switch off the load. The nodes that service the thermostatically controlled loads also have the ability to monitor temperature and modulate the voltage to the load.

This chapter discusses the thermal characteristics of the three thermostatically controlled loads the nanogrid controller uses to implement demand side management, namely the water heater, storage heater and refrigerator. A control strategy for the water heater and storage heater is presented that delegates a ratio of available PV power to each, taking into consideration the uncontrollable loads operating and the urgency of the thermostatically controlled loads. The urgency measure is derived from the thermal characteristics of the thermostatically controlled loads, calculating which is expected to have the higher power draw over the day and ensuring it receives adequate power. This control strategy alters the duty 
cycle of a buck converter embedded in the control node, altering the voltage to the load and hence the power draw.

A control strategy for a refrigerator is also presented with the goal of controlling the frequency of on/off cycles depending on the availability of PV power. The control node achieves this by setting upper/lower temperature thresholds and limits, cooling the refrigerator to its lower limit when PV power is available and allowing the temperature oscillate between the lower threshold and limit. When insufficient PV power is present, the temperature of the refrigerator increases to its upper limit and oscillates between its upper threshold and limit.

Ten daily household load curves are modelled to test the nanogrid controller's ability to reduce grid power consumed. The ten houses are simulated with a week of winter and summer solar irradiance data, each tested with and without the nanogrid controller. The consumption of grid power is compared and it is found that on average, in winter the controller has the ability to reduce grid power consumed by $41.75 \%$ while in summer $46.8 \%$, giving a yearly average reduction of $44.28 \%$. 


\section{Chapter 5}

\section{Interconnected Nanogrid Network}

Nanogrids are often described as a "bottom up" approach to power systems due to their modular nature. This has the advantage of lending itself to creating larger power systems by interconnecting multiple nanogrids, forming a microgrid structure as shown in Fig. 5.1. It focuses on a hierarchical approach to power distribution from nanogrid, to microgrid and the national grid. This hierarchy utilises the semi-autonomous control structures within the nanogrid to alleviate some of the stresses caused by intermittent power production/consumption (demand side management (DSM), supply side management (SSM)). These subsystems are then interfaced to form the microgrid, adding further intelligence and creating one bi-directional point of connection to the national grid. Power can then be shared between nanogrids via the network, decreasing the effects of an intermittent power supply while taking advantage of diverse power consumption patterns of the houses within the network. From the microgrid, power can be sold to, and/or bought from the national grid via the single point of common coupling. The grid can then be used as a supplementary power supply and incentives can be negotiated with the utility companies to help stabilise the grid. The microgrid can also be advantageous to the 
users during outages, with the ability to island from the national grid.

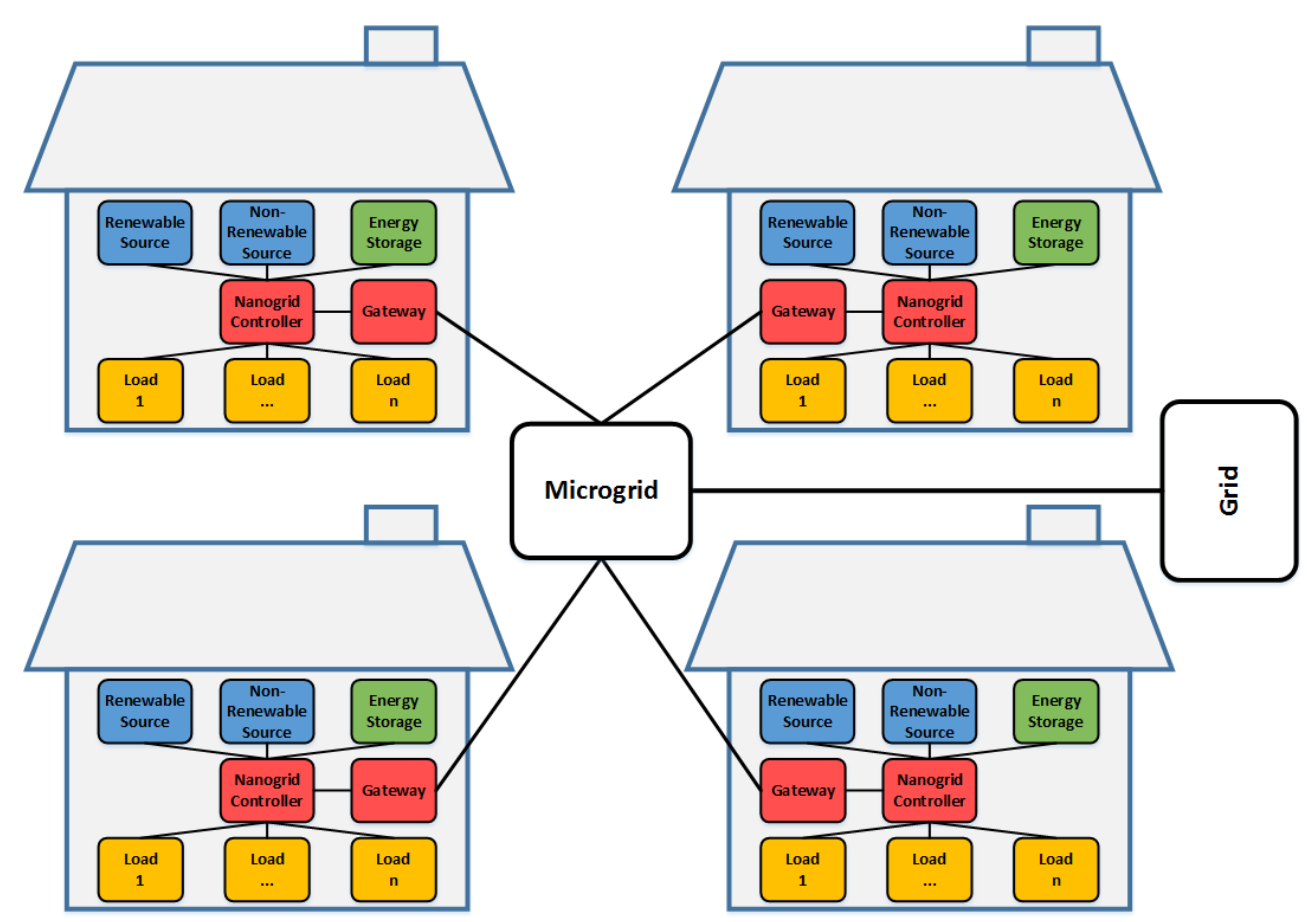

Figure 5.1: Microgrid made up of multiple nanogrids

This chapter explores the potential to reduce grid power consumed by a small cluster of interconnected houses. It introduces a novel control scheme that uses the thermostatically controlled loads within the cluster of houses to increase the correlation between the total consumption and production of the microgrid. The maximum power point tracking signal is used to observe available PV power with the goal of servicing the highest consuming loads within the cluster, ultimately reducing the amount of grid power consumed by the microgrid.

There are three scenarios of interest to establish if there is indeed an advantage to implementing a combined control scheme. The first is an uncontrolled cluster of houses, the second individual nanogrid controls within the cluster, and the last is the combined control system. The grid 
power consumed by each of these structures is then compared to discover which has the ability to reduce the cluster's consumption by the largest amount.

\subsection{Nanogrid Network Scenarios}

In this section the topology of each scenario of interest is presented and explained. An in-depth analysis of the equations that govern the power sharing within the combined control system (subsection 5.1.3) is also given.

\subsubsection{Uncontrolled Nanogrid Network}

The uncontrolled nanogrid network, shown in figure 5.2, is a cluster of houses with ability to share PV power produced before the point of common coupling connects them to the grid. As the name would suggest, there is no control involved within the cluster of houses, other than the maximum power point tracker which gives an equivalent power source when comparing the three scenarios (for fair testing). The constant voltage converter also performs its function, ensuring the cluster operates at 380V DC.

While no control is implemented, it was found that implementing a point of common coupling to the grid was advantageous to the reduction in grid power consumed. This is demonstrated in figures 5.3 and 5.4 where two houses are producing $2.5 \mathrm{~kW}$ of $\mathrm{PV}$ power, house one has a load which exceeds this by $300 \mathrm{~W}(2.8 \mathrm{~kW}$, between $t=2$ and $t=5)$ and house two consumes $2 k W$ (between $t=3$ and $t=6$ ). In figure 5.3 the two houses are connected to the grid individually, and it can be observed that house one draws the deficit $300 \mathrm{~W}$ of power from the grid. In figure 5.4 the houses have a point of common coupling before they are connected to the grid. This ensures the second house supplies the first with the required $300 \mathrm{~W}$ 
of power, alleviating the need to draw power from the grid. While this is an "ideal" scenario to demonstrate how this interaction occurs, it was found to take place within the simulated household curves considered for these tests (but difficult to display in an appropriate manner), typically supplying partial load consumption.

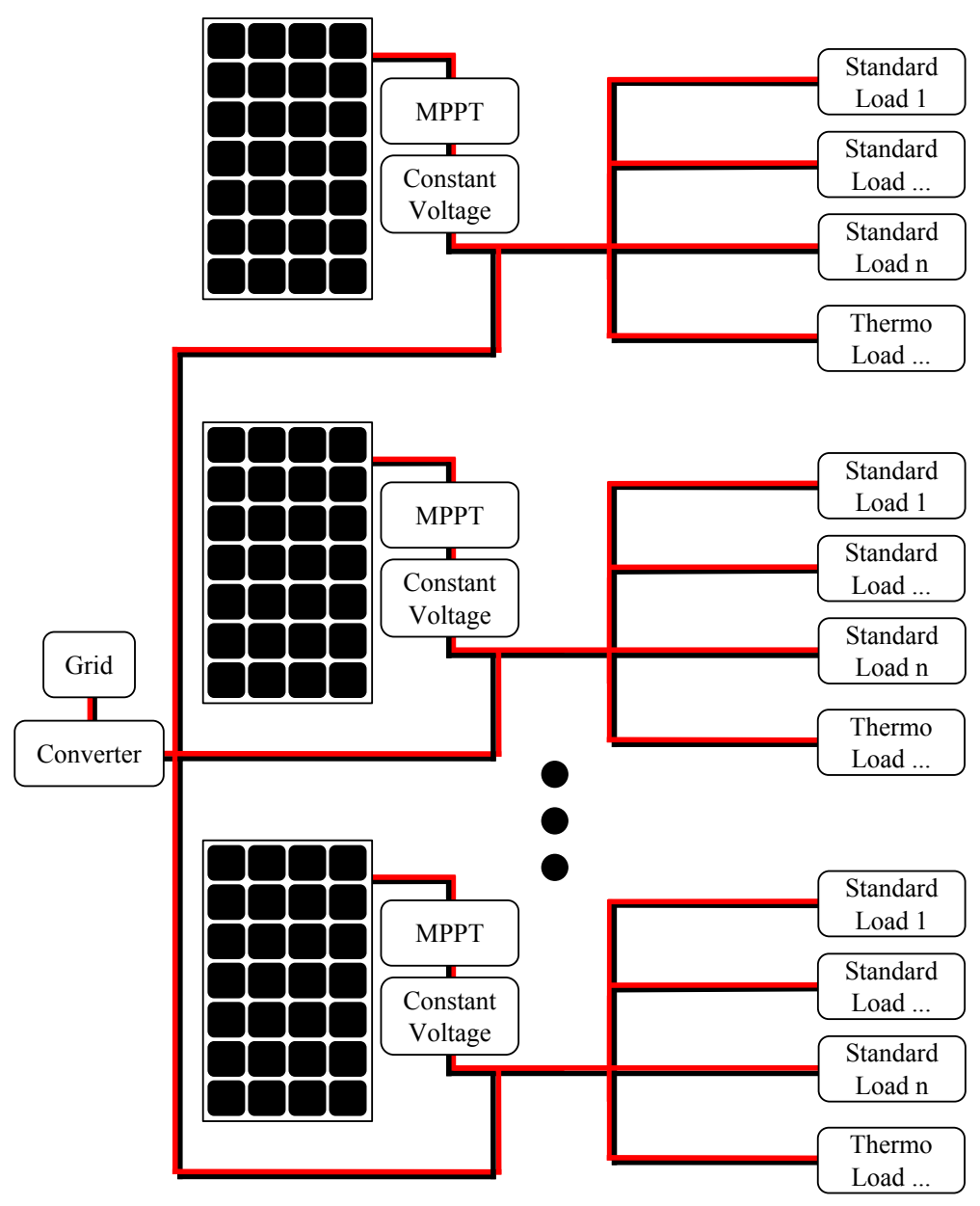

Figure 5.2: Microgrid made up of multiple nanogrids 

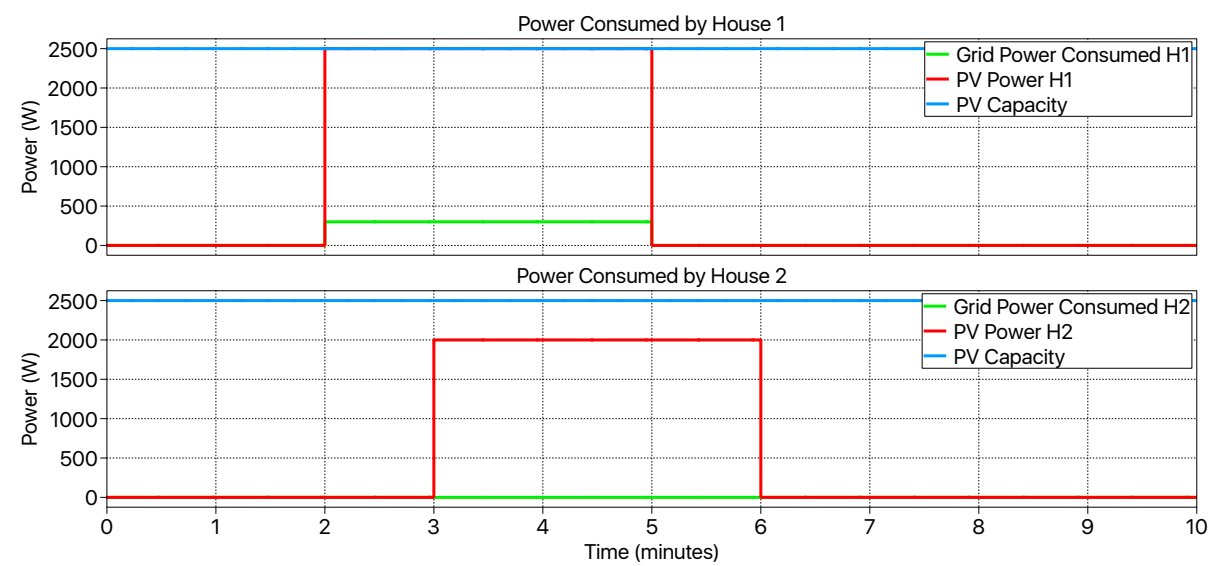

Figure 5.3: Two individual uncontrolled house scenario showing grid power consumed
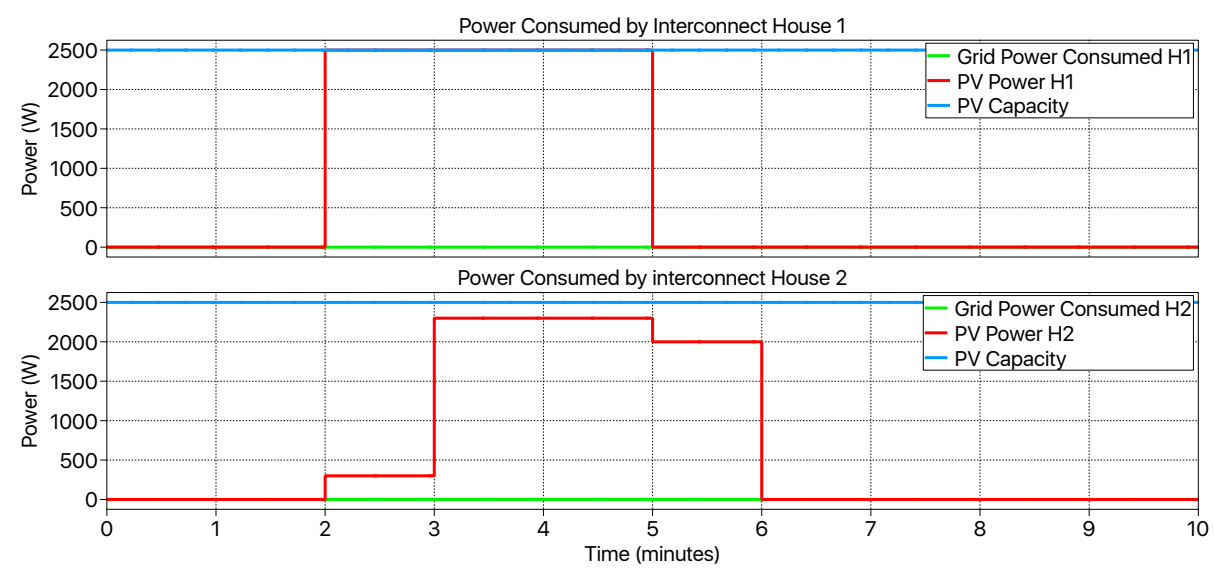

Figure 5.4: Two commonly coupled uncontrolled house scenario showing no grid power consumed 


\subsubsection{Individually Controlled Nanogrid Network}

The individually controlled nanogrid network houses retain the same level of control as discussed in chapter 4 . Each house is equipped with a nanogrid controller, ensuring the thermostatically controlled loads maximise the use of the available local PV power. The houses are connected, with the ability to share power within the cluster before a point of common coupling connects them to the grid. Each nanogrid controller knows only the production and consumption of the individual house, with no knowledge of the other houses within the cluster. Figure 5.5 shows the block diagram of the cluster in which it can be seen that each nanogrid has the ability to island from the cluster, as does the cluster from the grid (via the converter). 


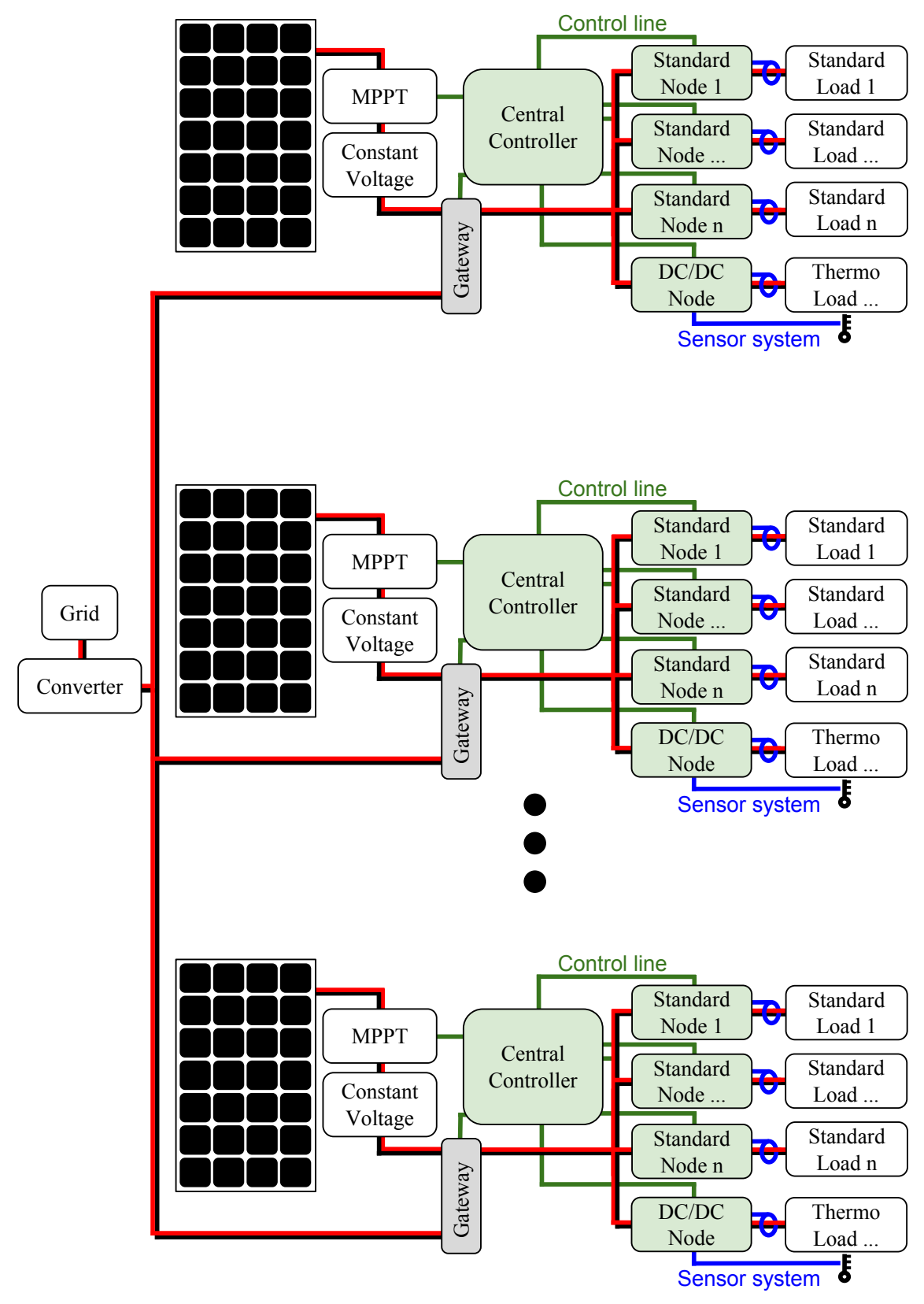

Figure 5.5: Block diagram of the interconnected nanogrid topology with individual control systems 


\subsubsection{Combined Control Nanogrid Network}

A progression of the individually controlled nanogrid network, the combined control nanogrid network, expands the control strategy from multiple individual systems, to one larger network. The motivation behind combining the nanogrid control schemes (rather than individual control) is to improve the network's ability to reduce power consumed from the grid.

The network can be thought of as a step up in the hierarchical structure of the nanogrid. Where the central controller was the top tier (over the node controllers), now the interconnected nanogrid controller adopts this role. As the block diagram displayed in figure 5.6 indicates, the nanogrid's central controller still coordinates the node controllers, but now the interconnected nanogrid controller coordinates interactions between each of the nanogrids in the cluster.

This means the control strategy is not only aware of the consumption and production of the individual houses, but of all the houses combined within the cluster. With this also comes the following additional advantages:

- Having a central controller within a community allows control law to be implemented/updated from a central location from which it is passed to the nanogrid controllers. If accessible from a public location, it minimises the intrusions these updates may otherwise cause.

- This topology can also make data available from a central location which can be used to fine tune the system and identify faults.

- While a system with a central controller can be accused of being prone to mass failure due to communication breakdown within the single centralised location, the nanogrids themselves can still operate independently. This means that in the worst case scenario, the cluster's behaviour is equivalent to that of the individually controlled nanogrid network it is being compared to (in this thesis). 


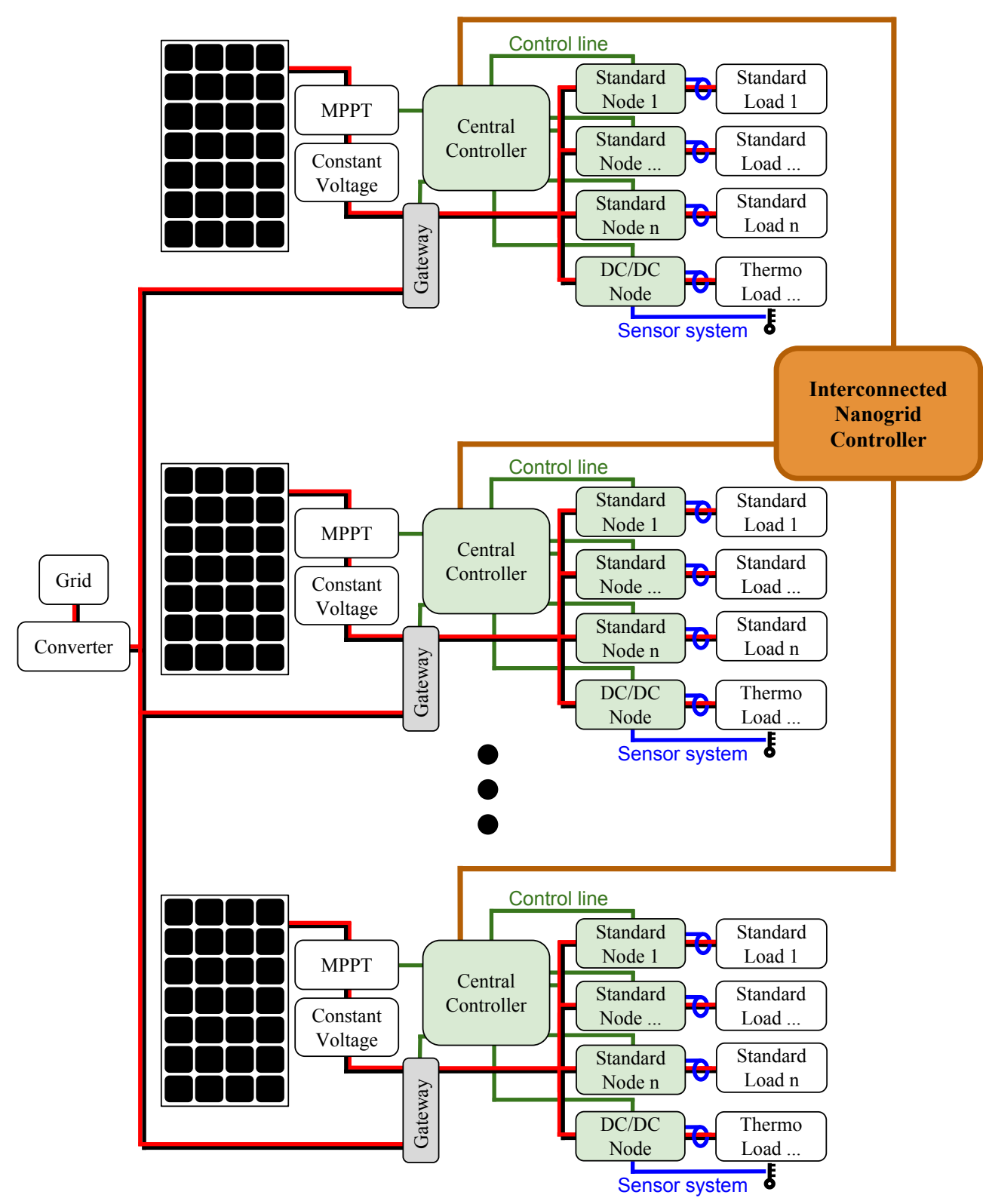

Figure 5.6: Block diagram of the interconnected nanogrid topology with combined control 
In order to create a nanogrid network control strategy, the equations given in chapter 4 need to be generalised to accommodate any number of interconnected houses, each with thermostatically controlled loads. To implement combined control law, the duty cycle calculated for each thermostatically controlled load must consider all other loads and supplies operating in the network.

Equation (5.1) shows the maximum power point tracking supply signal for the nanogrid network. It is a summation of all the available PV power within the nanogrid network. Just as the nanogrid's loadline can be diverse, so can the PV capacity of each house.

$$
P_{M_{P P T_{\text {micro }}}}=P_{\text {In } n_{\text {micro }}}=\sum_{i=1}^{j} V_{I n_{i}} I_{I n_{i}}
$$

Where " $\mathrm{j}$ " is the number of interconnected nanogrids, $P_{I n_{\text {micro }}}$ is the PV power produced by each house while $V_{I n_{i}}$ and $I_{I n_{i}}$ refer to the voltage and current produced by each house respectively.

The power delivered to each of the nanogrid network's thermostatically controlled loads by the control law must also be calculated. Equations (5.2) through (5.5) show how the duty cycle $(D)$ is calculated, as a function of current $\left(I_{I n}, I_{o}\right)$, for the buck converter present in the thermostatically controlled load's node. It considers the efficiency of the buck converter $(\mathscr{E})$, output/input power ( $P_{o}$ and $P_{\text {In }}$ respectively), and output/input voltage ( $V_{o}$ and $V_{\text {In }}$ respectively).

$$
\begin{gathered}
V_{o}=D V_{I n} \\
P_{o}=\mathscr{E} P_{I n} \\
D V_{I n} I_{o}=\mathscr{E} V_{I n} I_{I n}
\end{gathered}
$$




$$
D=\frac{\mathscr{E} V_{I n} I_{I n}}{V_{I n} I_{o}}=\frac{\mathscr{E} I_{I n}}{I_{o}}
$$

Equations (5.6) and (5.7) consider the new variable $P_{M P P T_{\text {micro }}}$ and also introduce $V_{I n_{\text {micro }}}$ a summation of the voltages $\left(V_{I n_{i}}\right)$ produced by the combined PV installations. This is used to derive the current produced by the interconnected nanogrid network $\left(I_{I n_{\text {micro }}}\right)$. The duty cycle determining the output voltage of a thermostatically controlled load's control node can then become a function of the power generated by the nanogrid network (5.8).

$$
\begin{gathered}
V_{\text {In } n_{\text {micro }}}=\frac{\sum_{i=1}^{j} V_{I n_{i}}}{j} \\
I_{\text {In }_{\text {micro }}}=\frac{P_{M P P T_{\text {micro }}}}{V_{I_{\text {micro }}}} \\
D=\frac{\mathscr{E} P_{M P P T_{\text {micro }}}}{I_{o} V_{\text {In }}}
\end{gathered}
$$

Although equation (5.8) gives the duty cycle for the control node, it does not consider other loads operating within the nanogrid network. The duty cycle will need to be adjusted to consider the uncontrolled and thermostatically controlled loads operating in the network.

To do so, equation (5.9) is used to calculate the consumption of all uncontrolled loads consuming power within the nanogrid network. These are loads that the consumer controls and expects an output when they are switched on. Such loads are not controlled within the nanogrid to ensure the comfort of the user.

$$
L_{\text {total }_{\text {micro }}}=\sum_{m=1}^{n} L_{\text {total }_{m}}
$$

Where $\mathrm{n}$ is the number of loads operating, that are not thermostatically controlled. 
Next the measure of urgency of each thermostatically controlled load needs to be calculated. Equation (5.10) is used to calculate an estimated "on" period for each thermostatically controlled load, based on its current temperature, usage and thermal characteristics. The premise of this calculation is that the load that will consume the largest amount of power for a particular time period (day) is the most urgent and needs to be serviced by PV power. The variable $x$ relates to a load being powered while $x_{1}$ is used if a load is not drawing power. For the water heater, equations (5.11) and (5.12) are used and the space heater, equations (5.13) and (5.14) (variables for water and storage heater equations explained in tables 5.1 and 5.2 respectively).

$$
u_{T}=P \frac{\log (x)}{\log (x)+\log \left(x_{1}\right)} / d a y
$$

for water heater:

$$
x=\frac{k}{T_{W}-\frac{\dot{m} c T_{i}+h A T_{a}+q}{\dot{m} c+h A}}
$$

where $k$ is the constant of integration.

$$
x_{1}=\frac{k_{1}}{T_{W}-\frac{\dot{m} c T_{i}+h A T_{a}}{\dot{m} c+h A}}
$$

where $k_{1}$ is the constant of integration.

for space heater:

$$
x=\frac{w}{T_{b}-p}
$$

where $p=\frac{Q_{\text {In }}+(a+b+c) T_{R}}{a+b+c}, a=\frac{k_{f b} A_{f b}}{l_{f b} M_{b} c_{b}}, b=\frac{k_{s} A_{s}}{l_{s} M_{b} c_{b}}, c=\frac{k_{v n} A_{v n}}{M_{b} c_{b}}$ and $w$ is the constant of integration

$$
x_{1}=\frac{w_{1}}{T_{b}-T_{R}}
$$

where $w_{1}$ is the constant of integration. 
Table 5.1: Explanation of variables in Eqn. (5.11) and (5.12)

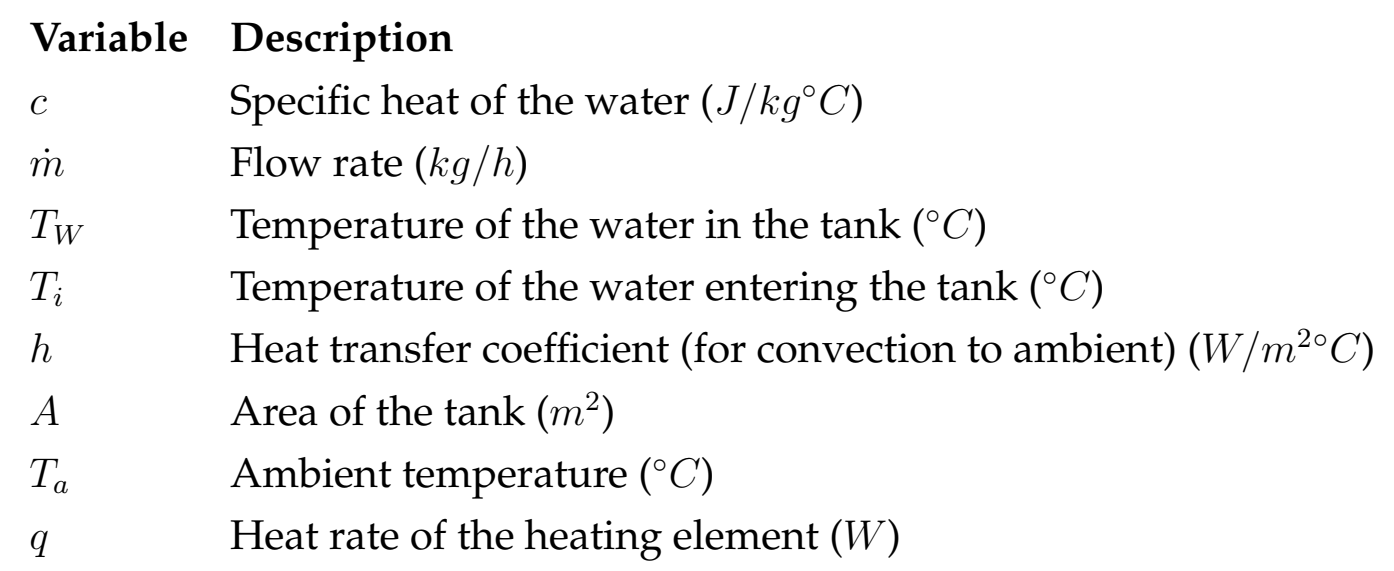

Table 5.2: Explanation of variables in Eqn. (5.13) and (5.14)

\section{Variable Description}

$M_{b} \quad$ Mass of the bricks $(\mathrm{kg})$

$c_{b} \quad$ Specific heat of the bricks $\left(J / \mathrm{kg}^{\circ} \mathrm{C}\right)$

$T_{b} \quad$ Temperature of the bricks $\left({ }^{\circ} \mathrm{C}\right)$

$T_{R} \quad$ Temperature of the room $\left({ }^{\circ} \mathrm{C}\right)$

$Q_{\text {In }} \quad$ Input power $(W)$

$k_{f b} \quad$ Thermal conductivity of front and back $\left(W / m^{\circ} \mathrm{C}\right)$

$A_{f b} \quad$ Area of the front and back $\left(\mathrm{m}^{2}\right)$

$l_{f b} \quad$ Thickness of the front and back $(m)$

$k_{s} \quad$ Thermal conductivity of the sides/top/bottom $\left(W / m^{\circ} \mathrm{C}\right)$

$A_{s} \quad$ Area of the sides/top/bottom $\left(\mathrm{m}^{2}\right)$

$l_{s} \quad$ Thickness of the sides/top/bottom $(m)$

$k_{v n} \quad$ Natural convection heat transfer coefficient $\left(\mathrm{W} / \mathrm{m}^{2 \circ} \mathrm{C}\right)$

$A_{v n} \quad$ Heat transfer area of the surface $\left(m^{2}\right)$

The measure of urgency is then converted to a ratio as shown in equation (5.15). This creates a hierarchy of the most to least urgent loads and gives a scaling factor for the duty cycle which is calculated in equation 
(5.16). This duty cycle is the signal given to a control node (controlling load $y$ ) by the central controller, ensuring the load receives the ratio of available PV power that is allocated.

This means, within the nanogrid network, the loads that are likely to draw the largest quantity of power over a given period of time (day), will be serviced with the majority of the available PV power. It stands to reason that as a load receives power, heating its thermal mass, its measure of urgency descends until another load becomes more urgent and is turned on.

$$
m_{\text {microy }}=\sum_{y=1}^{z} \frac{u_{T_{y}}}{\sum_{w=1}^{z} u_{T_{w}}}
$$

Where $z$ is the number of thermostatically controlled loads within the cluster of houses

$$
D_{\text {ratioy }}=m_{\text {microy }} \frac{\mathscr{E}\left(P_{M P P T_{\text {micro }}}-L_{\text {total }} l_{\text {micro }}\right)}{\left.I_{o_{y}} V_{\text {In }}\right)}
$$

Figure 5.7 shows the power consumption of a three house network and displays the ratio of power consumed by each water and storage heater within the cluster. It also shows the total consumption which closely mirrors the available PV power.

The safety measures discussed in chapter 4 remain active in the network and override control law. These are as follows, with in-depth explanations given in chapter 4 :

- Water Lower Temperature Threshold: The water heater will be switched on, regardless of $\mathrm{PV}$ power availability, if a lower temperature threshold is reached.

- Room Temperature: Rooms will be kept at a specific temperature regardless of PV power availability. 
- Upper Temperature Limits Both the water and storage heaters have upper temperature limits which will not be exceeded.

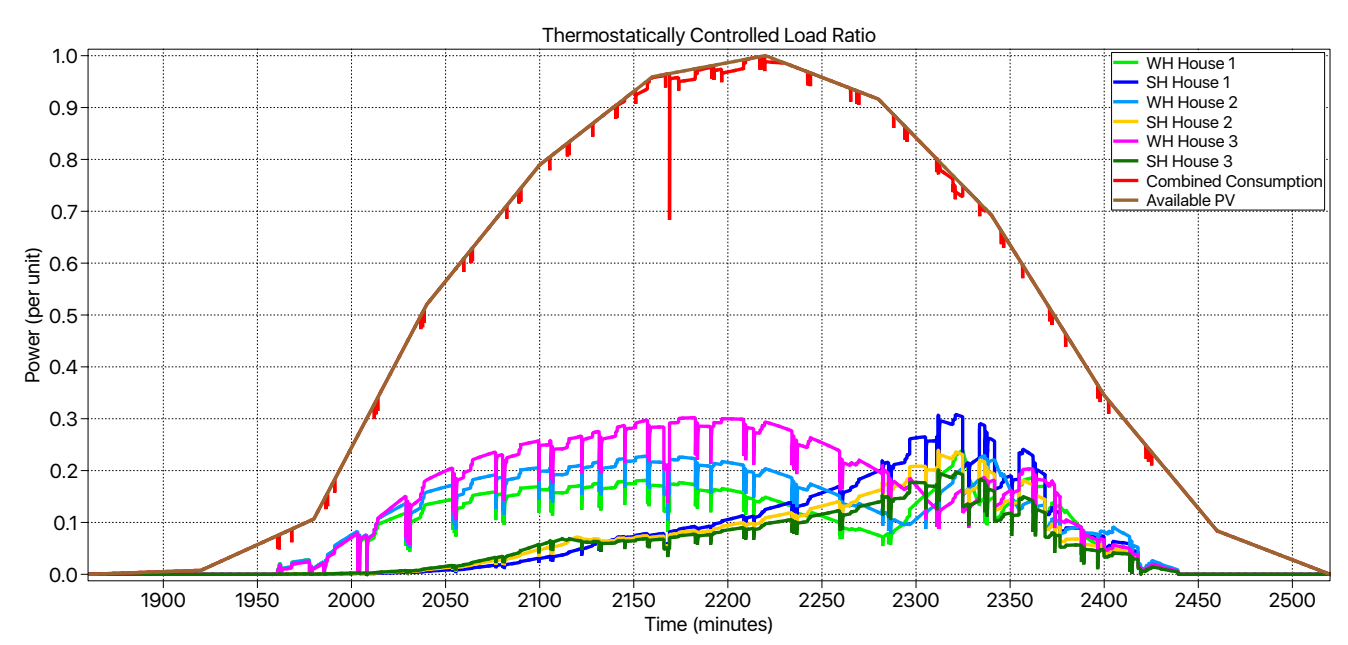

Figure 5.7: Power consumption of 3 house network showing load ratio

\subsection{Simulation, Results and Discussion}

In order to evaluate the success of a combined interconnected nanogrid control strategy, a variety of simulated scenarios needed to be implemented. This included the combined control, individually controlled nanogrids with a common coupling to establish whether or not the combined control could further reduce grid power consumed, and the uncontrolled nanogrids with a common coupling as a baseline grid consumption for the cluster. The household consumption patterns of houses one through seven, shown in chapter 4 , figure 4.20 , were used for the simulated scenarios. These were considered in relation to the PV production curves also shown in chapter 4, displayed in figure 4.19 (this plot shows the output of a $6 \mathrm{~kW}$ PV installation). Appendix A presents the on/off times for all loads used within 
the 10 houses, along with refrigerator parameters, shower times/lengths and hot water cylinder characteristics.

In order to show a correlation between the number of houses connected and a reduction in grid power consumed, each of the three scenarios (combine control, individual control and uncontrolled) were simulated with two houses connected, increasing the number of interconnected houses by one each iteration of the simulation, until seven houses were reached (at which point the correlation was adequately established and the simulations became too large to continue).

The results of these simulations are shown in figures 5.8, 5.9, 5.10, and in tables 5.3 and 5.4. Figures 5.8 and 5.9 show the collective grid consumption of each scenario as the number of houses within the cluster increases. Fig 5.8 displays the summer scenario where it can be seen that the uncontrolled consumption is the largest, and as the number of houses in the cluster increases, so to does the deviation between the combined and individually controlled nanogrid networks (with the combined control consuming less grid power than the individual).

A similar trend can be seen in 5.9 (winter consumption) between the uncontrolled and two controlled nanogrid networks. However, the combined and individually control nanogrid networks are much closer matched. This is due to the reduction in solar irradiance during the winter (compared to summer) and an increase in consumption due to regular use of the storage heater. In this situation, where the consumption heavily outweighs the production, the system can do little to further improve the cluster's ability to intelligently distribute the available PV power. Both the individual and combined control schemes use all available PV.

Figure 5.10 shows a direct comparison between the individual and combined control scenarios to quantify the magnitude to which the combined control has reduced the grid power consumption of the cluster (when compared to the individual control). The plot displays, as a percentage, this reduction for the summer, winter, and yearly grid consumption. It 
can be seen that the largest yearly reduction is approximately $7 \%$, which is achieved with 5 houses connected.

Tables 5.3 and 5.4 display the consumption of each scenario modelled in numerical format (for clarity), giving a $k W h /$ day context.

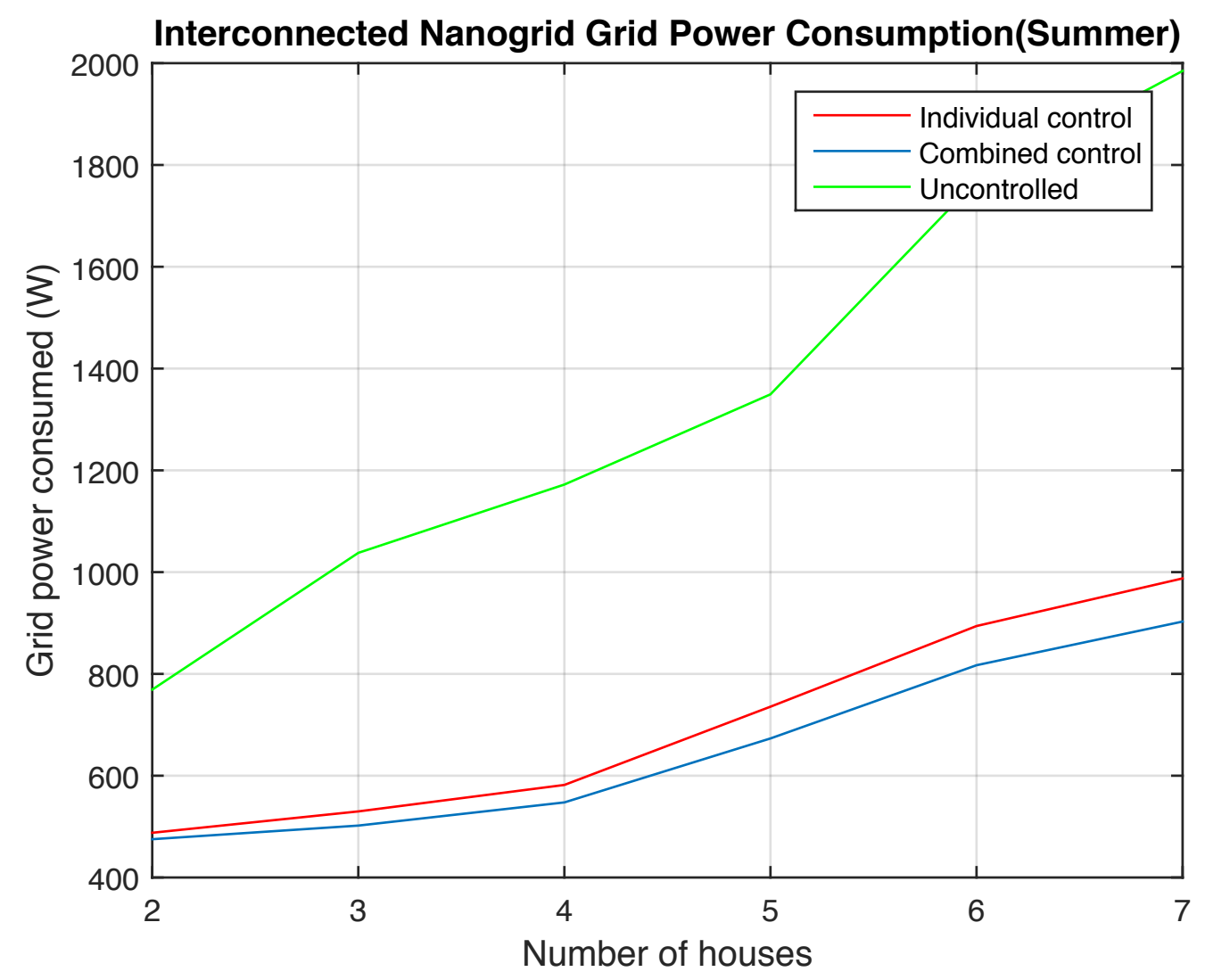

Figure 5.8: Summer consumption of 2 to 7 house clusters (Uncontrolled, individually controlled and combined control)

While comparisons have been made between three interconnected nanogrid solutions, it is also of interest to compare the network with the consumption of unconnected households. In figure 5.11, the accumulative consumption ( 2 to 7 houses) of the individually grid tied uncontrolled households are compared to the interconnected nanogrid network's combined 


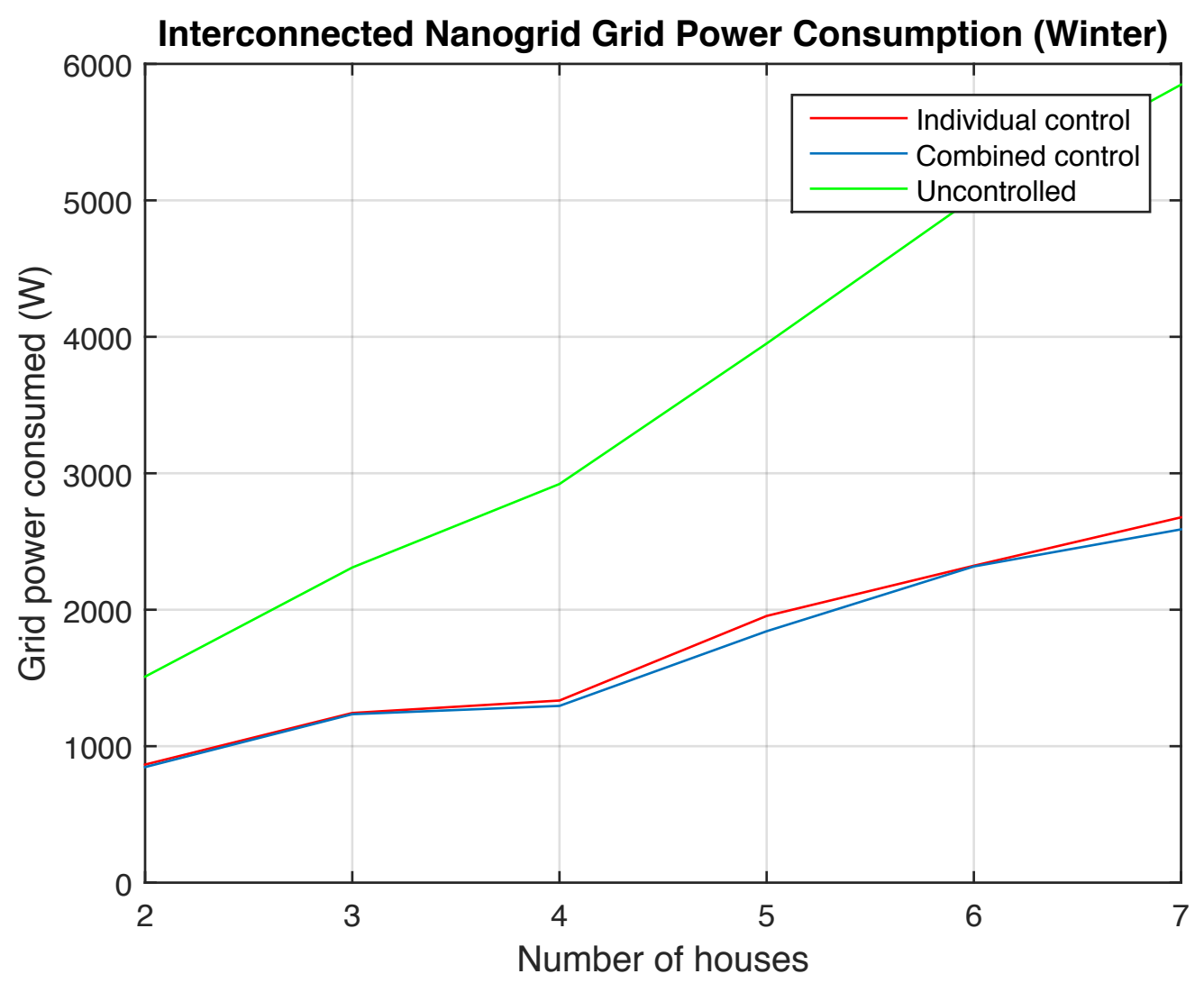

Figure 5.9: Winter consumption of 2 to 7 house clusters (Uncontrolled, individually controlled and combined control)

control solution. It shows that increasing the number of households in the network reduces the grid power consumption of the cluster, with two households yielding a $45 \%$ reduction and seven households, the largest reduction, delivering $61 \%$.

\subsubsection{The Effect of Varied PV Capacities}

As discussed above, the PV capacity in the winter is often not sufficient to meet the loads operating in various households, reducing the effectiveness of the control strategy. To demonstrate this point, the five household 


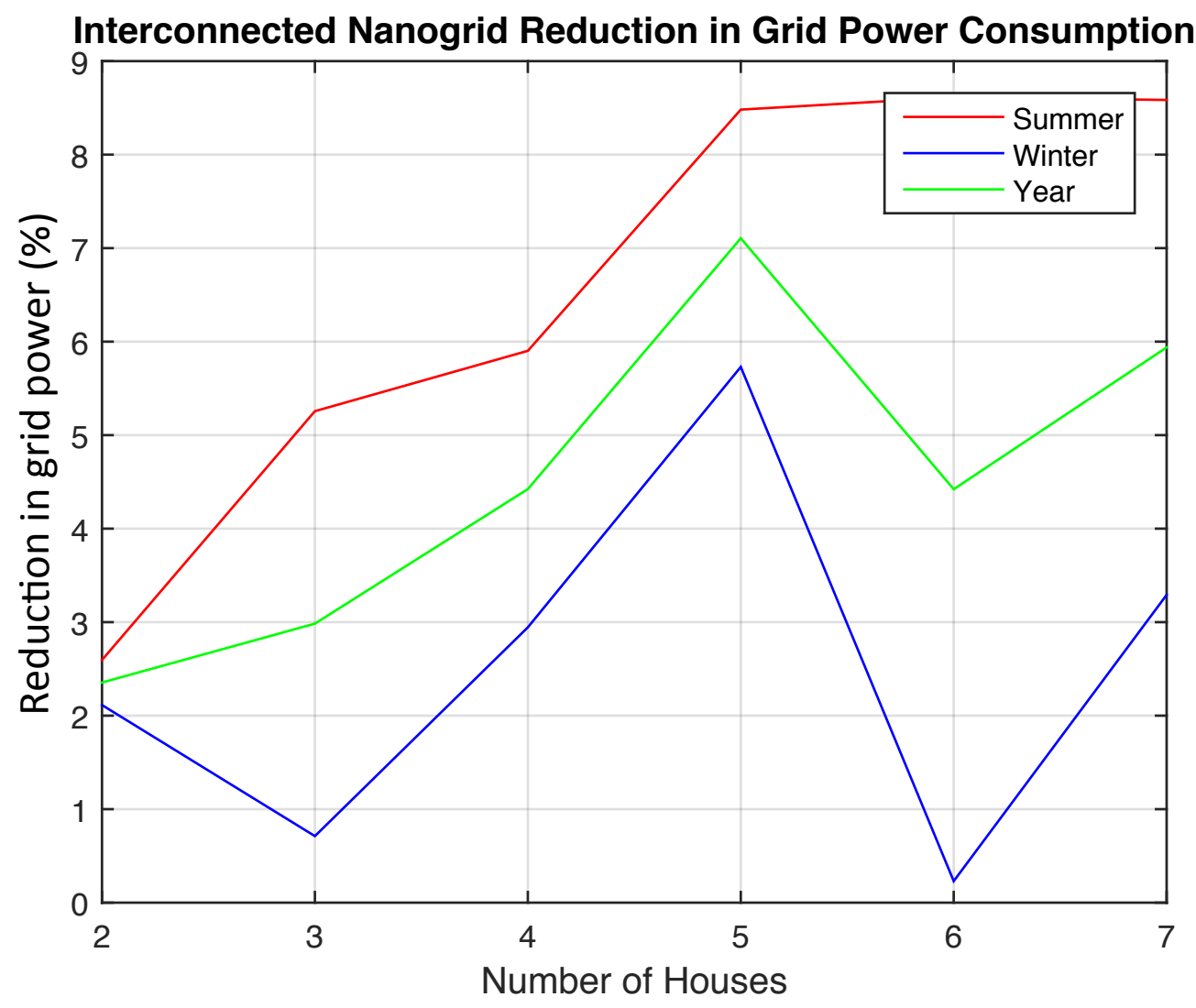

Figure 5.10: Reduction in grid power consumed by 2 to 7 house clusters (Uncontrolled, individually controlled and combined control)

uncontrolled and combined control scenarios were simulated with a variety of PV capacities $(1 k W, 2 k W, 3 k W, 6 k W, 8 k W$ and $10 k W)$. Figure 5.12 shows the reduction in grid power consumed when the combined control interconnected nanogrid network is compared to the uncontrolled interconnected nanogrid network scenario. It can be observed that the reduction in grid power consumed increases with the increase in PV capacity. With the largest PV capacity installed $(10 \mathrm{~kW})$, the reduction is $58 \%$. As mentioned above, the three standard test scenario simulated in this section had a PV installation of $6 \mathrm{~kW}$. Comparing the $6 \mathrm{~kW}$ PV installation with the 
Table 5.3: Comparison of power purchased by a cluster of households, with increasing size, in Wellington, NZ during Winter

\begin{tabular}{|l|l|l|l|}
$\begin{array}{l}\text { Number of } \\
\text { houses in cluster }\end{array}$ & $\begin{array}{l}\text { Uncontrolled } \\
\text { kWh/day }\end{array}$ & $\begin{array}{l}\text { Individual Control } \\
\text { kWh/day }\end{array}$ & $\begin{array}{l}\text { Combined Control } \\
\text { kWh/day } \\
2\end{array}$ \\
36.23 & 20.77 & 20.33 \\
3 & 55.43 & 29.84 & 29.63 \\
4 & 70.11 & 32.03 & 31.09 \\
5 & 94.82 & 46.91 & 44.22 \\
6 & 120.45 & 55.74 & 55.61 \\
7 & 140.35 & 64.25 & 62.14
\end{tabular}

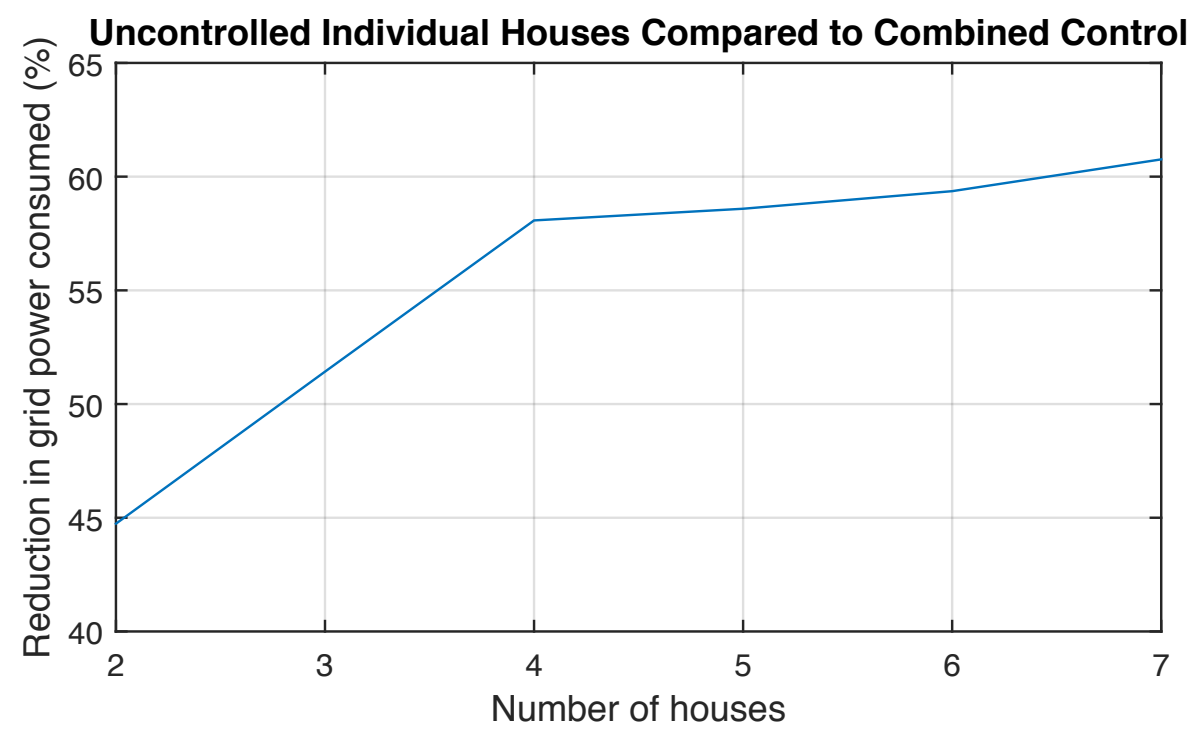

Figure 5.11: Reduction in grid power consumed by uncontrolled, individual houses when compared to combined control connected houses

$10 \mathrm{~kW}$ shown in figure 5.12, a further $6 \%$ reduction can be achieved. 
Table 5.4: Comparison of power purchased by a cluster of households, with increasing size, in Wellington, NZ during Summer

\begin{tabular}{|l|l|l|l|}
$\begin{array}{l}\text { Number of } \\
\text { houses in cluster }\end{array}$ & $\begin{array}{l}\text { Uncontrolled } \\
\text { kWh/day }\end{array}$ & $\begin{array}{l}\text { Individual Control } \\
\text { kWh/day }\end{array}$ & $\begin{array}{l}\text { Combined Control } \\
\text { kWh/day }\end{array}$ \\
2 & 18.46 & 11.71 & 11.41 \\
3 & 24.91 & 12.72 & 12.05 \\
4 & 28.13 & 13.96 & 13.14 \\
5 & 32.38 & 17.65 & 16.15 \\
6 & 42.46 & 21.46 & 19.61 \\
7 & 47.63 & 23.7 & 21.67
\end{tabular}




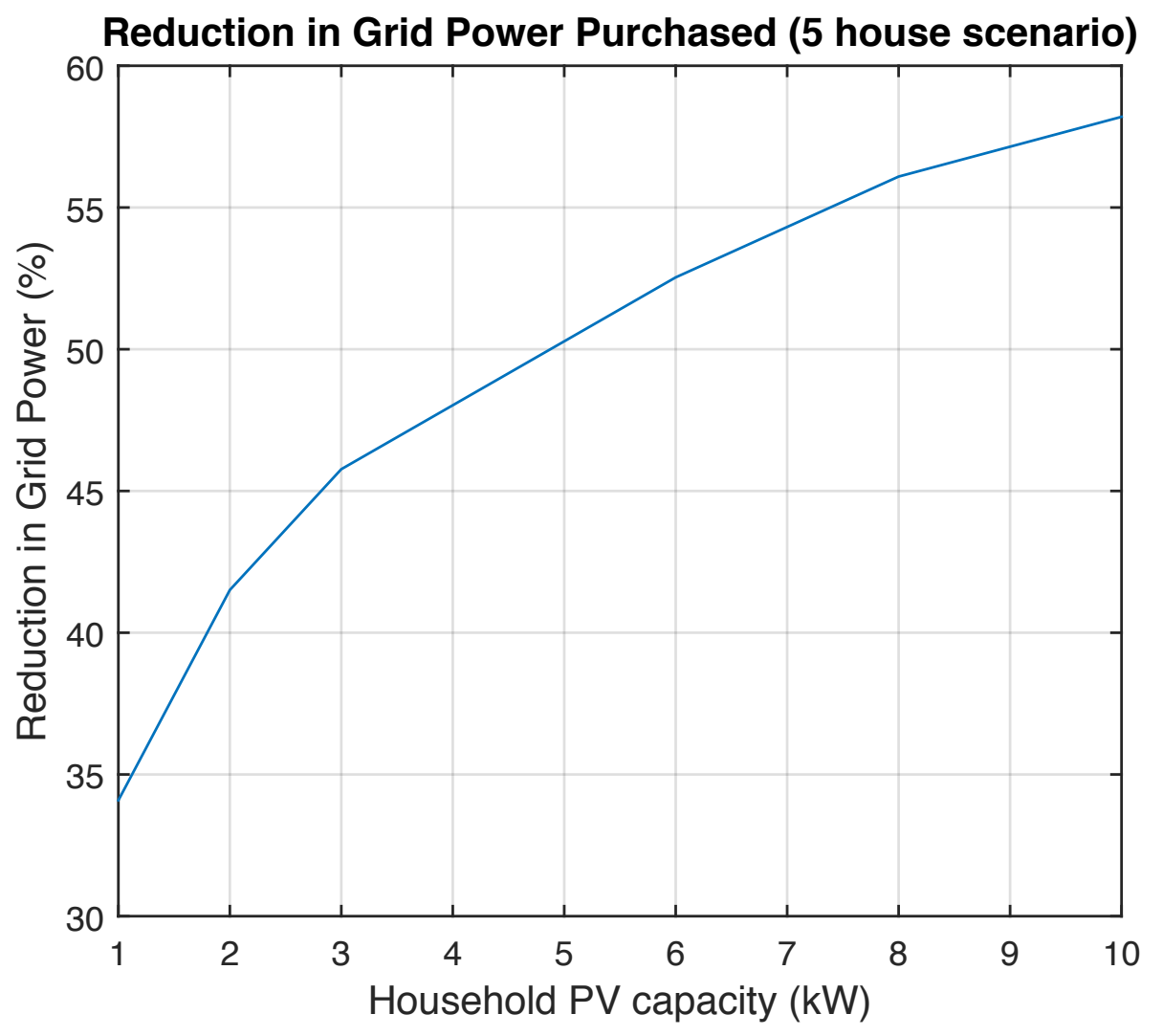

Figure 5.12: Reduction in grid power consumed by 5 house clusters with varied PV capacities (Uncontrolled and combined control) 


\subsection{Chapter Summary}

In this chapter, a novel control system is presented with the objective of creating a hierarchical power system that ensures the efficient use of locally produced PV power within a small cluster of houses. The thermostatically controlled loads within the interconnected nanogrid network are not only shifted, but modulated to increase the correlation between the power consumption and local PV production.

The maximum power point tracking signal is used to observe the availability of local PV power. From this variable, an algorithm is produced to control the duty cycle of a buck converter, which alters the voltage supplied to the thermostatically controlled loads. This algorithm not only considers local PV production, but the consumption of the loads that are not TCL.

The algorithm then considers the expected consumption of each of the TCLs within the cluster of houses, creating a ratio variable which delegates the appropriate power to each of the TCLs. This ensures the loads that will consume the most power over the day are serviced with the largest ratio of power, while the less urgent loads only consume a small amount of power. As the urgent loads receive the majority of the power, they drop in urgency, eventually becoming the less urgent loads within the cluster.

The combined control is simulated under a number of conditions (a week summer and a week winter), with clusters ranging from 2 houses to 7 . The total grid power consumed by the combined control system is then compared to the grid power consumed by a cluster of uncontrolled houses, and a cluster of individually controlled houses. The results show that the combined control scenario can improve on the uncontrolled clusters by as much as $55 \%$, while the improvement when compared to the individually control nanogrid cluster is as much as $7 \%$.

If the combined nanogrid network controller is compared to uncontrolled houses, not in a cluster, the reduction in grid power consumed is 
as much as $61 \%$. 


\section{Chapter 6}

\section{Conclusions and Future Work}

The centralised power grid is an amazing feat of interdisciplinary engineering, capable of supplying power to millions of households globally. But with a system of this magnitude there are often new challenges, unforeseen consequences and room for improvement. In the case of centralised power generation, the challenges involve environmental impact (carbon emissions), efficiency (line losses) and robustness (susceptibility to outages due to long distance transmission).

Distributed generation, in the form of small-scale renewable energy, has the potential to negate these issues, offering a clean energy source and localised generation. However, small-scale renewable energy is not without fault, presenting the challenge of an intermittent power source. Intermittency, in the case of $\mathrm{PV}$, refers to a mismatch of high power production times with a household's high consumption time. This essentially leaves a large amount of unused PV power (which can be sold to the grid but buyback prices are often low) and a household which still needs to purchase the majority of its power from the national grid. This is a situation which needs to be overcome in order to see the acceptance of small-scale $\mathrm{PV}$ systems as a viable option for individuals and users within small communities.

The research presented in this thesis addresses intermittency through 
the use of a nanogrid (a controlled power distribution system for a single household) which utilises thermostatically controlled loads to increase the correlation between a household's power consumption and production. It then investigates the impact connecting multiple nanogrids, forming an interconnected nanogrid network, can have to further reduce the effects of intermittency for a small community.

Research into the use of nanogrids, thermostatically controlled loads and interconnected nanogrid networks is represented in literature, creating a strong knowledge base of successful implementation and potential for improvement. While nanogrid control and hardware are readily discussed, the definition of the nanogrid itself is vague and varies. The nanogrid control literature focuses heavily on supply side management for stability, efficiency and grid regulation. However, it neglects to investigate the use of demand side management to motivate the uptake of PV systems and using the PV's maximum power point tracker to implement DSM.

The research presented in the literature surrounding thermostatically controlled loads is typically focused on pursuing goals set out by grid utility companies such as grid stabilisation and peak power reduction. Some research in the field of household control exists, however, the research fails to offer independent control strategies, utilising multiple thermostatically controlled loads.

Interconnected nanogrid network research is a relatively new topic, where the majority of the literature presented is conceptual. While some work has delved into supply side management, demand side management control strategies, specifically strategies that consider all nanogrids within the larger entity forming a cohesive control structure, is not yet presented within the literature.

It is clear to see, from the gaps in the literature, that research into nanogrids and interconnected nanogrids can be progressed in the area of demand side management through the use of thermostatically controlled 
loads, to incentivise PV installations at a household level.

To achieve this ambitious task, three objectives were set; The first, to define the nanogrid structure so it could be discussed as a stand alone power system. The second, to create a nanogrid control strategy that will increase the correlation between power consumption and production, utilising thermostatically controlled loads. And lastly, to expand the control strategy to facilitate an interconnected nanogrid network which will allow the sharing of power within a cluster of houses. A summary of the implementation and the extent to which the goals were achieved follows:

1. In order to define the nanogrid structure, the various characteristics used within the literature to describe a nanogrid were collated. The advantages and disadvantages of each were presented and analysed with the goal of reducing ambiguity around the power structure. From this, the key defining factors were used to create the following concise definition:

"A nanogrid is a power distribution system for a single house/small building, with the ability to connect or disconnect from other power entities via a gateway. It consists of local power production powering local loads, with the option of utilising energy storage and/or a control system."

2. To create a nanogrid controller that increased the correlation between PV power production and household consumption, two initial items of knowledge were required: The available PV power at any particular time and household loads that could be shifted without causing discomfort to the residents. To obtain knowledge of the available PV power, the novel approach of using the maximum power point tracking signal was derived. Meaning that regardless of the load's behaviour, the control system could obtain PV production data, making it ideal for the purpose. Thermostatically controlled loads, specifically the water heater, storage heater and refrigerator, were selected to implement the shifting of a household's consumption. Due to 
their slow thermal dynamics, large power consumption and ability to store energy in the form of heat, they presented a large portion of daily consumption that could be shifted with no discomfort to the households residents. With these variables in place, a control strategy was developed that delegated a percentage of the available PV power, after standard household loads were accounted for, to water and storage heater. This ratio was based on the expected power draw of either load over a day, with the load requiring the most power receiving a higher ratio. As these loads were resistive in nature, by altering the voltage at their input, it allowed the power to be modulated to achieve this control strategy. The refrigerator also contributed to DSM with a separate algorithm that minimised its consumption outside of PV production times. To test the algorithm, ten households were simulated with a variety of consumption curves that considered the diversity observed in summer and winter. The solar irradiance for a week in summer and winter (Kelburn, Wellington, New Zealand) was also obtained to achieve a realistic test scenario. The scenarios were simulated under two conditions, controlled and uncontrolled, in order to quantify the nanogrid's ability to reduce grid power consumed. It was found that the system had the ability to reduce the grid power consumed by as much as $61.86 \%$, with a minimum reduction of $22.38 \%$. The average reduction across all test scenarios was $44.28 \%$.

3. While the single household nanogrid achieved a remarkable reduction in grid power consumed, the pursuit of further grid power reduction led to the investigation of interconnected nanogrid networks. The concept stems from the diversity in consumption and production that occurs within a community. To utilise this characteristic, an interconnected nanogrid network control strategy was developed. The control strategy was made up of the maximum power point tracking signal within each house, collating the combined produc- 
tion. It then observed the consumption of all uncontrollable loads within the network. With this information, an algorithm, which considered all thermostatically controlled loads within the cluster of houses, was implemented. A percentage of the available PV power was delegated to each thermostatically controlled load based on its "urgency", ie a measure of which load was likely to draw the most power over a specific period (day). The loads with the largest power draw were served with the majority of available PV power, while the loads with the lower power draw, a lesser percentage. As each load was serviced, by default its "urgency" would decrease, ensuring the loads that initially presented a low "urgency" would in turn become the more urgent and receive a higher ratio of power. In order to quantify the success of the solution, three simulated scenarios were established. The first was an uncontrolled network, the second a network of nanogrids with individual control and the last, a combined control strategy. The size of the cluster was increased from two to seven interconnected households, with varied consumption patterns and summer/winter conditions (Higher consumption in winter and each season having the appropriate weekly solar irradiance data for Kelburn, Wellington, New Zealand). The grid consumption of each scenario, over a simulated week, was monitored and compared. The first insight showed that, compared to individually grid connected houses, even the uncontrolled network displayed a reduction in grid consumption. The results also showed that the combined control, when compared to the uncontrolled cluster, had the ability to reduce grid power consumed by as much as 55\%, the minimum being $42 \%$ (two houses). When compared to the individually controlled nanogrids, the results were much closer with a maximum reduction of $7 \%$ and a minimum of $2 \%$. This comparison was made assuming an identical PV consumption curve, but as discussed in the future work, the combined control strategy could present a much 
higher reduction in grid power consumed (when compared to the individually controlled nanogrids) given varied PV curves (due to topographical variations for example). For completeness, a comparison was also made between the combined control and individually grid connected uncontrolled houses. It was found that the combined control strategy can reduce the grid power consumed by as much as $61 \%$ in this case.

The achievement of the research objectives leads to the major research contributions of this thesis:

\section{Major research contributions}

1. This thesis presents a rigorous analysis of the general nanogrid definitions given within the literature, discussing their merits and weaknesses from which a concise definition of a nanogrid structure is derived. The traditional supply side management control structures are presented and extended to include demand side management. A new control structure which improves the hybrid central control strategy is also presented.

2. This thesis develops a novel nanogrid control scheme that makes use of thermostatically controlled loads to address intermittency of photovoltaic (PV) modules, negating the need for traditional storage and enabling the user to reduce grid power consumed. This strategy shifts away from direct or indirect control signals received from the utilities and introduces the concept of using a maximum power point tracking signal to instantaneously shift electricity consumption, dynamically matching local PV production. Simulated under a variety of load and solar irradiance conditions, the nanogrid control scheme shows the ability to reduce grid power consumed by $44 \%$.

3. This thesis presents a control scheme that facilitates the interconnection of multiple nanogrids. This scheme extends the capabilities of 
the single nanogrid control to dynamically match the consumption and production of a cluster of interconnected households. This control scheme further reduces the effect of intermittency, taking advantage of diversity of consumption within a cluster of houses. A comparison of grid power consumed by the cluster of houses is presented, considering uncontrolled, individually controlled and the combined control scenarios. The simulated tests show that, compared to an uncontrolled nanogrid network, the combined control can reduce grid power consumed by as much as $55 \%$, while a $7 \%$ decrease is seen when comparing the combined control with the individually controlled nangrid networks. When compared to an uncontrolled individual house scenario, the combined control interconnected nanogrids can reduce the power purchase from the grid by as much as $61 \%$.

This thesis has proven that increasing the correlation between PV power produced and a household's power consumption, through the use of DSM, reduces the negative effects of intermittency and ultimately a household's grid consumption. This increases the viability of small scale PV systems at a residential level, which encourages the uptake of carbon neutral, distributed energy.

\subsection{Future Work}

During the course of this research, a number of topics presented themselves as opportunities to further this work. These are as follows:

- Practical implementation: The next logical step in this research would see a physical implementation of the nanogrid and nanogrid network solutions. This would highlight any real world issues that did not present themselves in the simulated scenarios, an example is the effect of electromagnetic interference (EMI) which has not been 
considered in the model. A nanogrid with the capability of operating autonomously, controlled and uncontrolled, should be created. Long term observation of the power flows and environmental conditions should be monitored to enable real world comparisons between the two solutions. A community of nanogrids should then be established, with the ability to implement combined control and further observations should be made.

- Financial analysis: Once the practical implementation has occurred, a financial analysis should be conducted. This would see a cost and life cycle analysis of the control system's central controller and control nodes. The financial saving achieved by the reduction in grid power consumed when the control system is active should be quantified. The ultimate goal of the financial analysis should be to discover whether the control system increases the financial viability of small scale PV systems at a household level.

- Nanogrid network varied solar irradiance patterns: While the solution presented in this research considers a single solar irradiance pattern for all houses within the nanogrid network, this may not always be the case. Topographical variations, such as tree placement, valleys or hills might see households receive sun at different times of day. This may be where a network approach to sharing power benefits occupants immensely. Take for example a cluster of households situated half on one side of a valley, and half on the opposite side. If morning sun is received by side " $a$ ", and evening received by side " $b$ ", " $a$ " may supply " $b$ " in the morning and vice versa in the evening. This is a situation that should be further explored with the three nanogrid network solutions (uncontrolled, individually controlled and combined control).

- Cold storage devices: The storage heater is a key device in making this control system capable of consuming large amounts of PV 
power. This does work under the assumption that heating is required, making it a system compatible with countries (eg New Zealand) with colder climates. In order to maximise the solution for countries closer to the equator, where cooling is required, an equivalent to the storage heater must be found that can be used to cool households. Ideally this solution will be resistive in nature, making air conditioning units less ideal. Exploration into the use of thermoelectric devices could see the solution thrive in warmer climates, if the efficiency of these devices is improved.

- Communication systems: In both the nanogrid and nanogrid network, communication plays an important role in transactions between the microgrid, central and node controllers. Future research would see a cohesive communications system implemented. As discussed in chapter 3, PLCs could be pursed to create a robust system that negates the need for additional communications lines. Wireless communication could also be possible if security and robustness were considered.

- Nanogrid network pricing scheme: As household PV installations may vary in size, leading to certain households in a cluster supplying more power, financial compensation should be considered. This would be an algorithm written into the microgrid controller that monitors power flows in and out of each house in the cluster. A cost of power flowing within the network would be assigned that would be of mutual benefit to both seller and buyer, further motivating the cluster. The seller would receive more compensation than that offered by the grid (eg greater than the 10c/ kWh offered in New Zealand) and the buyer would buy for less than offered by the grid (eg less than the 28c/kWh offered in New Zealand). The algorithm could monitor the total power purchased by the cluster and rather than money being exchanged between occupants, it could calculate 
the ratio that each customer would need to pay towards the cluster's power bill. 


\section{Bibliography}

[1] S. Kalambe and G. Agnihotri, "Loss minimization techniques used in distribution network: bibliographical survey," Renewable and Sustainable Energy Reviews, vol. 29, pp. 184 - 200, 2014.

[2] A. M. Haidar, K. Muttaqi, and D. Sutanto, "Smart grid and its future perspectives in australia," Renewable and Sustainable Energy Reviews, vol. 51, pp. $1375-1389,2015$.

[3] S. Uski and I. Kim, "Assessment of wind power impact on power system transmission losses," in IEEE PES Innovative Smart Grid Technologies, Europe, pp. 1-5, Oct 2014.

[4] P. J. Maliszewski, E. K. Larson, and C. Perrings, "Environmental determinants of unscheduled residential outages in the electrical power distribution of phoenix, arizona," Reliability Engineering and System Safety, vol. 99, pp. $161-171,2012$.

[5] A. Pahwa, "Effect of environmental factors on failure rate of overhead distribution feeders," in IEEE Power Engineering Society General Meeting, 2004., pp. 691-692 Vol.1, June 2004.

[6] P. Friedlingstein, R. Houghton, G. Marland, J. Hackler, T. A. Boden, T. Conway, J. Canadell, M. Raupach, P. Ciais, and C. Le Quere, “Update on co2 emissions," Nature Geoscience, vol. 3, no. 12, pp. 811-812, 2010. 
[7] D. Akinyele, R. Rayudu, and N. Nair, "Global progress in photovoltaic technologies and the scenario of development of solar panel plant and module performance estimation application in nigeria," Renewable and Sustainable Energy Reviews, vol. 48, pp. 112 - 139, 2015.

[8] D. Akinyele, R. Rayudu, and N. Nair, "Development of photovoltaic power plant for remote residential applications: The socio-technical and economic perspectives," Applied Energy, vol. 155, pp. 131 - 149, 2015.

[9] H. Holtorf, T. Urmee, M. Calais, and T. Pryor, "A model to evaluate the success of solar home systems," Renewable and Sustainable Energy Reviews, vol. 50, pp. 245 - 255, 2015.

[10] P. Basak, S. Chowdhury, S. H. nee Dey, and S. Chowdhury, "A literature review on integration of distributed energy resources in the perspective of control, protection and stability of microgrid," Renewable and Sustainable Energy Reviews, vol. 16, no. 8, pp. 5545 - 5556, 2012.

[11] J. J. Justo, F. Mwasilu, J. Lee, and J.-W. Jung, "Ac-microgrids versus dc-microgrids with distributed energy resources: A review," Renewable and Sustainable Energy Reviews, vol. 24, pp. 387 - 405, 2013.

[12] C. Rae and F. Bradley, "Energy autonomy in sustainable communitiesa review of key issues," Renewable and Sustainable Energy Reviews, vol. 16, no. 9, pp. 6497 - 6506, 2012.

[13] Y. Cao, X. Wang, Y. Li, Y. Tan, J. Xing, and R. Fan, "A comprehensive study on low-carbon impact of distributed generations on regional power grids: A case of jiangxi provincial power grid in china," Renewable and Sustainable Energy Reviews, vol. 53, pp. 766 - 778, 2016.

[14] P. Paliwal, N. Patidar, and R. Nema, "Planning of grid integrated distributed generators: A review of technology, objectives and tech- 
niques," Renewable and Sustainable Energy Reviews, vol. 40, pp. 557 570, 2014.

[15] S. Sivarasu, E. C. Sekaran, and P. Karthik, "Development of renewable energy based microgrid project implementations for residential consumers in india: Scope, challenges and possibilities," Renewable and Sustainable Energy Reviews, vol. 50, pp. 256 - 269, 2015.

[16] P. Descateaux, M. F. Astudillo, and M. B. Amor, "Assessing the life cycle environmental benefits of renewable distributed generation in a context of carbon taxes: The case of the northeastern american market," Renewable and Sustainable Energy Reviews, vol. 53, pp. 1178 - 1189, 2016.

[17] F. F. Yanine and E. E. Sauma, "Review of grid-tie micro-generation systems without energy storage: Towards a new approach to sustainable hybrid energy systems linked to energy efficiency," Renewable and Sustainable Energy Reviews, vol. 26, pp. 60 - 95, 2013.

[18] M. Y. Suberu, M. W. Mustafa, and N. Bashir, "Energy storage systems for renewable energy power sector integration and mitigation of intermittency," Renewable and Sustainable Energy Reviews, vol. 35, pp. $499-514,2014$.

[19] D. Akinyele and R. Rayudu, "Review of energy storage technologies for sustainable power networks," Sustainable Energy Technologies and Assessments, vol. 8, pp. $74-91,2014$.

[20] P. Twomey and K. Neuhoff, "Wind power and market power in competitive markets," Energy Policy, vol. 38, no. 7, pp. 3198 - 3210, 2010. Large-scale wind power in electricity markets with Regular Papers.

[21] E. K. Stigka, J. A. Paravantis, and G. K. Mihalakakou, "Social acceptance of renewable energy sources: A review of contingent valua- 
tion applications," Renewable and Sustainable Energy Reviews, vol. 32, pp. $100-106,2014$.

[22] S. J. Oliva and I. F. MacGill, "Estimating the economic value of distributed pv systems in australia," in Innovative Smart Grid Technologies Asia (ISGT), 2011 IEEE PES, pp. 1-8, Nov 2011.

[23] Ministry of Business Innovation and Employment, "Salesbased electricity costs 2016." http://www.mbie.govt.nz/infoservices/sectors-industries/energy/energy-datamodelling/statistics/prices/electricity-prices/sales-basedresidential-prices.pdf.

[24] A. Miller, M. Hwang, S. Lemon, E. G. Read, and A. Wood, "Economics of Photovoltaic Solar Power and Uptake in New Zealand," EEA Conference and Exhibition, Wellington, 2015.

[25] J. Bryan, R. Duke, and S. Round, "Decentralized generator scheduling in a nanogrid using dc bus signaling," in IEEE Power Engineering Society General Meeting, 2004., pp. 977-982 Vol.1, June 2004.

[26] J. Schonberger, R. Duke, and S. D. Round, "Dc-bus signaling: A distributed control strategy for a hybrid renewable nanogrid," IEEE Transactions on Industrial Electronics, vol. 53, pp. 1453-1460, Oct 2006.

[27] R. P. S. Chandrasena, F. Shahnia, A. Ghosh, and S. Rajakaruna, “Operation and control of a hybrid ac-dc nanogrid for future community houses," in 2014 Australasian Universities Power Engineering Conference (AUPEC), pp. 1-6, Sept 2014.

[28] S. H. Latha and S. C. Mohan, "Centralized power control strategy for $25 \mathrm{kw}$ nano grid for rustic electrification," in 2012 International Conference on Emerging Trends in Science, Engineering and Technology (INCOSET), pp. 456-461, Dec 2012. 
[29] D. Qu, M. Wang, Z. Sun, and G. Chen, "An improved dc-bus signaling control method in a distributed nanogrid interfacing modular converters," in 2015 IEEE 11th International Conference on Power Electronics and Drive Systems, pp. 214-218, June 2015.

[30] W. Zhang, F. C. Lee, and P. Y. Huang, “Energy management system control and experiment for future home," in 2014 IEEE Energy Conversion Congress and Exposition (ECCE), pp. 3317-3324, Sept 2014.

[31] A. Riccobono, M. Ferdowsi, J. Hu, H. Wolisz, P. Jahangiri, D. Mller, R. W. D. Doncker, and A. Monti, "Next generation automation architecture for dc smart homes," in 2016 IEEE International Energy Conference (ENERGYCON), pp. 1-6, April 2016.

[32] A. S. Morais and L. A. C. Lopes, "Interlink converters in dc nanogrids and its effect in power sharing using distributed control," in 2016 IEEE 7th International Symposium on Power Electronics for Distributed Generation Systems (PEDG), pp. 1-7, June 2016.

[33] A. Malkawi and L. A. C. Lopes, "Control of the power electronics interface of a pv source in a smart residential dc nanogrid," in 2016 IEEE Canadian Conference on Electrical and Computer Engineering (CCECE), pp. 1-4, May 2016.

[34] R. P. S. Chandrasena, F. Shahnia, S. Rajakaruna, and A. Ghosh, “Dynamic operation and control of a hybrid nanogrid system for future community houses," IET Generation, Transmission Distribution, vol. 9, no. 11, pp. 1168-1178, 2015.

[35] A. Brocco, "Fully distributed power routing for an ad hoc nanogrid," in 2013 IEEE International Workshop on Inteligent Energy Systems (IWIES), pp. 113-118, Nov 2013. 
[36] U. B. Mujumdar and D. R. Tutkane, "Parallel mppt for pv based residential dc nanogrid," in International Conference on Industrial Instrumentation and Control (ICIC), pp. 1350-1355, May 2015.

[37] J. Schonberger, S. Round, and R. Duke, "Autonomous load shedding in a nanogrid using dc bus signalling," in IECON 2006 - 32nd Annual Conference on IEEE Industrial Electronics, pp. 5155-5160, Nov 2006.

[38] P. Yi, X. Dong, A. Iwayemi, C. Zhou, and S. Li, "Real-time opportunistic scheduling for residential demand response," IEEE Transactions on Smart Grid, vol. 4, pp. 227-234, March 2013.

[39] M. Biabani, M. A. Golkar, A. Johar, and M. Johar, "Propose a home demand-side-management algorithm for smart nano-grid," in 4 th Annual International Power Electronics, Drive Systems and Technologies Conference, pp. 487-494, Feb 2013.

[40] S. Barker, A. Mishra, D. Irwin, P. Shenoy, and J. Albrecht, “Smartcap: Flattening peak electricity demand in smart homes," in 2012 IEEE International Conference on Pervasive Computing and Communications, pp. 67-75, March 2012.

[41] R. Adda, O. Ray, S. K. Mishra, and A. Joshi, "Synchronousreference-frame-based control of switched boost inverter for standalone dc nanogrid applications," IEEE Transactions on Power Electronics, vol. 28, pp. 1219-1233, March 2013.

[42] A. Goikoetxea, J. M. Canales, R. Sanchez, and P. Zumeta, "Dc versus ac in residential buildings: Efficiency comparison," in Eurocon 2013, pp. 1-5, July 2013.

[43] H. S. Kim, M. H. Ryu, J. W. Baek, and J. H. Jung, "High-efficiency isolated bidirectional ac-dc converter for a dc distribution system," IEEE Transactions on Power Electronics, vol. 28, pp. 1642-1654, April 2013. 
[44] H. Mamur and R. Ahiska, "Application of a dcdc boost converter with maximum power point tracking for low power thermoelectric generators," Energy Conversion and Management, vol. 97, pp. 265 272, 2015.

[45] D. Burmester, R. Rayudu, and T. Exley, "Single ended primary inductor converter reliance of efficiency on switching frequency for use in mppt application," in 2013 IEEE PES Asia-Pacific Power and Energy Engineering Conference (APPEEC), pp. 1-6, Dec 2013.

[46] M. Taghvaee, M. Radzi, S. Moosavain, H. Hizam, and M. H. Marhaban, "A current and future study on non-isolated dcdc converters for photovoltaic applications," Renewable and Sustainable Energy Reviews, vol. 17, pp. $216-227,2013$.

[47] S. G. Tesfahunegn, P. J. S. Vie, . Ulleberg, and T. M. Undeland, "A simplified battery charge controller for safety and increased utilization in standalone pv applications," in 2011 37th IEEE Photovoltaic Specialists Conference, pp. 002441-002447, June 2011.

[48] R. Sarath and P. Kanakasabapathy, "Switched-capacitor/switchedinductor cuk-derived hybrid converter for nanogrid applications," in 2015 International Conference on Computation of Power, Energy, Information and Communication (ICCPEIC), pp. 0430-0435, April 2015.

[49] S. Poshtkouhi, M. Fard, H. Hussein, L. M. D. Santos, O. Trescases, M. Varlan, and T. Lipan, "A dual-active-bridge based bi-directional micro-inverter with integrated short-term li-ion ultra-capacitor storage and active power smoothing for modular pv systems," in 2014 IEEE Applied Power Electronics Conference and Exposition - APEC 2014, pp. 643-649, March 2014.

[50] O. Ray and S. Mishra, "A multi-port converter topology with simultaneous isolated and non-isolated outputs," in IECON 2013 - 39th 
Annual Conference of the IEEE Industrial Electronics Society, pp. 71187123, Nov 2013.

[51] O. Ray and S. Mishra, "Boost-derived hybrid converter with simultaneous dc and ac outputs," IEEE Transactions on Industry Applications, vol. 50, pp. 1082-1093, March 2014.

[52] S. Poshtkouhi and O. Trescases, "Multi-input single-inductor dc-dc converter for mppt in parallel-connected photovoltaic applications," in 2011 Twenty-Sixth Annual IEEE Applied Power Electronics Conference and Exposition (APEC), pp. 41-47, March 2011.

[53] M. C. Mira, Z. Zhang, A. Knott, and M. A. E. Andersen, "Power flow control of a dual-input interleaved buck/boost converter with galvanic isolation for renewable energy systems," in 2015 IEEE Applied Power Electronics Conference and Exposition (APEC), pp. 30073012, March 2015.

[54] H. Keyhani and H. A. Toliyat, "Single-stage multistring pv inverter with an isolated high-frequency link and soft-switching operation," IEEE Transactions on Power Electronics, vol. 29, pp. 3919-3929, Aug 2014.

[55] A. S. U., S. S. Nag, and S. K. Mishra, "A multi-input single-control (misc) battery charger for dc nanogrids," in 2013 IEEE ECCE Asia Downunder, pp. 304-310, June 2013.

[56] F. Chen, R. Burgos, D. Boroyevich, and D. Dong, "Control loop design of a two-stage bidirectional ac/dc converter for renewable energy systems," in 2014 IEEE Applied Power Electronics Conference and Exposition - APEC 2014, pp. 2177-2183, March 2014.

[57] D. Dong, F. Luo, X. Zhang, D. Boroyevich, and P. Mattavelli, "Gridinterface bidirectional converter for residential dc distribution systems; part 2: Ac and dc interface design with passive compo- 
nents minimization," IEEE Transactions on Power Electronics, vol. 28, pp. 1667-1679, April 2013.

[58] D. Dong, I. Cvetkovic, D. Boroyevich, W. Zhang, R. Wang, and P. Mattavelli, "Grid-interface bidirectional converter for residential dc distribution systems; part one: High-density two-stage topology," IEEE Transactions on Power Electronics, vol. 28, pp. 1655-1666, April 2013.

[59] S. S. Nag and S. Mishra, "Current-fed dc/dc topology based inverter," in 2013 IEEE Energy Conversion Congress and Exposition, pp. 2751-2756, Sept 2013.

[60] S. S. Nag, R. Adda, O. Ray, and S. K. Mishra, "Current-fed switched inverter based hybrid topology for dc nanogrid application," in IECON 2013 - 39th Annual Conference of the IEEE Industrial Electronics Society, pp. 7146-7151, Nov 2013.

[61] R. Adda, O. Ray, S. Mishra, and A. Joshi, “Dsp based pwm control of switched boost inverter for dc nanogrid applications," in IECON 2012 - 38th Annual Conference on IEEE Industrial Electronics Society, pp. 5285-5290, Oct 2012.

[62] A. Tomy and A. J. Thomas, "Sepic derived hybrid converter with simultaneous ac and dc outputs," in 2016 IEEE Annual India Conference (INDICON), pp. 1-6, Dec 2016.

[63] O. D. Castle and A. E. Shahat, "Single-input - multi-output (simo) converter for nano-grids applications," in SoutheastCon 2017, pp. 15, March 2017.

[64] N. Isaacs, M. Camilleri, L. Burrough, K. Saville-smith, and R. F. Cresa, "Energy Use in New Zealand Households Final Report on the Household Energy End-use PRoject (HEEP)," Science And Technology, vol. 221, 2010. 
[65] N. Lu, P. Du, and Y. V. Makarov, "The potential of thermostatically controlled appliances for intra-hour energy storage applications," in 2012 IEEE Power and Energy Society General Meeting, pp. 1-6, July 2012.

[66] Z. Chen, L. Wu, and Y. Fu, "Real-time price-based demand response management for residential appliances via stochastic optimization and robust optimization," IEEE Transactions on Smart Grid, vol. 3, pp. 1822-1831, Dec 2012.

[67] E. C. Kara, M. Berges, B. Krogh, and S. Kar, "Using smart devices for system-level management and control in the smart grid: A reinforcement learning framework," in 2012 IEEE Third International Conference on Smart Grid Communications (SmartGridComm), pp. 8590, Nov 2012.

[68] N. Lu, "An evaluation of the hvac load potential for providing load balancing service," IEEE Transactions on Smart Grid, vol. 3, pp. 12631270, Sept 2012.

[69] Y. Zhang and N. Lu, "Parameter selection for a centralized thermostatically controlled appliances load controller used for intra-hour load balancing," IEEE Transactions on Smart Grid, vol. 4, pp. 21002108, Dec 2013.

[70] M. Alizadeh and A. Scaglione, "Least laxity first scheduling of thermostatically controlled loads for regulation services," in 2013 IEEE Global Conference on Signal and Information Processing, pp. 503-506, Dec 2013.

[71] E. C. Kara, Z. Kolter, M. Berges, B. Krogh, G. Hug, and T. Yuksel, "A moving horizon state estimator in the control of thermostatically controlled loads for demand response," in 2013 IEEE International 
Conference on Smart Grid Communications (SmartGridComm), pp. 253258, Oct 2013.

[72] E. Vrettos and G. Andersson, "Combined load frequency control and active distribution network management with thermostatically controlled loads," in 2013 IEEE International Conference on Smart Grid Communications (SmartGridComm), pp. 247-252, Oct 2013.

[73] M. A. Zehir, A. Batman, and M. Bagriyanik, "An event-driven energy management system for planned control of thermostatic loads," in 2013 IEEE Grenoble Conference, pp. 1-6, June 2013.

[74] H. T. Nguyen, D. Nguyen, and L. B. Le, "Home energy management with generic thermal dynamics and user temperature preference," in IEEE International Conference on Smart Grid Communications (SmartGridComm), pp. 552-557, Oct 2013.

[75] A. Abiri-Jahromi and F. Bouffard, "Characterizing statistical bounds on aggregated demand-based primary frequency control," in 2013 IEEE Power Energy Society General Meeting, pp. 1-5, July 2013.

[76] Y. Zhang and N. Lu, "Demand-side management of air conditioning cooling loads for intra-hour load balancing," in 2013 IEEE PES Innovative Smart Grid Technologies Conference (ISGT), pp. 1-6, Feb 2013.

[77] N. Lu, "Design considerations of a centralized load controller using thermostatically controlled appliances for continuous regulation reserves," in 2013 IEEE Power Energy Society General Meeting, pp. 1-1, July 2013.

[78] H. Wang, K. Meng, F. Luo, Z. Y. Dong, Z. Xu, and K. P. Wong, "A hierarchical optimization framework for aggregating thermostatically controlled loads to minimize real-time thermal rating of overhead distribution lines," in 2014 China International Conference on Electricity Distribution (CICED), pp. 1769-1773, Sept 2014. 
[79] A. K. Marinov, G. Verbi?, and A. C. Chapman, “An investigation into the economic benefits of fast-timescale demand response using thermostatically controlled loads on the nem," in 2014 Australasian Universities Power Engineering Conference (AUPEC), pp. 1-6, Sept 2014.

[80] C. Vivekananthan, Y. Mishra, and K. Rajashekara, "Energy efficient home with price sensitive stochastically programmable TCAs," in 40th Annual Conference of the IEEE Industrial Electronics Society, pp. 5357-5362, Oct 2014.

[81] M. Vanouni and N. Lu, "Improving the centralized control of thermostatically controlled appliances by obtaining the right information," IEEE Transactions on Smart Grid, vol. 6, pp. 946-948, March 2015.

[82] S. Grammatico, B. Gentile, F. Parise, and J. Lygeros, "A mean field control approach for demand side management of large populations of thermostatically controlled loads," in 2015 European Control Conference (ECC), pp. 3548-3553, July 2015.

[83] S. H. Tindemans, V. Trovato, and G. Strbac, "Frequency control using thermal loads under the proposed entso-e demand connection code," in 2015 IEEE Eindhoven PowerTech, pp. 1-6, June 2015.

[84] V. Trovato, S. H. Tindemans, and G. Strbac, "Leaky storage model for optimal multi-service allocation of thermostatic loads," IET Generation, Transmission Distribution, vol. 10, no. 3, pp. 585-593, 2016.

[85] S. H. Tindemans, V. Trovato, and G. Strbac, "Decentralized control of thermostatic loads for flexible demand response," IEEE Transactions on Control Systems Technology, vol. 23, pp. 1685-1700, Sept 2015.

[86] A. Abiri-Jahromi and F. Bouffard, "Contingency-type reserve leveraged through aggregated thermostatically-controlled loads part ii: 
Case studies," IEEE Transactions on Power Systems, vol. 31, pp. 19811989, May 2016.

[87] A. Abiri-Jahromi and F. Bouffard, "Contingency-type reserve leveraged through aggregated thermostatically-controlled loads part i: Characterization and control," IEEE Transactions on Power Systems, vol. 31, pp. 1972-1980, May 2016.

[88] M. Liu and Y. Shi, "Model predictive control for thermostatically controlled appliances providing balancing service," IEEE Transactions on Control Systems Technology, vol. 24, pp. 2082-2093, Nov 2016.

[89] Z. Pan, Q. Guo, and H. Sun, "A dynamic soft constraint method for thermostatically controlled appliances scheduling," in 2016 IEEE Power and Energy Society General Meeting (PESGM), pp. 1-5, July 2016.

[90] O. Erdinc, A. Tascikaraoglu, N. Paterakis, Y. Eren, and J. P. S. Catalao, “End-User Comfort Oriented Day-Ahead Planning for Responsive Residential HVAC Demand Aggregation Considering Weather Forecasts," IEEE Trans. on Smart Grid, vol. PP, no. 99, pp. 1-1, 2016.

[91] V. Trovato, F. Teng, and G. Strbac, "Role and benefits of flexible thermostatically controlled loads in future low-carbon systems.," IEEE Transactions on Smart Grid, vol. PP, no. 99, pp. 1-1, 2017.

[92] J. Liu, Q. Yang, and W. Yan, “Thermostatically controlled appliances for demand response based on an improved state queuing model," in 2017 29th Chinese Control And Decision Conference (CCDC), pp. 6016-6021, May 2017.

[93] K. Meng, D. Wang, Z. Y. Dong, X. Gao, Y. Zheng, and K. P. Wong, "Distributed control of thermostatically controlled loads in distribution network with high penetration of solar pv," CSEE Journal of Power and Energy Systems, vol. 3, pp. 53-62, March 2017. 
[94] A. Radaideh, U. Vaidya, and V. Ajjarapu, "Sequential set-point control for heterogeneous thermostatically controlled loads through an extended markov chain abstraction," IEEE Transactions on Smart Grid, vol. PP, no. 99, pp. 1-1, 2017.

[95] M. Vanouni and N. Lu, "A reward allocation mechanism for thermostatically controlled loads participating in intra-hour ancillary services," IEEE Transactions on Smart Grid, vol. PP, no. 99, pp. 1-1, 2017.

[96] C. Li, Y. Chen, F. Luo, Z. Xu, and Y. Zheng, "Real-time decision making model for thermostatically controlled load aggregators by natural aggregation algorithm," in 2017 IEEE International Conference on Energy Internet (ICEI), pp. 279-284, April 2017.

[97] C. Vivekananthan and Y. Mishra, "Stochastic ranking method for thermostatically controllable appliances to provide regulation services," IEEE Trans. on Power Systems, vol. 30, pp. 1987-1996, July 2015.

[98] M. Arora, S. Chanana, and A. Kumar, "A real time price based optimal scheduling mechanism for centralized air conditioning load," in 2014 Eighteenth National Power Systems Conference (NPSC), pp. 1-5, Dec 2014.

[99] K. McKenna and A. Keane, "Residential load modeling of pricebased demand response for network impact studies," IEEE Transactions on Smart Grid, vol. 7, pp. 2285-2294, Sept 2016.

[100] E. Ancillotti, R. Bruno, and M. Conti, "Smoothing peak demands through aggregate control of background electrical loads," in ISGT 2014, pp. 1-5, Feb 2014.

[101] M. Pipattanasomporn, M. Kuzlu, and S. Rahman, “An algorithm for intelligent home energy management and demand response analysis," IEEE Trans. on Smart Grid, vol. 3, pp. 2166-2173, Dec 2012. 
[102] P. Du and N. Lu, "Appliance commitment for household load scheduling," IEEE Trans. on Smart Grid, vol. 2, pp. 411-419, June 2011.

[103] D. Wang, H. Jia, C. Wang, N. Lu, M. Fan, W. Miao, and Z. Liu, "Performance evaluation of controlling thermostatically controlled appliances as virtual generators using comfort-constrained statequeueing models," IET Generation, Transmission Distribution, vol. 8, pp. 591-599, April 2014.

[104] A. Subramanian, M. Garcia, A. Domnguez-Garca, D. Callaway, K. Poolla, and P. Varaiya, "Real-time scheduling of deferrable electric loads," in 2012 American Control Conference (ACC), pp. 36433650, June 2012.

[105] L. Wang, Q. Yang, and W. Yan, "Residential thermostatically controlled appliances for smoothing tie line power based on multiple state-queueing model," in 2017 29th Chinese Control And Decision Conference (CCDC), pp. 3195-3200, May 2017.

[106] D. Wang, S. Ge, H. Jia, C. Wang, Y. Zhou, N. Lu, and X. Kong, "A demand response and battery storage coordination algorithm for providing microgrid tie-line smoothing services," IEEE Transactions on Sustainable Energy, vol. 5, pp. 476-486, April 2014.

[107] G. Sharma, L. Xie, and P. R. Kumar, "Large population optimal demand response for thermostatically controlled inertial loads," in 2013 IEEE International Conference on Smart Grid Communications (SmartGridComm), pp. 259-264, Oct 2013.

[108] M. A. A. Pedrasa, T. D. Spooner, and I. F. MacGill, "Coordinated scheduling of residential distributed energy resources to optimize smart home energy services," IEEE Transactions on Smart Grid, vol. 1, pp. 134-143, Sept 2010. 
[109] T. Hubert and S. Grijalva, "Modeling for residential electricity optimization in dynamic pricing environments," IEEE Transactions on Smart Grid, vol. 3, pp. 2224-2231, Dec 2012.

[110] G. Karmakar, A. Kabra, and K. Ramamritham, "Coordinated scheduling of thermostatically controlled real-time systems under peak power constraint," in IEEE 19th Real-Time and Embedded Technology and Applications Symposium (RTAS), pp. 33-42, April 2013.

[111] G. Karmakar and A. Kabra, "Energy-aware thermal comfort-band maintenance scheduling under peak power constraint," in IEEE Recent Advances in Intelligent Computational Systems (RAICS), pp. 122127, Dec 2013.

[112] A. L. Liu, G. Ledwich, and W. Miller, "Single household domestic water heater design and control utilising pv energy: The untapped energy storage solution," in IEEE PES Asia-Pacific Power and Energy Engineering Conference (APPEEC), pp. 1-5, Nov 2015.

[113] D. Boroyevich, I. Cvetkovic, R. Burgos, and D. Dong, "Intergrid: A future electronic energy network?," IEEE Journal of Emerging and Selected Topics in Power Electronics, vol. 1, pp. 127-138, Sept 2013.

[114] B. Nordman and K. Christensen, "Local power distribution with nanogrids," in 2013 International Green Computing Conference Proceedings, pp. 1-8, June 2013.

[115] B. Nordman, "Evolving our electricity systems from the bottom up," in Darnell Green Power Forum, 2009.

[116] D. Boroyevich, I. Cvetkovi, D. Dong, R. Burgos, F. Wang, and F. Lee, "Future electronic power distribution systems a contemplative view," in 2010 12th International Conference on Optimization of Electrical and Electronic Equipment, pp. 1369-1380, May 2010. 
[117] M. E. Khodayar and H. Wu, "Demand forecasting in the smart grid paradigm: Features and challenges," The Electricity Journal, vol. 28, no. 6, pp. $51-62,2015$.

[118] A. Werth, N. Kitamura, I. Matsumoto, and K. Tanaka, "Evaluation of centralized and distributed microgrid topologies and comparison to open energy systems (oes)," in 2015 IEEE 15th International Conference on Environment and Electrical Engineering (EEEIC), pp. 492-497, June 2015.

[119] B. Nordman and K. Christensen, "The need for communications to enable dc power to be successful," in 2015 IEEE First International Conference on DC Microgrids (ICDCM), pp. 108-112, June 2015.

[120] A. Werth, N. Kitamura, and K. Tanaka, "Conceptual study for open energy systems: Distributed energy network using interconnected dc nanogrids," IEEE Transactions on Smart Grid, vol. 6, pp. 1621-1630, July 2015.

[121] A. Bani-Ahmed, L. Weber, A. Nasiri, and H. Hosseini, "Microgrid communications: State of the art and future trends," in 2014 International Conference on Renewable Energy Research and Application (ICRERA), pp. 780-785, Oct 2014.

[122] D. Q. Oliveira, A. C. Z. de Souza, A. B. Almeida, M. V. Santos, B. I. L. Lopes, and D. Marujo, "Microgrid management in emergency scenarios for smart electrical energy usage," in 2015 IEEE Eindhoven PowerTech, pp. 1-6, June 2015.

[123] N. Liu, X. Yu, W. Fan, C. Hu, T. Rui, Q. Chen, and Z. Jianhua, “Online energy sharing for nanogrid clusters: A lyapunov optimization approach," IEEE Transactions on Smart Grid, vol. PP, no. 99, pp. 1-1, 2017. 
[124] P. Arboleya, C. G. M. P. Garcia, J. Garcia, and B. Mohamed, "Hierarchical coordination of a hybrid ac/dc smartgrid with central/distributed energy storage," in 2016 IEEE Energy Conversion Congress and Exposition (ECCE), pp. 1-7, Sept 2016.

[125] M. Nasir, N. A. Zaffar, and H. A. Khan, "Analysis on central and distributed architectures of solar powered dc microgrids," in 2016 Clemson University Power Systems Conference (PSC), pp. 1-6, March 2016.

[126] M. R. Sandgani and S. Sirouspour, "Energy management in a network of grid-connected microgrids/nanogrids using compromise programming," IEEE Transactions on Smart Grid, vol. PP, no. 99, pp. 1-1, 2017.

[127] A. Werth, M. Tokoro, and K. Tanaka, "Bottom-up and recursive interconnection for multi-layer dc microgrids," in 2016 IEEE 16th International Conference on Environment and Electrical Engineering (EEEIC), pp. 1-6, June 2016.

[128] I. Cvetkovic, D. Boroyevich, F. C. Lee, P. Mattavelli, D. Dong, L. Jiang, and Y. Chang, "Future home dc-based renewable energy nanogrid system," in Proceedings of the 2010 Conference on Grand Challenges in Modeling and Simulation, pp. 337-343, Society for Modeling and Simulation International, 2010.

[129] C. Sun, F. Sun, and S. J. Moura, “Data enabled predictive energy management of a pv-battery smart home nanogrid," in 2015 American Control Conference (ACC), pp. 1023-1028, July 2015.

[130] T. Momose, H. Hayakawa, H. Fujimoto, H. Kakigano, Y. Miura, and T. Ise, "Nano-grid: Small scale dc microgrid for residential houses with cogeneration system in each house," in International Gas Union Research Conference (IGRC 2008), pp. 2826-2833, October 2008. 
[131] R. Adda, O. Ray, S. Mishra, and A. Joshi, "Implementation and control of switched boost inverer for dc nanogrid applications," in 2012 IEEE Energy Conversion Congress and Exposition (ECCE), pp. 38113818, Sept 2012.

[132] B. Nordman and K. Christensen, "Dc local power distribution with microgrids and nanogrids," in 2015 IEEE First International Conference on DC Microgrids (ICDCM), pp. 199-204, June 2015.

[133] S. R and P. Kanakasabapathy, "Hybrid converter based on cuk topology to supply both ac and dc loads," in 2015 International Conference on Technological Advancements in Power and Energy (TAP Energy), pp. 387-392, June 2015.

[134] N. Lidula and A. Rajapakse, "Microgrids research: A review of experimental microgrids and test systems," Renewable and Sustainable Energy Reviews, vol. 15, no. 1, pp. 186 - 202, 2011.

[135] R. Zamora and A. K. Srivastava, "Controls for microgrids with storage: Review, challenges, and research needs," Renewable and Sustainable Energy Reviews, vol. 14, no. 7, pp. 2009 - 2018, 2010.

[136] E. Cetin, A. Yilanci, H. K. Ozturk, M. Colak, I. Kasikci, and S. Iplikci, "A micro-dc power distribution system for a residential application energized by photovoltaic wind/fuel cell hybrid energy systems," Energy and Buildings, vol. 42, no. 8, pp. 1344 - 1352, 2010.

[137] S. M. Brahma, "Fault location in power distribution system with penetration of distributed generation," IEEE Transactions on Power Delivery, vol. 26, pp. 1545-1553, July 2011.

[138] H. G. Yap and K. J. Tseng, "Towards a fault-tolerant grid interface system for dc power distribution networks in green buildings," in 2015 9th International Conference on Power Electronics and ECCE Asia (ICPE-ECCE Asia), pp. 1796-1802, June 2015. 
[139] E. Planas, J. Andreu, J. I. Grate, I. M. de Alegra, and E. Ibarra, " $\{A C\}$ and $\{\mathrm{DC}\}$ technology in microgrids: A review," Renewable and Sustainable Energy Reviews, vol. 43, pp. 726 - 749, 2015.

[140] A. H. Fathima and K. Palanisamy, "Optimization in microgrids with hybrid energy systems a review," Renewable and Sustainable Energy Reviews, vol. 45, pp. $431-446,2015$.

[141] S. Mishra and O. Ray, "Advances in nanogrid technology and its integration into rural electrification in india," in 2014 International Power Electronics Conference (IPEC-Hiroshima 2014 - ECCE ASIA), pp. 2707-2713, May 2014.

[142] D. Dong, F. Luo, W. Zhang, D. Boroyevich, P. Mattavelli, I. Cvetkovic, L. Jiang, and P. Kong, "Passive filter topology study of single-phase ac-dc converters for dc nanogrid applications," in 2011 Twenty-Sixth Annual IEEE Applied Power Electronics Conference and Exposition (APEC), pp. 287-294, March 2011.

[143] A. Karabiber, C. Keles, A. Kaygusuz, and B. B. Alagoz, "An approach for the integration of renewable distributed generation in hybrid dc/ac microgrids," Renewable Energy, vol. 52, pp. 251 - 259, 2013.

[144] S. Ahmadi, S. Shokoohi, and H. Bevrani, "A fuzzy logic-based droop control for simultaneous voltage and frequency regulation in an \{AC \} microgrid," International Journal of Electrical Power and Energy Systems, vol. 64, pp. 148 -155, 2015.

[145] A. A. Abdelsalam, H. A. Gabbar, and A. M. Sharaf, "Performance enhancement of hybrid ac/dc microgrid based d-facts," International Journal of Electrical Power and Energy Systems, vol. 63, pp. 382 - 393, 2014. 
[146] A. A. Memon and K. Kauhaniemi, "A critical review of $\{A C\}$ microgrid protection issues and available solutions," Electric Power Systems Research, vol. 129, pp. 23 - 31, 2015.

[147] M. Sechilariu, B. C. Wang, F. Locment, and A. Jouglet, " $\{D C\}$ microgrid power flow optimization by multi-layer supervision control. design and experimental validation," Energy Conversion and Management, vol. 82, pp. 1 - 10, 2014.

[148] W. W. Weaver, R. D. R. III, G. G. Parker, and D. G. Wilson, "Distributed control and energy storage requirements of networked dc microgrids," Control Engineering Practice, vol. 44, pp. 10 - 19, 2015.

[149] J. K. Schonberger, "Distributed control of a nanogrid using dc bus signalling," in Ph.D. dissertation, University of Canterbury. Electrical and Computer Engineering, 2006.

[150] O. Lucia, I. Cvetkovic, D. Boroyevich, P. Mattavelli, and F. C. Lee, "Design of household appliances for a dc-based nanogrid system: An induction heating cooktop study case," in 2013 TwentyEighth Annual IEEE Applied Power Electronics Conference and Exposition (APEC), pp. 1576-1583, March 2013.

[151] V. Sudev and S. Parvathy, "Switched boost inverter based dc nanogrid with battery and bi-directional converter," in $2014 \mathrm{In}$ ternational Conference on Circuits, Power and Computing Technologies [ICCPCT-2014], pp. 461-467, March 2014.

[152] U. B. Mujumdar and D. R. Tutkane, "Parallel mppt for pv based residential dc nanogrid," in 2015 International Conference on Industrial Instrumentation and Control (ICIC), pp. 1350-1355, May 2015.

[153] I. Cvetkovic, D. Dong, W. Zhang, L. Jiang, D. Boroyevich, F. C. Lee, and P. Mattavelli, "A testbed for experimental validation of a lowvoltage dc nanogrid for buildings," in 2012 15th International Power 
Electronics and Motion Control Conference (EPE/PEMC), pp. LS7c.5-1LS7c.5-8, Sept 2012.

[154] P. Cairoli, I. Kondratiev, and R. A. Dougal, "Controlled power sequencing for fault protection in dc nanogrids," in 2011 International Conference on Clean Electrical Power (ICCEP), pp. 730-737, June 2011.

[155] J. Mitra and S. Suryanarayanan, "System analytics for smart microgrids," in IEEE PES General Meeting, pp. 1-4, July 2010.

[156] A. Etxeberria, I. Vechiu, H. Camblong, and J.-M. Vinassa, "Comparison of three topologies and controls of a hybrid energy storage system for microgrids," Energy Conversion and Management, vol. 54, no. 1, pp. $113-121,2012$.

[157] J. M. Guerrero, J. C. Vasquez, J. Matas, L. G. de Vicuna, and M. Castilla, "Hierarchical control of droop-controlled ac and dc microgrids; a general approach toward standardization," IEEE Transactions on Industrial Electronics, vol. 58, pp. 158-172, Jan 2011.

[158] A. G. Tsikalakis and N. D. Hatziargyriou, "Centralized control for optimizing microgrids operation," in 2011 IEEE Power and Energy Society General Meeting, pp. 1-8, July 2011.

[159] I. Patrao, E. Figueres, G. Garcer, and R. Gonzlez-Medina, “Microgrid architectures for low voltage distributed generation," Renewable and Sustainable Energy Reviews, vol. 43, pp. 415 - 424, 2015.

[160] J. A. P. Lopes, C. L. Moreira, and A. G. Madureira, “Defining control strategies for microgrids islanded operation," IEEE Transactions on Power Systems, vol. 21, pp. 916-924, May 2006.

[161] N. Pogaku, M. Prodanovic, and T. C. Green, "Modeling, analysis and testing of autonomous operation of an inverter-based microgrid," 
IEEE Transactions on Power Electronics, vol. 22, pp. 613-625, March 2007.

[162] S. Mansour, G. Jos, I. Harrabi, and M. Maier, "Co-simulation of realtime decentralized vehicle/grid (rt-dvg) coordination scheme for e-mobility within nanogrids," in 2013 IEEE Electrical Power Energy Conference, pp. 1-6, Aug 2013.

[163] M. H. Shwehdi and S. R. Mohamed, "Proposed smart dc nano-grid for green buildings; a reflective view," in 2014 International Conference on Renewable Energy Research and Application (ICRERA), pp. 765769, Oct 2014.

[164] M. C. Kinn, "Proposed components for the design of a smart nanogrid for a domestic electrical system that operates at below $50 \mathrm{v}$ dc," in 2011 2nd IEEE PES International Conference and Exhibition on Innovative Smart Grid Technologies, pp. 1-7, Dec 2011.

[165] W. W. A. G. Silva, P. F. Donoso-Garcia, S. I. Seleme, T. R. Oliveira, C. H. G. Santos, and A. S. Bolzon, "Study of the application of bidirectional dual active bridge converters in dc nanogrid energy storage systems," in 2013 Brazilian Power Electronics Conference, pp. 609614, Oct 2013.

[166] M. Soshinskaya, W. H. Crijns-Graus, J. M. Guerrero, and J. C. Vasquez, "Microgrids: Experiences, barriers and success factors," Renewable and Sustainable Energy Reviews, vol. 40, pp. 659 - 672, 2014.

[167] S. J. Chatzivasiliadis, N. D. Hatziargyriou, and A. L. Dimeas, “Development of an agent based intelligent control system for microgrids," in 2008 IEEE Power and Energy Society General Meeting - Conversion and Delivery of Electrical Energy in the 21st Century, pp. 1-6, July 2008. 
[168] D. Neves, M. C. Brito, and C. A. Silva, "Impact of solar and wind forecast uncertainties on demand response of isolated microgrids," Renewable Energy, vol. 87, Part 2, pp. 1003 - 1015, 2016. Optimization Methods in Renewable Energy Systems Design.

[169] A. Kaur, J. Kaushal, and P. Basak, "A review on microgrid central controller," Renewable and Sustainable Energy Reviews, vol. 55, pp. 338 $-345,2016$.

[170] H. Borhanazad, S. Mekhilef, V. G. Ganapathy, M. Modiri-Delshad, and A. Mirtaheri, "Optimization of micro-grid system using \{MOPSO\}," Renewable Energy, vol. 71, pp. 295 - 306, 2014.

[171] M. Barnes, J. Kondoh, H. Asano, J. Oyarzabal, G. Ventakaramanan, R. Lasseter, N. Hatziargyriou, and T. Green, "Real-world microgrids-an overview," in 2007 IEEE International Conference on System of Systems Engineering, pp. 1-8, April 2007.

[172] A. Zidan, H. A. Gabbar, and A. Eldessouky, "Optimal planning of combined heat and power systems within microgrids," Energy, vol. 93, Part 1, pp. 235 - 244, 2015.

[173] N. Hatziargyriou, H. Asano, R. Iravani, and C. Marnay, "Microgrids," IEEE Power and Energy Magazine, vol. 5, pp. 78-94, July 2007.

[174] B. Nordman, K. Christensen, and A. Meier, "Think globally, distribute power locally: The promise of nanogrids," Computer, vol. 45, pp. 89-91, Sept 2012.

[175] A. T. Elsayed, A. A. Mohamed, and O. A. Mohammed, " $\{D C\}$ microgrids and distribution systems: An overview," Electric Power Systems Research, vol. 119, pp. 407 - 417, 2015.

[176] S. Pelland, D. Turcotte, G. Colgate, and A. Swingler, "Nemiah valley photovoltaic-diesel mini-grid: System performance and fuel saving 
based on one year of monitored data," IEEE Transactions on Sustainable Energy, vol. 3, pp. 167-175, Jan 2012.

[177] N. Garimella and N. K. C. Nair, "Assessment of battery energy storage systems for small-scale renewable energy integration," in TENCON 2009 - 2009 IEEE Region 10 Conference, pp. 1-6, Jan 2009.

[178] D. Dong, D. Boroyevich, R. Wang, and I. Cvetkovic, "A two-stage high power density single-phase ac-dc bi-directional pwm converter for renewable energy systems," in 2010 IEEE Energy Conversion Congress and Exposition, pp. 3862-3869, Sept 2010.

[179] D. Burmester, R. Rayudu, and W. Seah, "A comparison between temperature and current sensing in photovoltaic maximum power point tracking," in 2014 Eighteenth National Power Systems Conference (NPSC), pp. 1-6, Dec 2014.

[180] J. Zhang, Bidirectional DC-DC power converter design optimization, modeling and control (PhD dissertation). PhD thesis, Virginia Polytechnic Institute and State University, 2008.

[181] Y. C. Chuang and Y. L. Ke, "A novel high-efficiency battery charger with a buck zero-voltage-switching resonant converter," IEEE Transactions on Energy Conversion, vol. 22, pp. 848-854, Dec 2007.

[182] K. Garbesi, V. Vossos, and H.Shen, "Catalog of dc appliances and power systems," in U.S. department of energy, office of energy efficiency and renewable energy. Ernest Orlando Lawrence Berkeley National Laboratory, 2012.

[183] H. Wu, S. C. Wong, C. K. Tse, and Q. Chen, "Control and modulation of a family of bidirectional ac-dc converters with active power compensation," in 2015 IEEE Energy Conversion Congress and Exposition (ECCE), pp. 661-668, Sept 2015. 
[184] Y. H. Liao, "A novel reduced switching loss bidirectional ac/dc converter pwm strategy with feedforward control for grid-tied microgrid systems," IEEE Transactions on Power Electronics, vol. 29, pp. 1500-1513, March 2014.

[185] S. I. Ganesan, D. Pattabiraman, R. K. Govindarajan, M. Rajan, and C. Nagamani, "Control scheme for a bidirectional converter in a selfsustaining low-voltage dc nanogrid," IEEE Transactions on Industrial Electronics, vol. 62, pp. 6317-6326, Oct 2015.

[186] V. Vossos, K. Garbesi, and H. Shen, "Energy savings from direct-dc in u.s. residential buildings," Energy and Buildings, vol. 68, Part A, pp. $223-231,2014$.

[187] N. Horowitz, "Power supplies: a hidden opportunity for energy savings," Natural Resources Defense Council, Tech. Rep, 2002.

[188] M. M. H. Sajeeb, A. Rahman, and S. Arif, "Feasibility analysis of solar dc nano grid for off grid rural bangladesh," in 2015 3rd International Conference on Green Energy and Technology (ICGET), pp. 1-5, Sept 2015.

[189] X. Pei and Y. Kang, "Short-circuit fault protection strategy for highpower three-phase three-wire inverter," IEEE Transactions on Industrial Informatics, vol. 8, pp. 545-553, Aug 2012.

[190] H. imen, E. Oguz, Y. Oguz, and H. Oguz, "Power flow control of isolated wind-solar power generation system for educational purposes," in 2012 22nd Australasian Universities Power Engineering Conference (AUPEC), pp. 1-5, Sept 2012.

[191] A. Grandjean, J. Adnot, and G. Binet, "A review and an analysis of the residential electric load curve models," Renewable and Sustainable Energy Reviews, vol. 16, no. 9, pp. 6539 - 6565, 2012. 
[192] M. S. Sadabadi, A. Karimi, and H. Karimi, "Fixed-order decentralized/distributed control of islanded inverter-interfaced microgrids," Control Engineering Practice, vol. 45, pp. 174 - 193, 2015.

[193] W. W. Weaver, R. D. R. III, G. G. Parker, and D. G. Wilson, “Energy storage requirements of dc microgrids with high penetration renewables under droop control," International Journal of Electrical Power and Energy Systems, vol. 68, pp. 203 - 209, 2015.

[194] D. Burmester, R. Rayudu, and W. K. G. Seah, "A comparison between temperature and current sensing in photovoltaic maximum power point tracking," in 18th National Power Systems Conference (NPSC), pp. 1-6, Dec 2014.

[195] A. Maiti, K. Mukherjee, and P. Syam, “Design, modeling and software implementation of a current-perturbed maximum power point tracking control in a dc-dc boost converter for grid-connected solar photovoltaic applications," in 2016 IEEE First International Conference on Control, Measurement and Instrumentation (CMI), pp. 36-41, Jan 2016.

[196] C. Urayai and G. A. J. Amaratunga, "Single sensor boost converterbased maximum power point tracking algorithms," in TwentySixth Annual IEEE Applied Power Electronics Conference and Exposition (APEC), pp. 1238-1243, March 2011.

[197] R. Crews, "An-1820 lm5032 interleaved boost converter," Texas Instruments Application Report, pp. 1-5, May 2013.

[198] V. Salas, E. Olas, A. Barrado, and A. Lzaro, "Review of the maximum power point tracking algorithms for stand-alone photovoltaic systems," Solar Energy Materials and Solar Cells, vol. 90, no. 11, pp. 1555 - 1578, 2006. 
[199] Z. Iqbal, U. Nasir, M. T. Rasheed, and K. Munir, "A comparative analysis of synchronous buck, isolated buck and buck converter," in IEEE 15th International Conference on Environment and Electrical Engineering (EEEIC), pp. 992-996, June 2015.

[200] B. Hauke, "Basic calculations of a buck converter's power stage," in Texas Instruments Application Report SLVA477B, December 2015.

[201] G. Maimone, "Selecting l and c components in the power stage of the mc34700 switching regulators," in Freescale Semiconductor Application Note AN4067, November 2010.

[202] A. M. Rahimi, P. Parto, and P. Asadi, "Compensator design procedure for buck converter with voltage-mode error-amplifier," in International Rectifier Application Note AN-1162.

[203] M.Sen, "Mathematical analysis of engineering systems," Department of Aerospace and Mechanical Engineering, University of Notre Dame, Notre Dame, IN 46556, November 2008.

[204] A. G. Wiiliamson and S. Clark, "Domestic hot water options and solutions," in Centre for Advanced Engineering, University of Canterbury, p. 39, 2004.

[205] M. Roberge, L. Lamarche, S. Karjl, and A. Moreau, "Model of room storage heater and system identification using neural networks," in Proc of CLIMA 2000, p. 265, 1997.

[206] Faculty of Information Technology, "Future Internet Technologies," in University of Pannonia, pp. 1-22, 2012.

[207] National Institute of Water and Atmospheric research, "Niwa solar view." http:/ / solarview.niwa.co.nz. 
[208] M. Pipattanasomporn, M. Kuzlu, S. Rahman, and Y. Teklu, “Load Profiles of Selected Major Household Appliances and Their," IEEE Trans. on Smart Grid, vol. 5, no. 2, pp. 742-750, 2014. 
Appendix A

\section{Load Characteristics}


Table A.1: House 1 summer and winter loads within the modelled house

\begin{tabular}{|c|c|c|c|}
\hline Variable & Power (W) & $\begin{array}{l}\text { Summer on-off } \\
\text { times (min) }\end{array}$ & $\begin{array}{l}\text { Winter on-off } \\
\text { times (min) }\end{array}$ \\
\hline Kitchen light 1 & 18 & $0-450,1230-1440$ & $0-450,1080-1440$ \\
\hline Kitchen light 2 & 100 & $1020-1050$ & $1020-1050$ \\
\hline kettle (on for 3min) & 2000 & $390,1020,1200$ & $390,1020,1200$ \\
\hline Toaster (on for 3min) & 1100 & 450 & 450 \\
\hline Oven & 2550 & $1020-1080$ & $1020-1080$ \\
\hline Bathroom Light & 40 & $\begin{array}{l}\text { 1110-1155, } \\
1380\end{array}$ & $\begin{array}{l}1110-1155, \\
1380\end{array}$ \\
\hline Bedroom 1 clock & 5 & $\mathrm{~N} / \mathrm{a}$ & $\mathrm{N} / \mathrm{a}$ \\
\hline Bedroom 1 lamp & 25 & $1210-1380$ & $1170-1380$ \\
\hline Bedroom 1 light & 18 & $1200-1210$ & $1080-1170$ \\
\hline Bedroom 2 clock & 3 & $\mathrm{~N} / \mathrm{a}$ & $\mathrm{N} / \mathrm{a}$ \\
\hline Bedroom 2 lamp & 40 & $420-450,1260-1380$ & $420-450,1260-1380$ \\
\hline Bedroom 2 light & 40 & $420-450,1260-1380$ & $420-450,1260-1380$ \\
\hline Phone charger 1 & 5 & $0-495,1320-1440$ & $0-495,1320-1440$ \\
\hline Phone charger 2 & 5 & $0-495,1380-1440$ & $0-495,1320-1440$ \\
\hline Phone charger 3 & 5 & $0-495,1380-1440$ & $0-495,1320-1440$ \\
\hline Computer/Laptop 1 & 65 & $1080-1215$ & $1080-1215$ \\
\hline Computer/Laptop 2 & 60 & $0-495,1380-1440$ & $0-495,1380-1440$ \\
\hline Lounge lamp & 40 & $360-450,1200-1380$ & $360-450,1080-1140$ \\
\hline Lounge light & 120 & $1140-1170$ & $1140-1170$ \\
\hline Heater & 2100 & $\mathrm{~N} / \mathrm{a}$ & $1061-1154$ \\
\hline Stereo & 50 & $960-1025$ & $960-1025$ \\
\hline Television & 400 & $360-440,990-1320$ & $360-440,990-1320$ \\
\hline
\end{tabular}


Table A.2: House 2 summer and winter loads within the modelled house

$\begin{array}{lcll}\text { Variable } & \text { Power (W) } & \begin{array}{l}\text { Summer } \\ \text { times (min) }\end{array} & \begin{array}{l}\text { on-off } \\ \text { times (min) }\end{array} \\ \text { Kitchen light 1 } & 40 & 1250-1410 & 1050-1210 \\ \text { Dishwasher } & 1200 & 1200 & 1200 \\ \text { kettle (on for 3min) } & 1500 & 420,1070 & 420,1070 \\ \text { Toaster (on for 3min) } & 900 & 390,452 & 390,452 \\ \text { Oven } & 3400 & 1060-1120 & 1060-1120 \\ \text { Bathroom light } & 60 & 357-369,393-413 & 357-369,393-413 \\ \text { Bedroom 1 clock } & 5 & \mathrm{~N} / \mathrm{a} & \mathrm{N} / \mathrm{a} \\ \text { Bedroom 1 lamp } & 18 & 1329-1384 & 1329-1384 \\ \text { Bedroom 1 light } & 24 & 350-456 & 350-456 \\ \text { Bedroom 2 clock } & 6 & \mathrm{~N} / \mathrm{a} & \mathrm{N} / \mathrm{a} \\ \text { Bedroom 2 lamp } & 24 & 447-486,1230-1280 & 447-486,1230-1280 \\ \text { Bedroom 2 light } & 40 & 480-504,1205-1398 & 480-504,1205-1398 \\ \text { Phone charger 1 } & 3 & 0-595,1280-1440 & 0-595,1280-1440 \\ \text { Phone charger 2 } & 7 & 0-596,1280-1440 & 0-596,1280-1440 \\ \text { Phone charger 3 } & 5 & 0-595,1284-1440 & 0-595,1284-1440 \\ \text { Computer / Laptop 1 } & 55 & 1280-1440 & 1280-1440 \\ \text { Computer / Laptop 2 } & 65 & 0-475,1286-1440 & 0-475,1286-1440 \\ \text { Lounge lamp } & 60 & 360-450,1246-1387 & 360-450,1046-1387 \\ \text { Lounge light } & 60 & 1240-1270 & 1140-1170 \\ \text { Heater } & 1800 & \mathrm{~N} / \mathrm{a} & 1034-1144 \\ \text { Stereo } & 100 & 708-970 & 708-970 \\ \text { Television } & 500 & 365-443,1050-1220 & 365-443,1050-1220\end{array}$


Table A.3: House 3 summer and winter loads within the modelled house

$\begin{array}{lcll}\text { Variable } & \text { Power (W) } & \begin{array}{l}\text { Summer } \\ \text { times (min) }\end{array} & \begin{array}{l}\text { on-off } \\ \text { times (min) }\end{array} \\ \text { Kitchen light 1 } & 24 & 360-443,1250-1317 & 360-443,1050-1140 \\ \text { Kitchen light 2 } & 60 & 1250-11340 & 1050-1140 \\ \text { kettle (on for 3min) } & 2000 & 362,726,1230 & 362,726,1230 \\ \text { Toaster (on for 3min) } & 1200 & 421,482 & 421,482 \\ \text { Oven } & 850 & 978-1146 & 978-1146 \\ \text { Bathroom light } & 80 & 1170-1180, & 1272- \\ & & 1355 & 1350-1180, \\ \text { Bedroom 1 clock } & 6 & \mathrm{~N} / \mathrm{a} & \mathrm{N} / \mathrm{a} \\ \text { Bedroom 1 lamp } & 18 & 1290-1352 & 1190-1352 \\ \text { Bedroom 1 light } & 60 & 1260-1290 & 1160-1190 \\ \text { Bedroom 2 clock } & 4 & \mathrm{~N} / \mathrm{a} & \mathrm{N} / \mathrm{a} \\ \text { Bedroom 2 lamp } & 24 & 1402-1448 & 1402-1448 \\ \text { Bedroom 2 light } & 40 & 422-483,1350-1403 & 422-483,1350-1403 \\ \text { Phone charger 1 } & 7 & 0-455,1320-1440 & 0-455,1320-1440 \\ \text { Phone charger 2 } & 6 & 0-455,1380-1440 & 0-455,1320-1440 \\ \text { Computer/Laptop 1 } & 45 & 0-100,1110-1440 & 0-100,1110-1440 \\ \text { Lounge lamp } & 40 & 415-510,1200-1350 & 415-510,1200-1350 \\ \text { Lounge light } & 60 & 1246-1292 & 1246-1192 \\ \text { Heater } & 1500 & \mathrm{~N} / \mathrm{a} & 1080-1300 \\ \text { Television } & 150 & 420-480,1204-1350 & 420-480,1205-1350\end{array}$


Table A.4: House 4 summer and winter loads within the modelled house

$\begin{array}{lcll}\text { Variable } & \text { Power (W) } & \begin{array}{l}\text { Summer } \\ \text { times (min) }\end{array} & \begin{array}{l}\text { on-off } \\ \text { times (min) }\end{array} \\ \text { Kitchen light 1 } & 60 & 1253-1270 & 1153-1170 \\ \text { kettle (on for 3min) } & 1800 & 396,1330 & 396,1330 \\ \text { Toaster (on for 3min) } & 1000 & 360 & 360 \\ \text { Oven } & 1700 & 1254-1269 & 1154-1169 \\ \text { Bathroom light } & 40 & 330-340 & 330-340 \\ \text { Bedroom 1 clock } & 4 & \mathrm{~N} / \mathrm{a} & \mathrm{N} / \mathrm{a} \\ \text { Bedroom 1 lamp } & 40 & 328-360,1380-1410 & 328-360,1380-1410 \\ \text { Phone charger 1 } & 5 & 0-455,1320-1440 & 0-455,1320-1440 \\ \text { Computer/Laptop 1 } & 35 & 1065-1260 & 1065-1260 \\ \text { Computer/Laptop 2 } & 65 & 0-360,1110-1440 & 0-360,1110-1440 \\ \text { Lounge lamp } & 18 & 1200-1380 & 1100-1380 \\ \text { Lounge light } & 40 & 1250-1300 & 1050-1100 \\ \text { Heater } & 500 & \mathrm{~N} / \mathrm{a} & 1085-1370 \\ \text { Stereo } & 100 & 1144-1179 & 1144-1179 \\ \text { Television } & 300 & 1180-1380 & 1180-1380\end{array}$


Table A.5: House 5 summer and winter loads within the modelled house

$\begin{array}{lcll}\text { Variable } & \text { Power (W) } & \begin{array}{l}\text { Summer on-off } \\ \text { times (min) }\end{array} & \begin{array}{l}\text { Winter } \\ \text { times (min) }\end{array} \\ \text { Kitchen light 1 } & 18 & 387-452,1236-1367 & 387-452,1236-1367 \\ \text { Dishwasher } & 1200 & 607 & 607 \\ \text { kettle (on for 3min) } & 1500 & 427 & 427 \\ \text { Toaster (on for 3min) } & 1100 & 510 & 510 \\ \text { Oven } & 3400 & 1084-1165 & 1084-1165 \\ \text { Bathroom light } & 18 & 480-490,645-652 & 480-490,645-652 \\ \text { Bedroom 1 clock } & 3 & \mathrm{~N} / \mathrm{a} & \mathrm{N} / \mathrm{a} \\ \text { Bedroom 1 lamp } & 18 & 1276-1382 & 1176-1382 \\ \text { Bedroom 1 light } & 40 & 1230-1270 & 1090-1270 \\ \text { Bedroom 2 clock } & 5 & \mathrm{~N} / \mathrm{a} & \mathrm{N} / \mathrm{a} \\ \text { Bedroom 2 lamp } & 18 & 444-492,1200-1326 & 444-492,1100-1326 \\ \text { Bedroom 2 light } & 60 & 1285-1326 & 1285-1326 \\ \text { Phone charger 1 } & 5 & 0-146,1285-1440 & 0-146,1285-1440 \\ \text { Phone charger 2 } & 6 & 0-360,1285-1440 & 0-360,1285-1440 \\ \text { Phone charger 3 } & 5 & 0-247,1285-1440 & 0-247,1285-1440 \\ \text { Computer / Laptop 1 } & 65 & 570-870 & 570-870 \\ \text { Computer/Laptop 2 } & 65 & 1213-1285 & 1213-1285 \\ \text { Lounge lamp } & 24 & 420-450,1334-1400 & 420-450,1334-1400 \\ \text { Lounge light } & 100 & 1163-1270 & 1170-1230 \\ \text { Heater } & 500 & \mathrm{~N} / \mathrm{a} & 486-1269 \\ \text { Stereo } & 50 & 726-758 & 726-758 \\ \text { Television } & 200 & 665-870,1160-1285 & 665-870,1160-1285\end{array}$


Table A.6: House 6 summer and winter loads within the modelled house

$\begin{array}{lclll}\text { Variable } & \text { Power (W) } & \begin{array}{l}\text { Summer } \\ \text { times (min) }\end{array} & \begin{array}{l}\text { on-off } \\ \text { times (min) }\end{array} \\ \text { Kitchen light 1 } & 40 & 1250-1355 & 1050-1155 \\ \text { Dishwasher } & 1200 & 1150 & 1150 \\ \text { kettle (on for 3min) } & 2000 & 509,1178 & 509,1178 \\ \text { Toaster (on for 3min) } & 1200 & 480-485 & 480-485 \\ \text { Oven } & 3400 & 1021-1086 & 1021-1086 \\ \text { Bathroom light } & 24 & 1145-1200, & 1290- & 1145-1200, \\ & & 1320 & 1320 \\ \text { Bedroom 1 clock } & 6 & \mathrm{~N} / \mathrm{a} & \mathrm{N} / \mathrm{a} \\ \text { Bedroom 1 lamp } & 24 & 360-450 & 360-450 \\ \text { Bedroom 2 clock } & 5 & \mathrm{~N} / \mathrm{a} & \mathrm{N} / \mathrm{a} \\ \text { Bedroom 2 lamp } & 24 & 360-450,1238-1355 & 360-450,1238-1355 \\ \text { Bedroom 2 light } & 40 & 0-54,1310-1440 & 0-54,1310-1440 \\ \text { Phone charger 1 } & 6 & 960-1360 & 960-1360 \\ \text { Phone charger 2 } & 5 & 0-200,1400-1440 & 0-200,1400-1440 \\ \text { Computer /Laptop 1 } & 65 & 1260-1326 & 1260-1326 \\ \text { Computer / Laptop 2 } & 55 & 0-52,1324-1440 & 0-52,1324-1440 \\ \text { Lounge lamp } & 40 & 362-500,1200-1350 & 362-500,1100-1350 \\ \text { Lounge light } & 60 & 1200-1350 & 1100-1350 \\ \text { Heater } & 2100 & \mathrm{~N} / \mathrm{a} & 939-1217 \\ \text { Stereo } & 100 & 1050-1080 & 1050-1080 \\ \text { Television } & 400 & 367-400,1170-1310 & 367-400,1170-1310\end{array}$


Table A.7: House 7 summer and winter loads within the modelled house

$\begin{array}{lcll}\text { Variable } & \text { Power (W) } & \begin{array}{l}\text { Summer } \\ \text { times (min) }\end{array} & \begin{array}{l}\text { Winter } \\ \text { times (min) }\end{array} \\ \text { Kitchen light 1 } & 60 & 452-463,1219-1300 & 452-463,1119-1200 \\ \text { Dishwasher } & 1200 & 480 & 480 \\ \text { kettle (on for 3min) } & 1500 & 483-801 & 482-801 \\ \text { Toaster (on for 3min) } & 1100 & 1080 & 1080 \\ \text { Oven } & 2550 & 1144-1181 & 1144-1181 \\ \text { Bathroom light } & 40 & 1202-1210 & 1202-1210 \\ \text { Bedroom 1 clock } & 4 & \mathrm{~N} / \mathrm{a} & \mathrm{N} / \mathrm{a} \\ \text { Bedroom 1 lamp } & 24 & 1209-1215 & 1209-1215 \\ \text { Bedroom 2 clock } & 4 & \mathrm{~N} / \mathrm{a} & \mathrm{N} / \mathrm{a} \\ \text { Bedroom 2 lamp } & 40 & 450-526,1286-1420 & 450-526,1286-1420 \\ \text { Bedroom 2 light } & 80 & 450-470,1386-1399 & 450-470,1386-1399 \\ \text { Phone charger 1 } & 4 & 0-473,1315-1440 & 0-473,1315-1440 \\ \text { Phone charger 2 } & 6 & 504-864 & 504-864 \\ \text { Phone charger 3 } & 4 & 0-406,1420-1440 & 0-406,1420-1440 \\ \text { Computer/Laptop 1 } & 55 & 604-840 & 604-840 \\ \text { Computer/Laptop 2 } & 45 & 0-381,1410-1440 & 0-381,1410-1440 \\ \text { Lounge light } & 18 & 1199-1320 & 1199-1320 \\ \text { Heater } & 1000 & \mathrm{~N} / \mathrm{a} & 900-1230 \\ \text { Stereo } & 50 & 609-835 & 609-835 \\ \text { Television } & 100 & 921-963,1200-1264 & 921-963,1200-1264\end{array}$


Table A.8: House 8 summer and winter loads within the modelled house

$\begin{array}{lclll}\text { Variable } & \text { Power (W) } & \begin{array}{l}\text { Summer } \\ \text { times (min) }\end{array} & \begin{array}{l}\text { on-off } \\ \text { times (min) }\end{array} \\ \text { Kitchen light 1 } & 24 & 1258-1359 & 1058-1159 \\ \text { Kitchenlight 2 } & 60 & 459-524 & 459-524 \\ \text { kettle (on for 3min) } & 2000 & 543 & 543 \\ \text { Toaster (on for 3min) } & 1100 & 552 & 552 \\ \text { Oven } & 3400 & 1074-1124 & 1074-1124 \\ \text { Bathroom light } & 100 & 1140-1150, & 1388- & 1140-1150, \\ & & 1395 & 1395 \\ \text { Bedroom 1 clock } & 5 & \mathrm{~N} / \mathrm{a} & \mathrm{N} / \mathrm{a} \\ \text { Bedroom 1 lamp } & 24 & 1240-1250 & 1140-1150 \\ \text { Bedroom 1 light } & 40 & 365-454 & 365-454 \\ \text { Bedroom 1 clock } & 6 & \mathrm{~N} / \mathrm{a} & \mathrm{N} / \mathrm{a} \\ \text { Bedroom 1 lamp } & 60 & 0-23,1403-1440 & 0-23,1403-1440 \\ \text { Bedroom 1 light } & 24 & 370-405,1386-1403 & 370-405,1386-1403 \\ \text { Phone charger 1 } & 7 & 0-532,1274-1440 & 0-532,1274-1440 \\ \text { Phone charger 2 } & 4 & 0-310,1319-1440 & 0-310,1319-1440 \\ \text { Computer / Laptop 1 } & 65 & 380-1417 & 380-1417 \\ \text { Computer / Laptop 2 } & 45 & 0-456,1312-1440 & 0-456,1312-1440 \\ \text { Lounge lamp } & 40 & 368-450,1208-1306 & 368-450,1208-1306 \\ \text { Lounge light } & 24 & 1306-1400 & 1306-1400 \\ \text { Heater } & 2000 & \mathrm{~N} / \mathrm{a} & 972-1206 \\ \text { Stereo } & 80 & 960-1080 & 960-1080 \\ \text { Television } & 200 & 397-450,1233-1386 & 397-450,1233-1386\end{array}$


Table A.9: House 9 summer and winter loads within the modelled house

$\begin{array}{lclll}\text { Variable } & \text { Power }(\mathbf{W}) & \begin{array}{l}\text { Summer } \\ \text { times (min) }\end{array} & \begin{array}{l}\text { on-off } \\ \text { times (min) }\end{array} \\ \text { Kitchen light 1 } & 18 & 362-401,1200-1309 & 362-401,1200-1309 \\ \text { Dishwasher } & 1000 & 1308 & 1308 \\ \text { kettle (on for 3min) } & 1000 & 364,392 & 364,392 \\ \text { Oven } & 2550 & 1234-1259 & 1234-1259 \\ \text { Bathroom light } & 60 & 1275-1280, & 1299- & 1275-1280, \\ & & 1310 & 1310 \\ \text { Bedroom 1 clock } & 3 & \mathrm{~N} / \mathrm{a} & \mathrm{N} / \mathrm{a} \\ \text { Bedroom 1 lamp } & 18 & 420-487 & 420-487 \\ \text { Bedroom 1 light } & 40 & 1278-1355 & 1278-1355 \\ \text { Bedroom 2 clock } & 6 & \mathrm{~N} / \mathrm{a} & \mathrm{N} / \mathrm{a} \\ \text { Bedroom 2 lamp } & 24 & 415-490,1254-1285 & 415-490,1254-1285 \\ \text { Bedroom 2 light } & 40 & 417-432,1254-1268 & 417-432,1254-1268 \\ \text { Phone charger 1 } & 6 & 0-135,1320-1440 & 0-135,1320-1440 \\ \text { Phone charger 2 } & 4 & 0-434,1285-1440 & 0-434,1285-1440 \\ \text { Phone charger 3 } & 6 & 0-235,1170-1440 & 0-235,1170-1440 \\ \text { Computer / Laptop 1 } & 35 & 1076-1185 & 1076-1185 \\ \text { Computer / Laptop 2 } & 65 & 0-390,1319-1440 & 0-390,1319-1440 \\ \text { Lounge light } & 40 & 1230-1278 & 1030-1178 \\ \text { Heater } & 2000 & \mathrm{~N} / \mathrm{a} & 1000-1170 \\ \text { Stereo } & 40 & 1172-1292 & 1172-1292 \\ \text { Television } & 300 & 1074-1170 & 1074-1170\end{array}$


Table A.10: House 10 summer and winter loads within the modelled house

$\begin{array}{lcll}\text { Variable } & \text { Power (W) } & \begin{array}{l}\text { Summer on-off } \\ \text { times (min) }\end{array} & \begin{array}{l}\text { Winter } \\ \text { times (min) }\end{array} \\ \text { Kitchen light 1 } & 100 & 432-449,1202-1265 & 432-449,1102-1165 \\ \text { Kitchen light 2 } & 40 & 1197-1224 & 1097-1124 \\ \text { kettle (on for 3min) } & 2000 & 449,1183 & 449,1183 \\ \text { Toaster (on for 3min) } & 450 & 425 & 425 \\ \text { Oven } & 1700 & 1103-1126 & 1103-1126 \\ \text { Bathroom light } & 24 & 1320-1345 & 1320-1345 \\ \text { Bedroom 1 clock } & 5 & \mathrm{~N} / \mathrm{a} & \mathrm{N} / \mathrm{a} \\ \text { Bedroom 1 lamp } & 18 & 428-460,1399-1417 & 428-460,1399-1417 \\ \text { Bedroom 1 light } & 40 & 440-463,1350-1399 & 440-463,1350-1399 \\ \text { Phone charger 1 } & 7 & 0-455,1320-1440 & 0-455,1320-1440 \\ \text { Phone charger 2 } & 5 & 0-455,1399-1440 & 0-455,1399-1440 \\ \text { Computer/Laptop 1 } & 35 & 1065-1260 & 1065-1260 \\ \text { Computer/Laptop 2 } & 65 & 0-360,1110-1440 & 0-360,1110-1440 \\ \text { Lounge lamp } & 36 & 450-460,1210-1350 & 450-460,1110-1350 \\ \text { Lounge light } & 24 & 1200-1250 & 1050-1100 \\ \text { Heater } & 2000 & \mathrm{~N} / \mathrm{a} & 1085-1150 \\ \text { Television } & 200 & 1105-1399 & 1105-1399 \\ & & & \end{array}$

Table A.11: Refrigerator parameters

$\begin{array}{lcccccccccc}\text { Variable/house } & 1 & 2 & 3 & 4 & 5 & 6 & 7 & 8 & 9 & 10 \\ \text { Watts } & 150 & 150 & 200 & 150 & 150 & 360 & 200 & 200 & 360 & 150 \\ \begin{array}{l}\text { Initial temperature } \\ \text { Lower temp }\end{array} & 1 & 1.9 & 1.5 & 1 & 1.35 & 1.8 & 1 & 1.7 & 1 & 1.2 \\ \begin{array}{l}\text { threshold } \\ \begin{array}{l}\text { Upper } \\ \text { threshold }\end{array}\end{array} & & 1 & 1.5 & 1 & 1.2 & 1.5 & 1.3 & 0.9 & 1.67 & 1 \\ \text { temp } & 2 & 2.4 & 2.65 & 3.6 & 3.1 & 2.4 & 2 & 3.6 & 2.33 & 2.8\end{array}$


Table A.12: Hot water cylinder parameters

$\begin{array}{lllllllllll}\text { Variable/house } 1 & 2 & 3 & 4 & 5 & 6 & 7 & 8 & 9 & 10 \\ \text { Watts } & 2000 & 2000 & 3000 & 2000 & 2000 & 3000 & 2000 & 3000 & 2000 & 2000 \\ \text { Mass of water } & 135 & 177 & 250 & 88 & 135 & 300 & 180 & 250 & 177 & 135 \\ \begin{array}{l}\text { Diameter (M) } \\ \text { Length (M) }\end{array} & 0.488 & 0.488 & 0.58 & 0.488 & 0.488 & 0.58 & 0.58 & 0.58 & 0.488 & 0.488 \\ \begin{array}{l}\text { Inlet water } \\ \text { temp }\end{array} & 7 & 7 & 7 & 7 & 7 & 7 & 7 & 7 & 7 & 7 \\ \begin{array}{l}\text { Ambient } \\ \text { room temp }\end{array} & 20 & 20 & 20 & 20 & 20 & 20 & 20 & 20 & 20 & 20 \\ \begin{array}{l}\text { Low temp } \\ \text { threshold }\end{array} & 57 & 58 & 59 & 55 & 56 & 55 & 57 & 55.1 & 55 & 58 \\ \begin{array}{l}\text { High temp } \\ \text { threshold }\end{array} & 62.55 & 61 & 61 & 59.5 & 58 & 60 & 62 & 64 & 57.5 & 63.8\end{array}$

Table A.13: Shower times and length

$\begin{array}{lllllllllll}\text { Variable/house } & 1 & 2 & 3 & 4 & 5 & 6 & 7 & 8 & 9 & 10\end{array}$

$\begin{array}{lllllllllll}\text { Shower } 1 \text { time } & 1150 & 362 & 1174 & 334 & 485 & 1146 & 512 & 520 & 438 & 1328\end{array}$

$\begin{array}{lllllllllll}\text { Shower } 1 \text { length } & 5 & 4 & 6 & 3 & 4 & 5 & 5 & 4 & 5 & 7\end{array}$

$\begin{array}{lllllllllll}\text { Shower } 2 \text { time } & 1170 & 394 & 1279 & - & 650 & 1292 & 1257.5 & 1145 & 1277 & 1340\end{array}$

Shower 2 length $\quad 5 \quad 5 \quad 3 \quad-\quad \begin{array}{llllllll}5 & 3 & 4 & 5 & 4 & 4\end{array}$

Shower 3 time 1270 - 1350 - $\quad$ - $1313 \quad-13891302$ -

Shower 3 length 3 - 3 - 3 - 5 - 35 - 